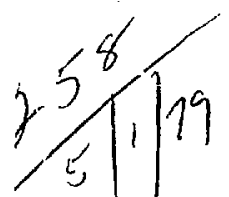

DR. 2509

\title{
THE DESIGN AND EXECUTION OF THE RAYLEIGH WAVE EXPERIMENTAL PROGRAM AT YUCCA LAKE, NEVADA
}

\author{
A. S. Kusubov
}

June 22, 1978

Work performed under the auspices of the U.S. Depanment of Energy by the UCLLL under contract number W-7405-ENG-48.

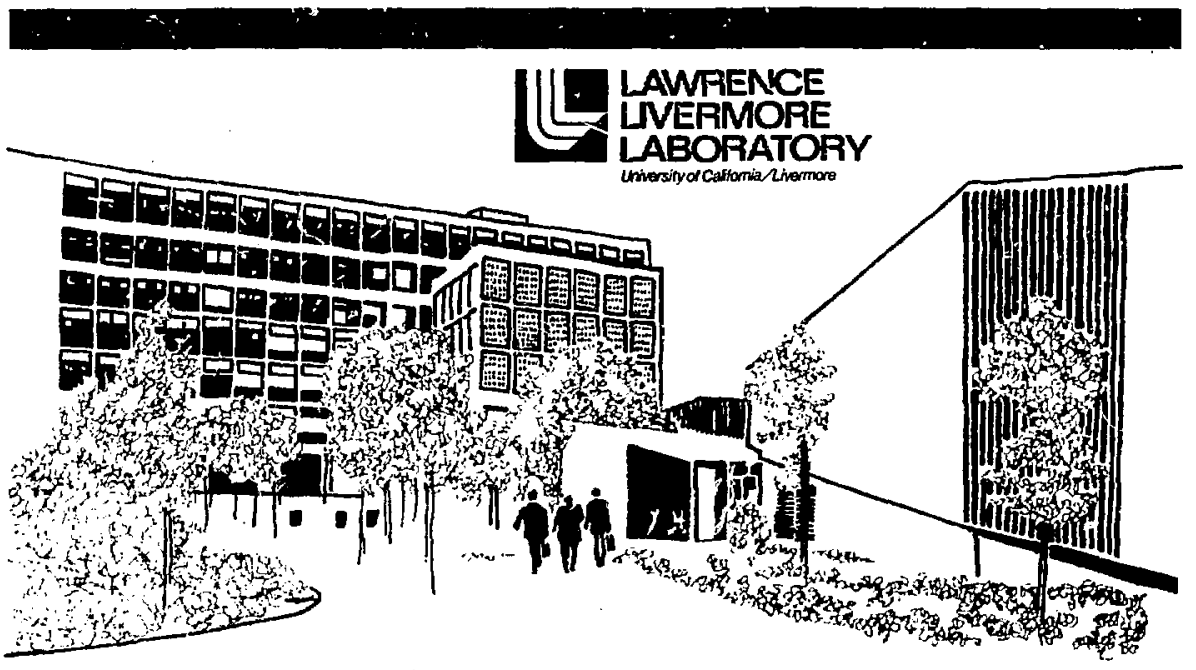




\title{
迆
}

\section{LAWRENCE LIVERMORE LABORATORY}

University of Cabtornia Livermore,Calitornia 94550

UCRL-52446

\section{THE DESIGN AND EXECUTION OF THE RAYLEIGH WAVE EXPERIMENTAL PROGRAM AT YUCCA LAKE, NEVADA}

\author{
A. S. Kusubov
}

MS. Date: June 22, 1978

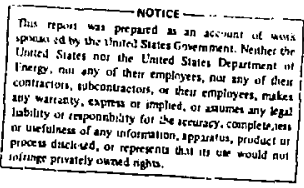




\section{PREFACE}

The intent of this document is not to summarize experimental results and draw conclusions based on rigorous analysis of test data, but rather to descrioe field test conditions and the data gathered that might be put to such rigorous analysis. Many assumptions underlying the design of experiments await further confirmation. Accordingly, the author has chosen to supply the typt of field-condition detail that might assist further research. For this reason, some of the material in the report is istentionally redundant on the assumption that more, rather than less detail would help recreale the conditions under which the test program was conducted and would provide a guide to the reliability of the data collected. All data are given in the form in which they were gathered: in general, distances and heavy charge weights are given in U.S. customary working units of measure, while times and small charge weights are given in SI units. (A conversion table is provided for convenience.)

Conversion Factors for Changirg U.S. Customary Units to the International System of Units (SI) (Symbits of SI units given in parentheses)

\begin{tabular}{|c|c|c|}
\hline To convert from & to & Mutiply by \\
\hline degree (angle) & radian (rad) & $1.745329 \mathrm{E}-02$ \\
\hline fool & meter (m) & 3.048000 F -01 \\
\hline Ips & meters per second (m/s) & 3.048000 E-01 \\
\hline inch & meter (m) & 2,540000 E-02 \\
\hline$i n .^{2}$ & meter $(1)$ & $6.451600 \mathrm{E} .04$ \\
\hline $\ln . / s$ & meters per second (m/s) & 2.540000 E-02 \\
\hline kilotons & Joules $(J)$ & $4.183000 \mathrm{E}+12$ \\
\hline pound (lb avoirdupois) & Iltogram (kg) & $4.535924 \mathrm{E}-01$ \\
\hline
\end{tabular}




\section{CONTENTS}

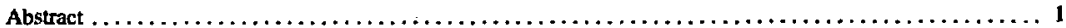

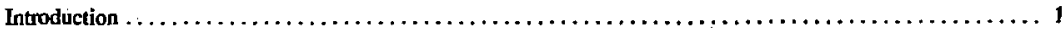

Program Objectives $\ldots \ldots \ldots \ldots \ldots \ldots \ldots \ldots \ldots \ldots \ldots \ldots \ldots \ldots \ldots \ldots \ldots \ldots \ldots \ldots \ldots \ldots \ldots, \ldots \ldots \ldots$

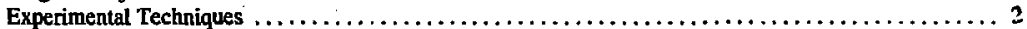

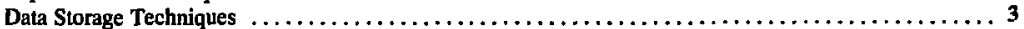

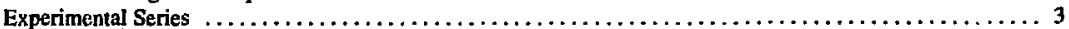

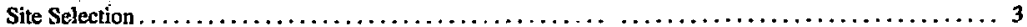

Nevada Test Site Geology $\ldots \ldots \ldots \ldots \ldots \ldots \ldots \ldots \ldots \ldots \ldots \ldots \ldots \ldots \ldots \ldots \ldots \ldots \ldots \ldots, \ldots$

Yucca Lake Bed Geology $\ldots \ldots \ldots \ldots \ldots \ldots \ldots \ldots \ldots \ldots \ldots \ldots \ldots \ldots \ldots \ldots \ldots \ldots \ldots \ldots$

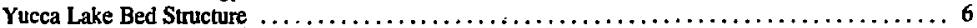

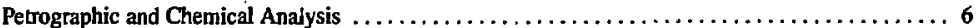

Description of Events $\ldots \ldots \ldots \ldots \ldots \ldots \ldots \ldots \ldots \ldots \ldots \ldots \ldots \ldots \ldots \ldots \ldots \ldots \ldots \ldots \ldots$

Depth-of-Burial Effect $\ldots \ldots \ldots \ldots \ldots \ldots \ldots \ldots \ldots \ldots \ldots \ldots \ldots \ldots \ldots \ldots \ldots \ldots \ldots, \ldots \ldots$

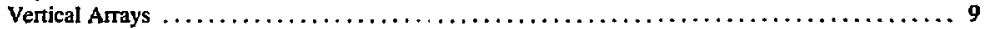

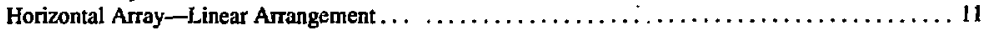

Horizontal Array-Circular Arrangement $\ldots \ldots \ldots \ldots \ldots \ldots \ldots \ldots \ldots \ldots \ldots \ldots \ldots \ldots \ldots \ldots$

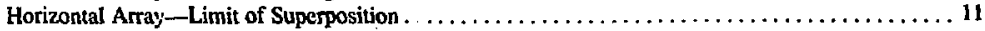

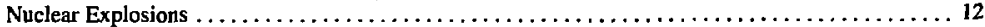

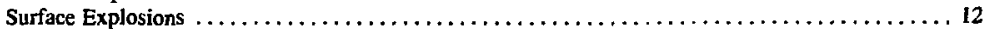

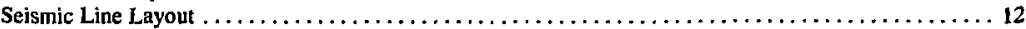

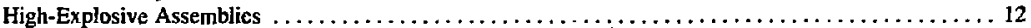

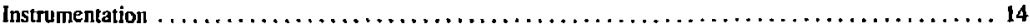

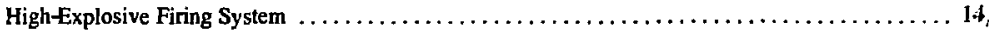

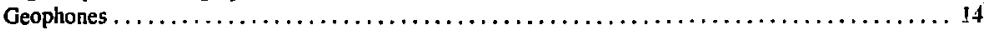

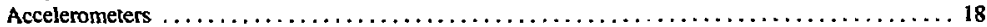

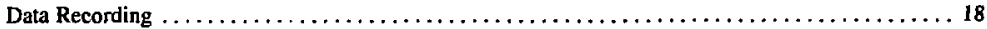

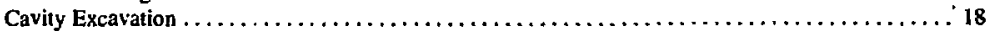

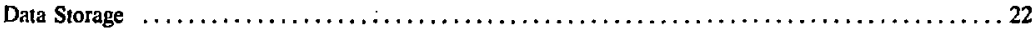

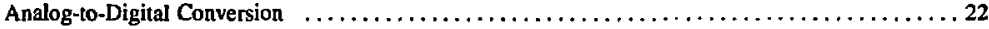

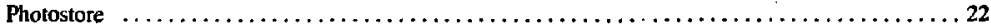

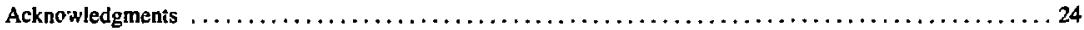

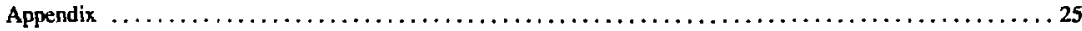

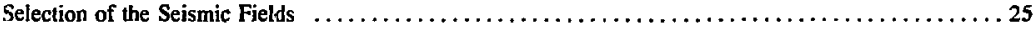

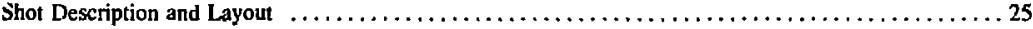

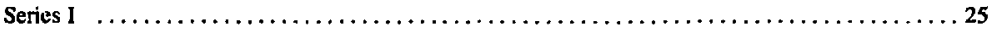

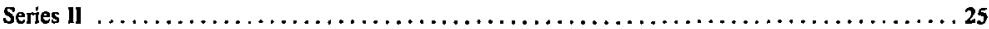

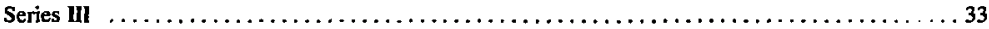

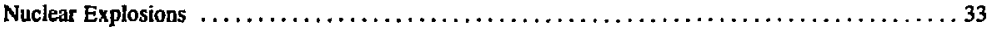

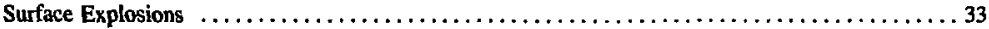

Firing System of the Small-Scale High-Explusive Charges

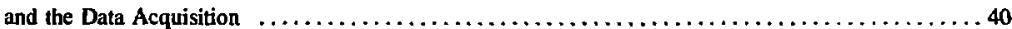

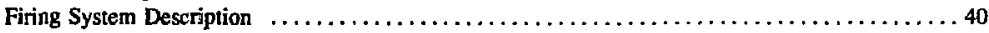

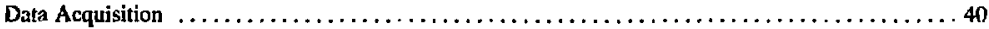

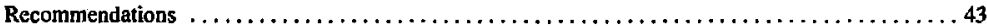

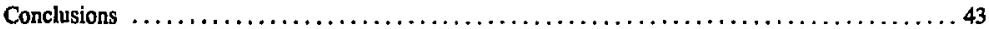

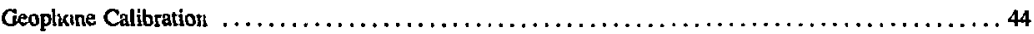

Frequency Response Curves and Specifications $\ldots \ldots \ldots \ldots \ldots \ldots \ldots \ldots \ldots \ldots \ldots \ldots \ldots \ldots, 44$

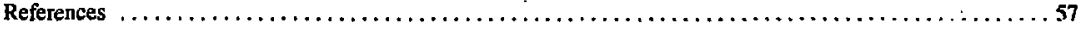




\section{ABSTRACT}

Design and fielc? execution of seismic experiments are described that recorded the characteristics of seismic signals from single and multiple explosions conducted at the Nevada Test Site in Yucca Flat, Nevada. Most of the data were obtained from small-scale underground explosions (total yields ranged from a fraction of a pound to $100 \mathrm{lb}$ of explosives) that were designed to permit characterization of seismic signals as a function of explosive-source configuration. Other data were from explosions conducted in the area by others: two underground nuclear detonations with yields below $40 \mathrm{kt}$ each and several surface explosions whose yields ranged from $700 \mathrm{lb}$ to 100 tons. The project included a comprehensive study of the Yucca lake bed, close-range recording of seismic signals from explosions, and excavation of cavities generated by small-scale high-explosive charges.

\section{INTRODUCTION}

The experimental data described in this report were collected during a series of tests conducted in 1973-74 and were processed in 1975-76. The data set is a unique collection of seismograms generated by explosions arranged to explore the effects of a variety of basic geometric configurations of emplacement holes. The main objective of the experimental program was twofold: to determine the relative Rayleigh-wave magnitude generated by small-scale explosions at different depths and to study the interaction of Rayleigh waves generated by multiple explosions, examining both as they relate to Jiscrimination between earthquakes and explosions. The program was initiated in conjunction with the Lawrence Livermore Laboratory (LLL) computermodeling prugranı dealing with Rayleigh-wave generating efficiency related to detecting and determining the magnitude of nuclear explosions. Poteltially, this project is of particular interest because of its integrated approach, and because traditionally, experimenta! and theoretical work on primary waves ( $P$ waves) has taken precedence over work on explosivegenerated surface waves (Rayleigh waves, R-waves) because of the difficulty inherent in conducting and interpreting the results of surface-wave experiments. ${ }^{1}$ In addition, the need to contain large underground explosions and interest in using explosives to mine and excavate large masses of rock both call for better understanding of the formation of explosive-generated surface waves.

For a number of years the ratio of magnitudes of the R-wave to the P-wave (R/P) (Fig. 1) has been used by the scientific community worldwide to discriminate between earthquakes and explosions. Typically, the $\mathrm{R} / \mathrm{P}$ ratio for an explosion is much smaller than that for an earthquake $e^{2}$. However, the possibility of altering the $\mathbf{R} / \mathbf{P}$ ratio by programmed firing of several simul- taneous or saquential charges to disguise explosiongenerated seismic signals is a matter of strious concern for those involved in detecting nuclear explosions. Other aspects of detection and identification include discriminating between multiple and single explosions as well as determining the magnitude of explosions.

Understanding ground motions generated by explosions is not limited to detection or magnitude-determination scenarios, alone. If we assume that the magnitude of the Rayleigh wave is directly related to the fracture envelope of the source, an immediate application of the basic understanding of the Rayleigh-wave formation would result in determining the efficiency of underground explosions to fracture rock for fossil-fuel recovery or to fracture coal for in situ gasification. In addition, it would help determine the integrity of explosively formed underground storage reseryoirs. Other applications of ground-motion study from explosions lie in the areas of reactor siting and bulk storage or transfer facilities of explosive mixtures. such as condensed natural gas and oil byproducts.

To accomplish the program objective and gain an insight into other related problems, some 150 small-scale high-explosive charges with yields ranging from $<1-100 \mathrm{lb}$ were detonated in the alluvial deposit of the Yucca Lake at the LLL Nevada Test Site (NTS). Several thousand pounds of high explosives were expended and around 5,000 si 'smograms were recurded. In addition seismic signals from underground nuclear explosions with yields up to $40 \mathrm{kt}$ and surface explosions with yields up to 100 tons were recorded for scaling and modeling purposes in connection with the Threshold Test Ban Treaty (TTBT) and the Comprehensive Test Ban Treaty (CTBT), as well as other arpplications of explosive excavation and fracturing. 


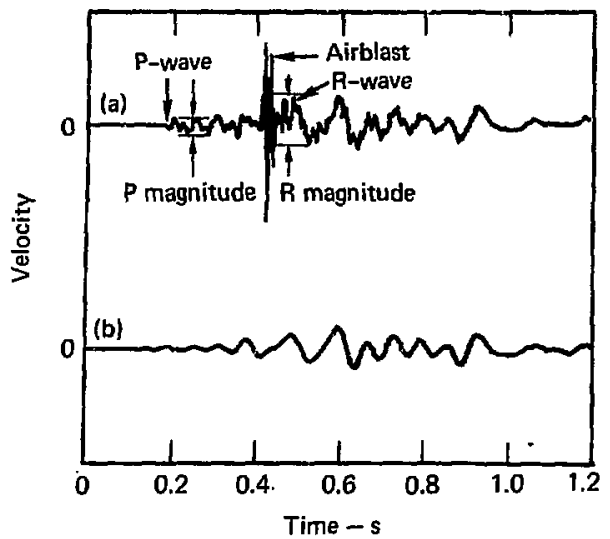

Fig. 1. Typical seismogram recorded 300 it from $1-$ Ib surface explosion, and with the definition of $R$ and $P$ magnitudes; (a) unfiltcred record and (b) same record filtered by $40-\mathrm{Hz}$ low-pass nitter.

For the sake of completeness, every shot has been catalogued and no distinction has been made as to the quality of records, which at this writing still have not been analyzed. A cursory analysis revealed that double-ranging the gain of amplifiers in several instances would have been desirable, since the noise induced by the electrical power generators and tape-drive units was close to the amplitude at the actual P-wave signal. The choice of delays between explosions also could have been improved with due consideration of preliminary results. Unfortunately, however, the field work had to be conducted to meet a very tight budgetary schedule and experiments were performed without the benefit of feedback from shots fired earlier in the series.

The wave-propagation research was complemented by a comprehensive study of the Yucca lake bed and by a seismic source study that consisted of excavating several cavities generated by contained explosions to obtain first-hand information on cavity and crack formation from single and multiple explosions. The prelim:nary results of this program were reported elsewhere. ${ }^{3}$

The overall program is best viewed by considering, in turn, the program objectives, the experimental techniques, and, finally, the computational data storage techniques.

\section{Program Objectives}

The objective of the Rayleigh Wave Experimental Program was to determine experimentally the ratio of magnitudes of the $R$-wave to the $P$-wave (the $R / P$ ), for single and multiple explosions as a function of six facins:

- Depth of burial-effects of single tinarges detonated at different depths.

- Directional firing-effects of multiple charges detonated in vertical and horizontal arrays simultaneously or with programmed time delays.

- Spatial distribution of charges-effects or multiple charges detonated in vertical and horizontal arrays with varinus spacings between charges.

- Magnitude of charges.

- Frequency.

- Azimuth.

\section{Experimental Techniques}

The field program included five techniques:

- In siu geophysical logging and seismic refraction survey of the experimental area to determine the density and sound-velocity distribution of the lake bed.

- Laboratory determination of the physical and chemical properties of the iake bed to characterize the playa deposit in mineralogical and geological terms.

- Magnetic tape recording of seismic signals from explosions detected by triaxial and uniaxial geophones with natural frequencies ranging between 1 and $4.5 \mathrm{~Hz}$. The geophones were the primary instrumentation for the entire series of experiments.

- Spall measurements with accelerometers to determine the effect of spall on the Rayleigh-wuve magnitude. 
- Postshot excavation of cavities to gain firsthand information on spall and cavity formation and to determine the difference in crack formation between simultaneous and sequential explosions.

\section{Data Storage Techniques}

Three procedures were used to make the seismic data readily available for processing and for comparison with theoretical results:

- Initial data capture was achieved via tape reconding in analog form.
The experimental data were converted from analog to digital form.

- The digitized data were stored on magnetic tapes and in binary microfilm form on photostore in the LLL computer facility.

The tapes serve as master files and offer a direct plotting capability of the digitized data with minimal processing. The data stored on photostore constitute an intermediate file available for in-depth analysis of the seismic signals: they are accessible through the LLL internal timesharing computer network.

\section{EXPERIMENTAL SERIES}

The NTS experiments can be divided into two categories. The first consists of experiments fielded by LLL and specifically designed to meet the objectives of the Rayleigh-wave program. These experiments consisted of small-scale underground explosions and are described below. The second category includes nuclear and surface explosions. These explosions were part of experiments unrelated to the Rayleigh-wave program. However, they oftered a unique opportunity to extend the data base of the Rayleigh-wave study. They were recorded without interfering with their primary objective.

\section{Site Selection}

The playa deposit of Yicca Lake at (NTS)* was chosen to conduct the small-scale high-explosive experiments for two reasons. First, handling high-explosive charges according to federal regulations and the limited availability of support ruled out virtually atl avaitable sites but NTS. Second, the playa deposit offered the most uniform deposit at NTS and was believed to be the closest approximation to an ideal half-space. Unfortunately, in the course of our investigations, a previously undetected velocity contrast was discovered at a depth of about $28 \mathrm{ft}$, complicating data interpretation more than had been anticipated.

\section{Nevada Test Site Geology}

The NTS is located within the Great Basin, which consists generally of linear mountain ranges and valleys lying between the Colorado Plateau on the east and the Sierra Nevada range on the west. 5 The deep basin that

*The NTS is located in Nye County, Neveda, approximately 60 miles north of Las Vegas. Yucca Lake is bordered by E680 000, N790 000, N810 000 , E695 000 and is located roughly in the enst central part of the Test Site (Fig. 2). Sce also Ref. 4. underlies Yucca Flat was formed relatively recently and is mainly of post-Miocene Age. The thick alluvial depusit corresponds to late Tertiary and Quatemary deposits (10-4 million years old). The relative youth of the fault scarps and seismicity indicate that the deep trough underlying the Yucca Flat is still being formed.

The most important Cenozoic structural feature of NTS is a series of norh-nırhwest-trending, predominantly east-dipping faults. From these faults, the centrally localed Yucca fault is of particular interest to the current series of experiments because of its proximity to the experimental area. It is the youngest fault of the test site region and was probably formed by a large earthquake. The fault dips at the surface about $75-80^{\circ}$, and extends horizontally for approximately 20 miles in the northerly direction starting at the Yucca lake. There has been no reliable way to date the formation of this fault, its age could be estimated at between 1,000 and 10,000 years from a comparison of its degree of erosion with scarps of known age.

\section{Yucca Lake Bed Geology}

Lake beds similar to Yucca Lake are a common festure in the Southwestern Nevada desert and are typically termed "dry lakes." The surface area of the Yucca playa is a little over a square mile, is flat to within a fraction of a foot, yellow in color, and scarred by deep cracks in the Southem end (Fig. 3). Occasionally, in early spring or after a heavy storm, it is a real lake, but less than a foot deep (Fig. 4). Most of the summer it is a dry, hot lake bed providing a relatively uniform firing and diagnostics platform (Fig. 5).

The playa or silt deposit has been deposited by the runoffs from adjacent hills and is a very fine, uniformly compacted and highly impermeable substance. The top of the lake bed is hard enough to be used as a landing strip for larger transpor planes. The playa thickness overlying the volcanic tuff and alluvium varies frum about 500 feet in the southen end of the lake to 2000 feet in the northem part (Fig. 6). 


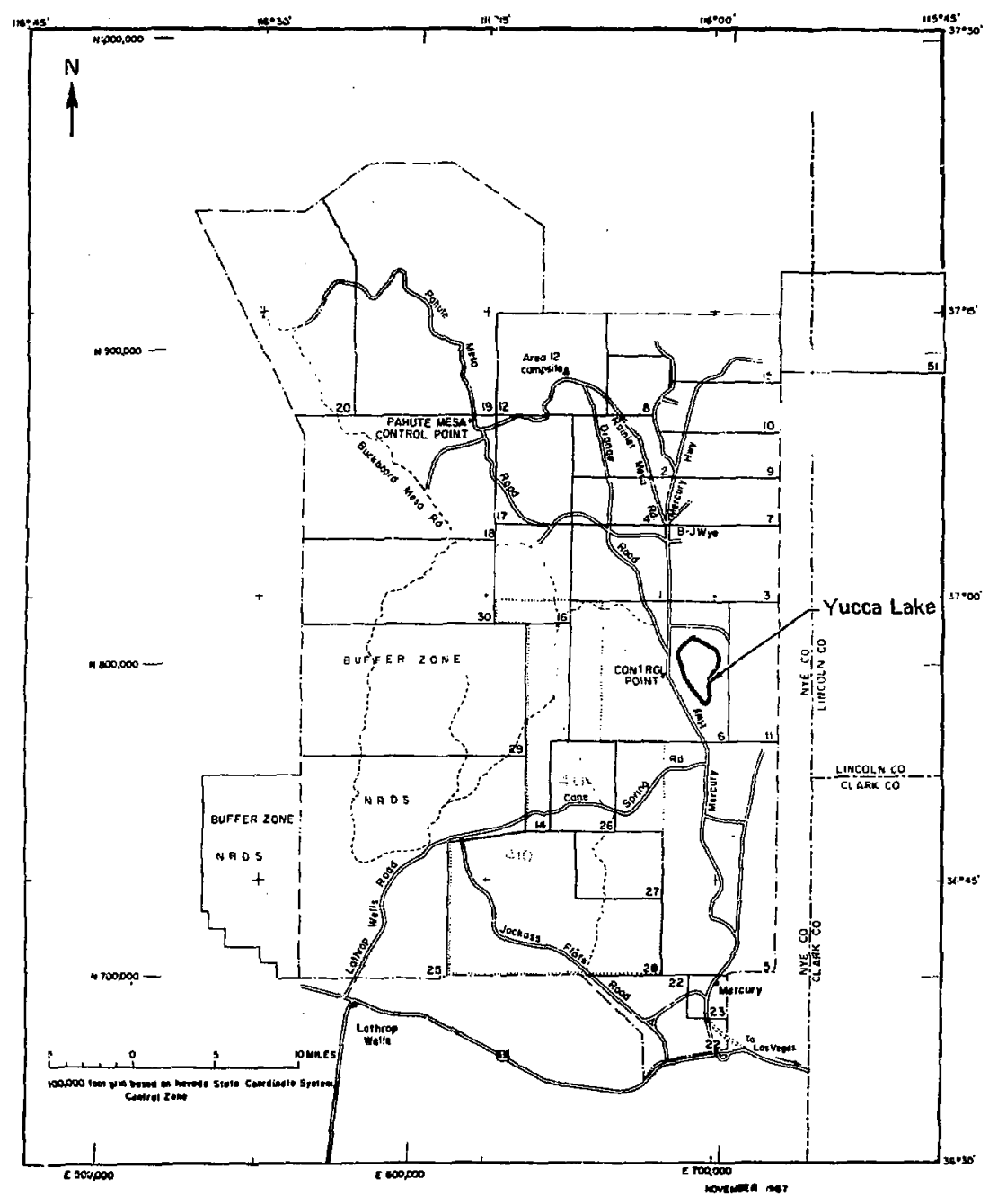

Fig. 2. Nevada Test Site. 


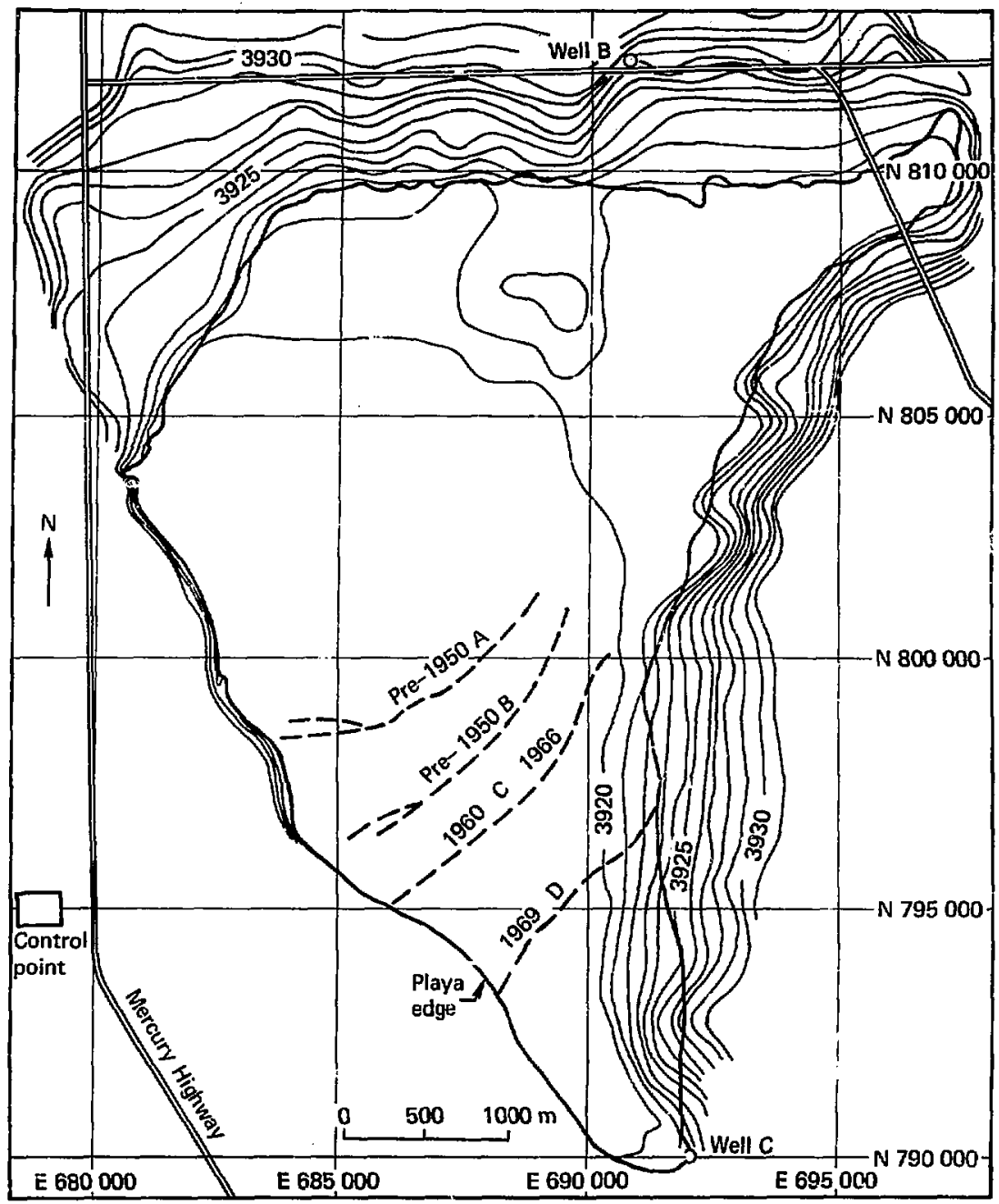

Fig. 3. Map of Yucch Late showing cracks and detsled topography. Letters identify cracks discussed in text. 


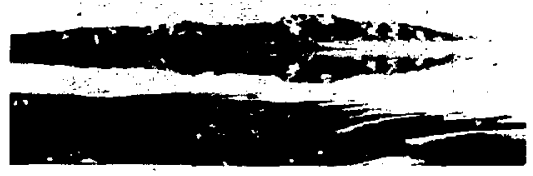

Fig. 4. Yucca Lake after a rainstorm.

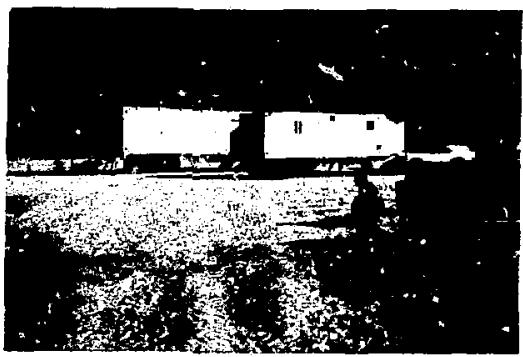

Fig. 5. Yucca Lake during the dry season. View is of djagnostics facility.

The deep cracks in the southem end of the lake are less than 30 years old and, judging from the large quantity of water that flows into them when they are new, they must go to considerable depth. From stress measurements and cther estimates it is assumed that the crack spacing is approximately equal to the crack dipth. With spacing between cracks ranging from 1,300 feet (between cracks $A$ and $B$ ) to 2,200 feet (between cracks $C$ and D), cracks could extend well into the rocks beneath the alluvium (Fig. 6). The depth of the cracks and thelr regular spacing and orientation with adjacent fault scarps strongly suggest that they are not the well-known shallow polygonal desication cracks of desert playas, rather they are of tectonic origin.

Other less prominant, but important features of the lake bed area are expressions of the southern end of the Yucca fault that tak the form of two concealed lault lines-one skirting the westem shore of the lake and the other cutting across the eastern side of the lake bed (Fig. 6). Erosion has completely destroyed the scarp in this area; observing these fault lines would be rather difficult had they not turned, in places, into drainage ditches.

\section{Yucca Lake Bed Structure}

The density of ihe lake bed obtained by iogging is shown in Fig. 7. For the first $300 \mathrm{ft}$, it seemed to he very uniform with a value around $1.7 \mathrm{~g} / \mathrm{cm}^{3}$. The sound velocity data, on the other hand, show distinctive layering (Fig. 8) and the sonic velocity at the depth of $300 \mathrm{ft}$ has alnost double the velocity recorded at the depth of a few tens of feet. The difference between the density and sonic data can be attributed to water saturaton of the lower layers since the density measuring tool used is insensitive to water content.*

Seismic refraction strvey data are shown schemat:cally in Fig. 9. They consist of the arrival times of the P-wave (longitudinal wave) plotted as sunction of distance from the explosion and clearly identify an upper layer of the lake bed, confirming the in situ soundvelocity measurements. This conclisic. is based on the fact that for a medium consisting of a singie layer, the P-wave arrival times fit along a straight ine with the slope of the linte equal to the reciprocal of the sound velocity and with the time intercept going through zero for surface explosions. However, if the medium has a second layer characterized by a higher sound velocity, then such a plot will exhibit a break similar to the one show $n$ in Fig. 9. The slope of the second line characterizing the second layer will be equalito the recijrocal of the second sound velocity and its time intercept will correspond in the depth of the first layer, which can be calculated from Snell's Law.

From the refraction survey we calculate the solnd velocity of the first layer to be 1250 fps and for the se:ond layer $2857 \mathrm{fps}$. The calculated depth of the first layer is abort $\mathbf{2 8} \mathrm{ft}$ which is in good ageement with in siru sound velocity measurements.

The " $R$ " lines in Fig. 9 correspond to the Rayleigh-wave velocities. The wave itself exhibits some dispersion because of layering; judging from its velocity (which is about $1200 \mathrm{fps}$ ); it appears to be associated with the second layer.

The seismic refraction survey was supplemented by in situ shear-velocity measurements with a down-hole geophone and an improvised shear-wave generator consisting of a 6-ft-long 2-by-4 coupled to the ground by the weight ot a pickup truck and activated by tapping the end of the 2-by-4 with a sledge hammer. The best available data for the structure ine lake bed is stimmarized in Table 1 .

\section{Petrographical and Chemical Analysis}

The oplical analysis of the playa samples revealed that the deposit is a clay of submicroscopic size with particle size less then $5 \mu \mathrm{m}$. ${ }^{6}$ The principal minerals are guartz, illite (a clay mineral structurally related to the micas), heulandite and clinoptitotite (zeolites), calcite, and $\mathrm{Na}-\mathrm{K}$ feldspar. In addition, trace amounts of chlorite (another type of mica) were present. The Na-K

-The downhole logging of density and in situ sound velocity measurements were cunducted by the Birdwell Division of Seismograph Service Curporation. 


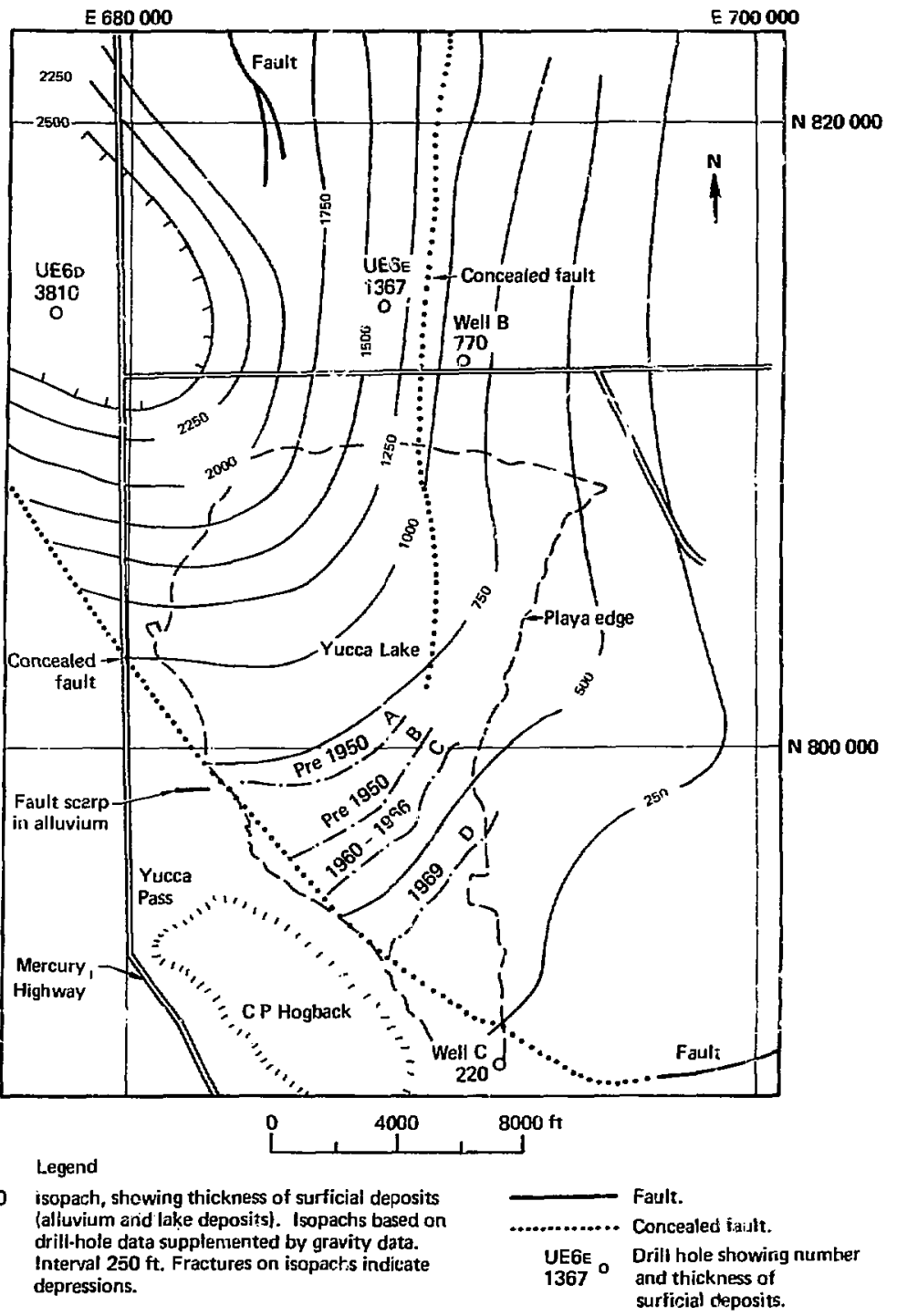

Fig. 15. Map of thickness of Yucea Lake teposits of playa and alluviom. Cracks and faults stown are discussrd in tert. 


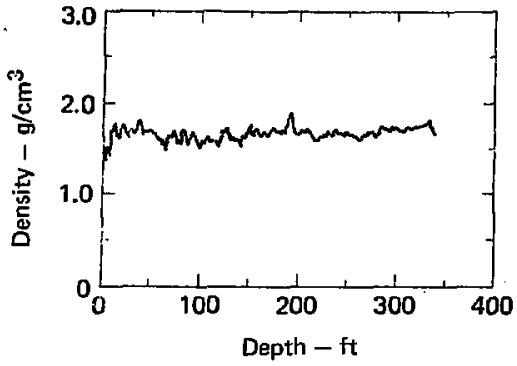

Fig. 7. Density distribution of Yucea playg, conducled by Birdwell.

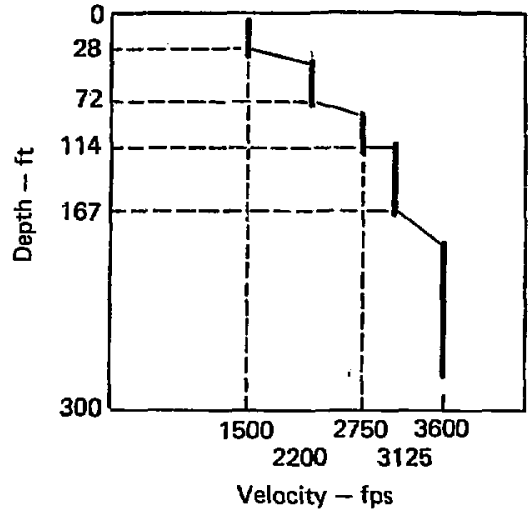

Fig. 8. Sonic velocity distribution of Yueca plnya, condueted by Birdwell.

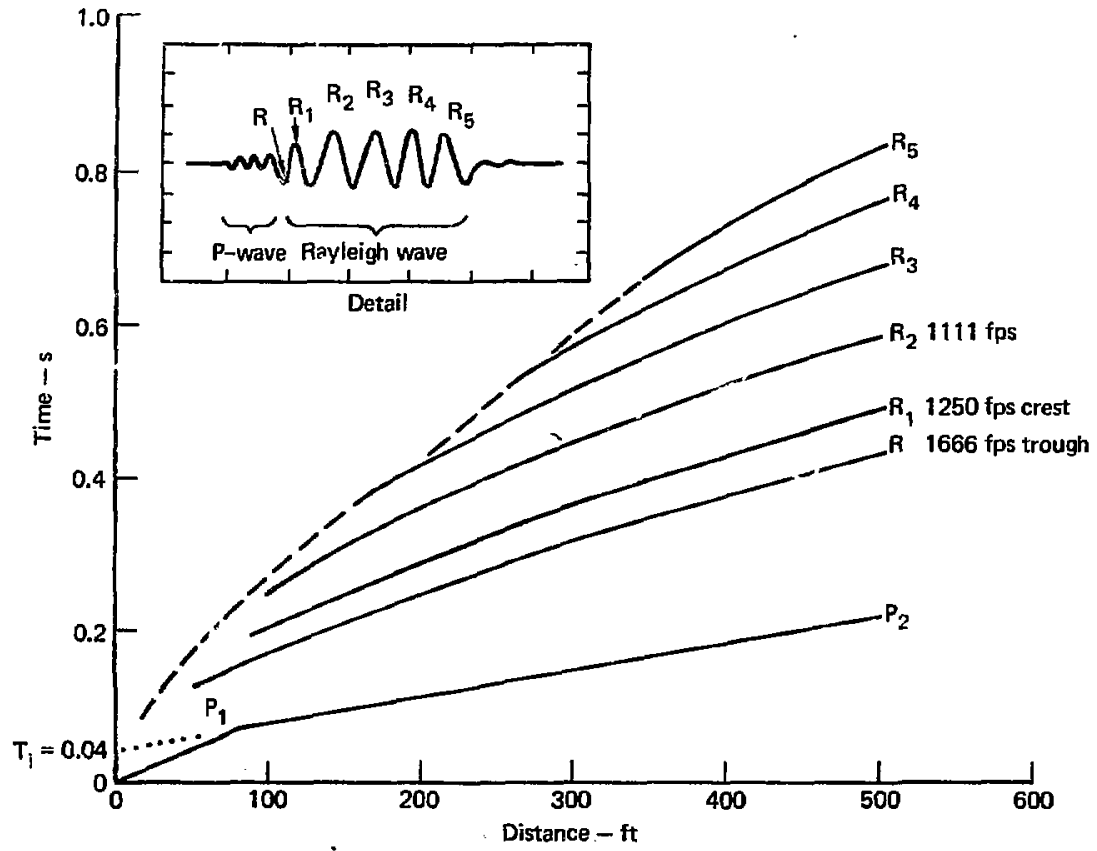

Fig. 9. Sihematic of the selsmic refraction survey of Yuces playa, with the reciprocel of the stope corresponding to the respective

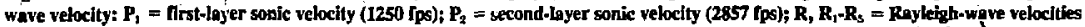

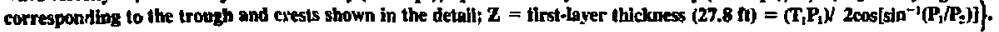


Table 1. Structure of the lake bed deposit

\begin{tabular}{lccc}
\hline $\begin{array}{l}\text { Layer ard } \\
\text { depth }\end{array}$ & $\begin{array}{c}\text { Longitudinal } \\
\text { velocity, } \\
\mathrm{fps}\end{array}$ & $\begin{array}{c}\text { Shear } \\
\text { velocity, } \\
\mathrm{fps}\end{array}$ & $\begin{array}{c}\text { Grain } \\
\text { deasity, } \\
\text { d/cms }\end{array}$ \\
\hline $\begin{array}{l}\text { First } \\
(0-28 \mathrm{n})\end{array}$ & 1250 & 496 & 1.3 \\
$\begin{array}{l}\text { Second } \\
(28-100+\mathrm{ft})\end{array}$ & 2870 & 1140 & 1.6 \\
\hline
\end{tabular}

Grain density $=3,0 \mathrm{~g} / \mathrm{cm}^{3}, \mathrm{H}_{2} \mathrm{O} \%-14 \%$.

feldspar appeared to be a plagioclase, probably a variety of albite.

The $x$-ray analysis of the playa samples substantiated the optical analysis and showed a medium amount of quariz, illite, $\mathrm{K}, \mathrm{Na}$, feldspar, small amounts of heulandite and clinoptilolite and very low amounts (about 5\%) of calcite.?

The natural state of water content of the core sample varied between $11-i 4 \mathrm{wt} \%$ and the grain density of dried samples was about $3.0 \mathrm{~g} / \mathrm{cm}^{3}$.

The water content was determined by establishing the weight difference in core samples after drying for four days at $105^{\circ} \mathrm{C} .{ }^{8}$ The grain density was determined by helium volumetry in a Beckman Pycnometer on subsamples that had previcusly been dried for the water content determination and then allowed to return to ambient temperature and humidity. After the grain volume was measured, the samples were redried and weighed so that the grain density of the samples could be calculated without absorbed moisture.

The grain density seemed unusually high for NTS samplis, but can probably be accounted for by possible trace amounts of magnetite, which would raise the grain deisity and which is not easily detected on the $x$-ray pattem.

On the basis of all the data, the sediment could be called a mudstone or silty claysrone.

\section{Description of Events}

The recorded experiments consisted of underground explosions ranging from $1 / 9 \mathrm{lb}(50 \mathrm{~g})$ to $40 \mathrm{kt}$ and surface explosions ranging from 1 lh to 100 :ons of high explosive (Fig. 10). The depth of the underground experiments varied from 2 to $50 \mathrm{ft}$ for explosions up to $100 \mathrm{lb}$ and exceeded $1000 \mathrm{ft}$ for kiloton explosions.

Most of the recorded seismic signals were generated by small-scale $(\leqslant 100 \mathrm{lb}$ ) undergnound experiments designed to study the characteristics of the surface and ground motions from underground explosions. These experiments consisted of single and multiple explosions and were grouped for fielding into three experimental series described in the Appendix. Single explosions were designed to determine the effect of the depth of burial on the efficiency of Rayleigh-wave generation and for cross-correlation with multiple explosions, as described below. Multiple explosions consisting of two to four charges were fired simultanecusly or sequentially and were designed to determine the effect of various spacings and delays between explosions arranged in vertical and horizontal arrays. To gair, a basic understanding of wave interactions, seismograms from each multifle-explosion array were complemented by a separate set of ground-motion records from experiments in which each explusion of the array was detonated separately. Additionally, seismograms were rccorded from single explosions of equivalent weight to the multiple explosions and detonated at depths corresponding to the center of each array. The remaining seismic signals were generated by single nuclear undetground detonations and single high-explosive surface detonations conducted by other experimental Erivups.

In the subsequent paragraphs thę events are grouped according to' their main experinental objective; the exact location and description of each experiment is given in the Appendix.

\section{Depta-of-Burial Erfect}

Since the Rayleigh wave is a surface wave, it : postulated that the distance between the explosion anu the surface along which the wave propagates play a dominant role in the efficiency of Rayleigh-wave generation.

Rulev $^{9}$ and Viecelli ${ }^{10}$ support the conclusion that a maximum in the generating efficieucy of the Rayleigh wave exists that is associated with depth. The mechanism of this effect is not understood. Viecelli proposed that the "slap down" caused by spall is the dominant factor. This assumption, however, can be disputed, since Rayleigh waves can also be formed without the "slap diown."

To gain $:$ physical understanding of this effect, single charges manging from $50 \mathrm{~g} \mathrm{to} 100 \mathrm{lb}$ were detonated in emplacement holes from 2 to 50 ft deep. Due to the nature of this investigation, single explosions from every series are represented in this study.

\section{Vertical Arrays}

The second series of experiments (Series II) was designed to look at the effect of directional firing in vertical sequences of explosions (Fig. 11). These experiments consisted of detonating three equally spaced $150-\mathrm{g}$ charges arranged in a vertical array with spacings bctween the charges varying from 8-1 ft, single $150-\mathrm{g}$ charges buried at depths corresponding to each single explosion of the arrays, single $450-\mathrm{g}$ charges buried at tepths representing the center of each array and distributed $450-\mathrm{g}$ charges 20 and 16 feet long. The directional firing consisted of detonating the arrays "up," "down," and simultaneous.

For a vertical array consisting of multiple charges, "up" indicentes that the charges were detonated sequentially upwards staning with the lowest charge, 
Surface explosions

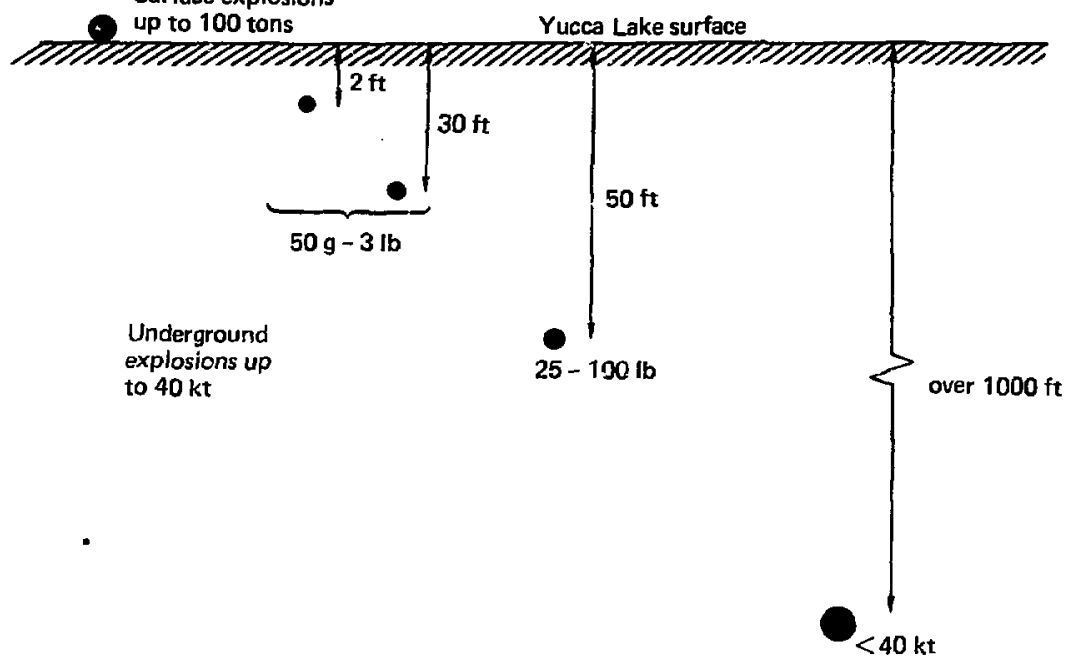

Fig. 10. Summary of selsmic experiments.

Yucca Lake surface

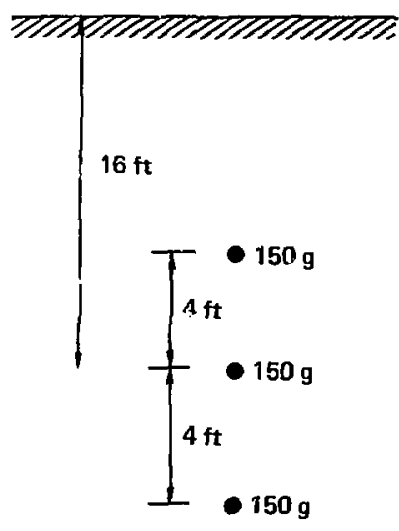

(a)

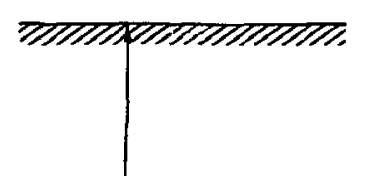

$16 \mathrm{ft}$

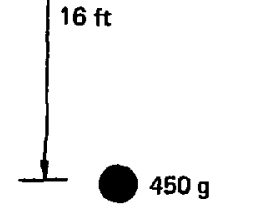

(b)

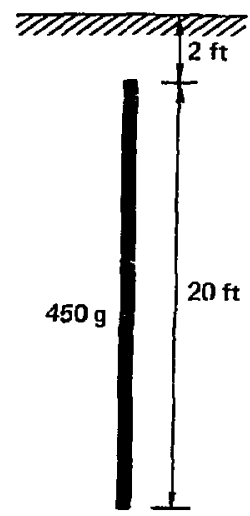

(c)

Fig. 11. Vertical arrays; (a) niutiple charges; (b) single charge, at a depth equal to the centar of the multiple charges; and (c) distributed change. 
"down" means that the upper charge was detonated first, and simultaneous, of course, means that all charges in the array were detonated simultaneously.

Detonating "up" for a distributed charge means initiating the charge at the bottom and letting the detonation move upwards, firing "down" means to detonate the charge at the top.

Due to the proximity of individual charges in the multiple explosion expcriments, the maximum delay between the explosions had to be 1.5 times the travel lime of the sound wave between the extremities of adjacent charges. This restriction was imposed by the NTS safety requirements to prevent damage or accidental detonation of charges by shock waves from adja cent explosions. Maximum delay between the detonations was $3.6 \mathrm{~ms}$, corresponding to a spacing between the center of charges of $8 \mathrm{ft}$. Minimum delay between the charges was equal to a fraction of a millisecond, corresponding to a spacing between the center of charges of $1 \mathrm{ft}$.

Previously published data on vertically distributed charges by Shock, "Musgrave et al., ${ }^{12}$ and Martner et al. ${ }^{13}$ are somewhat sketchy and incomplete as far as the seismic net layout and recording of the seismic signals are concerned. There is also no direct comparison to equivalent signal charges detonated at equivalent depths.

\section{Horizontal Array-Linear Arrangement}

The effect of directional firing in a horizontal array was studied in Series IIID, which consisted of sequential detonation at a depth of 12 feet of three 1-lb charges separated by about $37 \mathrm{ft}$. single 3-lb charges, and single 1-jb charges (Fig. 12). In these experiments, a much longer delay could be introduced between the explosions since the charges were located far enough apart to prevent accidental damage or detonation by shock waves generated from adjacent charges. Maximum delay in this series was $200 \mathrm{~ms}$ and the minimum delay was 17 $\mathrm{ms}$. The 200-ms delay corresponded approximataly to the frequency of the Rayleigh wave and the 17-ms cillay to the average frequenc:, of the P-wave.

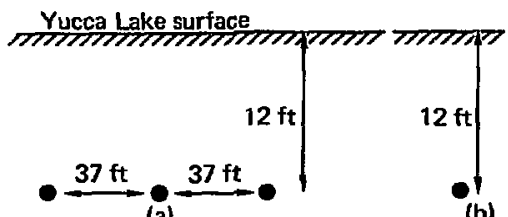

Fig. 12. Horizontal array, linear arrangement: (a) three 1-1b charges detonaled sequentially and simultuneously; and (b) single l-1b and $3-1 b$ charges.

\section{Horizontal Array - Circular Arrangement}

The study of three charges arranged in a horizonial linear array was extended by Series IIIC experiments consisting of detonating at a depth of 12 feet simultaneously four spatially distributed 1 -lb charges, single 4-lb charges, and single $1-\mathrm{lb}$ eharges. In this serics of $\mathrm{cx}-$ periments, a circular charge was approximated by four charges fired simultaneonsiy (Fig. 13). The radius "d" of this quasi-circle was $\mathbf{4 0} \mathrm{ft}$ for the first set of experiments and $80 \mathrm{ft}$ for the second set. The radii of these circles were chosen to be approximately one-half and one-quanet the wavelength of the Rayleigh wave to have some nominal relation to wave interference.

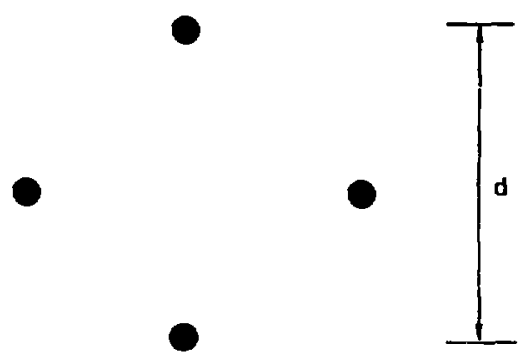

Fig. 13. Horkentel array, circular arrangerment: four 1-16 charges 12 it deep detonated simulianeously with spacing $\mathrm{I}=40$, $80 \mathrm{ft}$.

\section{Horizontal Array - I imit of Superposition}

Since the underlying principle of all multipleexplosion experiments is the superposition of two or more seismic waves. Series IIB experiments were designed to check the principle of superposition in its simplest form. This was achieved by recording seismic signals from two explosions at the same depth and varying only one parameter-the distance between the explosions. Prior to this series it was postulated thar Rayleigh-wave generating efficiency would pass a maximum at some predetermined distance between the charges and that the mechanism for such Rayleighwave enhancement could be related to the total elastic damage radius of the source encompassing, both charges in a dipole-related fashion.

The experimental configuration for this series of experiments consisted of simuitaneously detonating two single charges at a depth of $50 \mathrm{ft}$ (Fig. 14). The simultaneous explosions were 25 and $50 \mathrm{lb}$ each with spacings between the charges varying from 5 to $100 \mathrm{ft}$. The single charges were 25,50 , and $100 \mathrm{lb}$ each. 
Yucca Lake surface

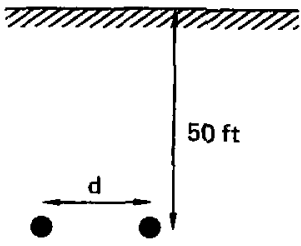

(a)

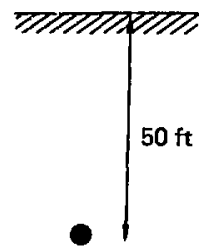

(b)
Fig. 14. Horizontal array, timit of superposition: (a) two 25-lb or 50-lb charges detonated simultaneously with spacing a varying from 5 to $1010 \mathrm{f}$ and (b) single 25-, 50-, and 100-lb charges.

\section{Nuclear Explosions}

To extend the dynamic renge of the smail-scale high-explosive experiments and acyuire the necessary field experience for design and selection of suitable instrumentation for peaceful nuclear explosions (PNE) moniloring activities associated with TTBT and CTBT. seismic signals from nearby nuclear explosions were recorded without interference with the main purpose of these explosions. The seismic signals were generated by single underground explosions below $40 \mathrm{kt}$ each conducted in the northern part of the Yucca Valley, and were recorded by geophones located on the surface of the Yucca Lake bed. The depths of the explosions were 210 and $466 \mathrm{~m}$ respectively.

\section{Surface Explosions}

The surface explosions were part of the PRE-MINE THROW IV series of experiments ${ }^{14}$ and were condusted for the Defense Nuclear Agency (DNA) by Physies Intemational Co. (PI). The purpose of these explosions was to obtain accurate ground-motion and crateryolume data for high-explosive detonations. The main objective in recording the seismic signals generated by these explosions was to observe the air-blast coupling to the Rayleigh wave as well as to bridge the gap hetween the small -scale explosive experiments and nuclear explosions. These experiments were conducted on the surface of the Yucca Lake bed and consisted of $0.5,7.1$, and 100.0 tons of high explosive, respectively. As with the nuclear explosions, paricipation in the surface experiments did not interfere with the main objective of these experiments.

\section{Seismic Line Layout}

The seismic lines for most of the small-scale highexplosive underground shots were laid out to observe the formation of the Rayleigh wave as a function of distance from the explosion and to gain an understanding of the azimuthal propagation of the seismic disturbance (Fig. 15). The spacing between the geophones varied from about 25 ft near the explosion to several hundred feet for geophones iucated furthest from the seismic source. The maximi'm length of the seismic line for the small-scale underground high-explosive charges was $2300 \mathrm{ft}$.

Signals from nuclear explosions were detected by the same geophones as for the small-scale high-explosive experiments, the distance from thic nuclear explosions to the nearest geophone was about $16 \mathrm{mi}$.

For surface explosions, the seismic line uxtended up to 5000 fi from the explosions and was in line with the main Physics Intemational ground motion line show's in Fig. 35.

The description and exact location of seismic lines with respect to each firing field is given in the Appendix.

\section{High-Explosive Assemblies}

The ideal high-explosive source for the seismic wave study would. of course, have been a spherical charge, but the difficult assembly of such charges prompted the substitution of cylindrical charges.

Due to the large number and variety of highexplosive charges involved, plastic explosive Composition C-4 (60\% TNT, 40\% RDX, with plastic binder) was used for all small-scale underground explosions. The plastic explosive was chosen over the better characterized solid explosive, since charges could then be made by simply packing C.4 into a desired container, rather than machining or pressing the solid explosive.

A typical high-explosive assembly is shown in Fig. 16. Charges up to $4 \mathrm{lb}$ had one detonator and were placed in a cardboard container; charges of $25 \mathrm{lb}$ and over were contained in a sheet metal cylinder and had two detonators as a safety measure.

For most of the charges the tengtt.- co-diameter ratio was kept to less than 2. However, for charges of $25 \mathrm{lb}$ and over, it was not econcmical to bore holes more than $8 \mathrm{in}$. in diameter, and thus the charges were made into long cylinders. For example, the largest charge weighing $100 \mathrm{lb}$ consisted of a cylinder 8 in. in diameter by 5 fi long.

Initially, standard Reynolds High Voltage RP-1, 1.5 mil bridgewire headers with 1/2-inch tetryl pellet boosters were used to initiate the charges. This assembly, however, proved to have a rather fragile bridgewire for field use and a relatively short shelf life, causing several misfires. The problem was traced to oil from Compusition C-4 which would penetrate in several weeks the silastic coating of the tetryl pellet and desensitize the booster. 


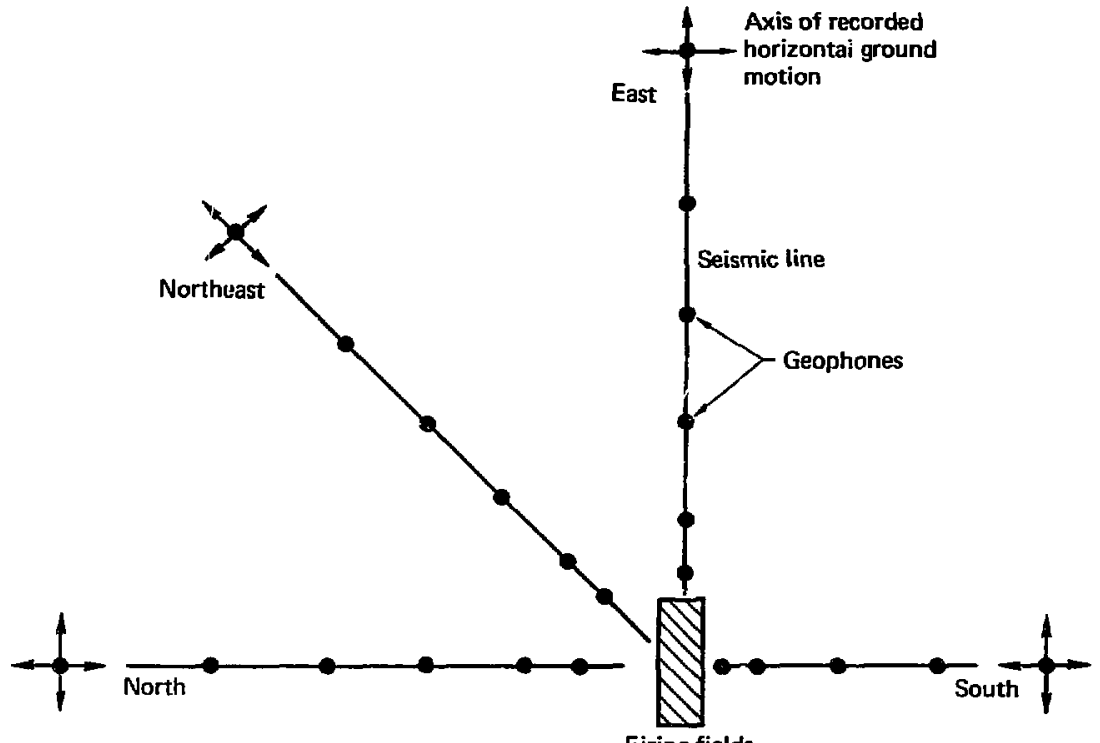

Firing fields

Fig. 15. Selsmic line layout for small-scale underground explosions.

To prevent further misfires, custom-mad; Reynolds RP-1 boosted detonators were used (Fig. 17). The new Reynolds assembly consisted of a 5-mil exploding bridgewire, initiating low-density PETN, high-density PETN, and high density RDX booster. The assembly was sealed in a brass container to eliminate the possibility of oil penetration from $\mathrm{C}-4$ into the detonator assembly.

The 20- and 16-ft-long distributed charges were manufactured by Explosive Technology, Inc. They consisted of $450 \mathrm{~g}$ PETN enclosed in aluminum tubing about $\mathrm{I} / 2 \mathrm{in}$. o.d. The charges were initiated by a single Reynolds RP-1 Detonator boosted by a 1/2-in. Tetryl pellet, providing a reliable charge with a long shelf life, since C-4 was not involved in the assembly.

To function as an exploding bridgewire detonator, electrical energy is applied to the bridgewire. The amount of energy has to be great enough to heat the wire to vaporization. Within a few ns after vaporization, the inertia of the wire material is overcome and the wire explodes, giving off a shock wave and the contained thermal energy. In general, the shock wave from the wire travels about $1500 \mathrm{~m} / \mathrm{s}$. As the shock wave travels through the low-density PETN, a detonation is initiated the: builds up to approximately 5000 $\mathrm{m} / \mathrm{s}$, close to the normal detonation velocity of the low-density explosive. Subsequentially, the detonation wave moves into the high-density PETN and the shock wave again increases, due to the higher density of the explosive to about $8000 \mathrm{~m} / \mathrm{s}$. The final detonation velocily in PETN has enough energy to detonate the RDX booster explosive, which in turn initiates the Composition C-4 charge. The arrangement of high explosives in a detonator assembly according to their sensitivities and energy release to initiate a larger highexplosive charge is commonly referred to as the "detonation train."

The primary reason for using exploding-bridgewire detonators is their inherent safety characteristics and reliability. Thus, only secondary explosives were used in all parts of the high-explosive assembly, and the high voltage necessary to initiate the explosion prevented accidental detonation. 


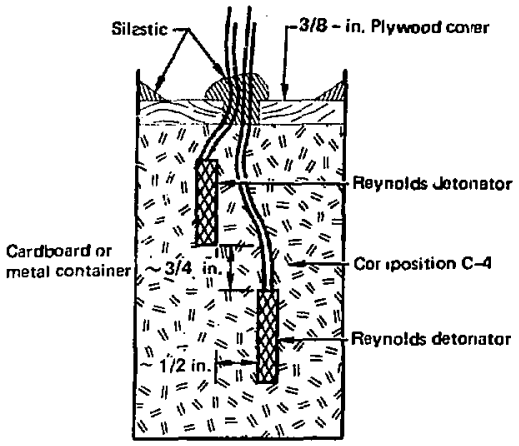

Fig. 16. High-explosive assembly.

\section{Instrumentation}

The electronic equipment necessary to fire the highexplosive charges and to record the ground motion was located in an air-conditioned instrument trailer powered by two diesel generators from a nearby powergenerating trailer. The trailer complex also included a portable high-explosive magazine for storage of charges prior to firing (Fig. 5). Postshot excavation ef explosive-generated cavities was carried out with a backhoe and handtools.

\section{High-Explosive Firing System}

The small-scale high-explosive charges were detonated by exploding the bridgewire within the detunator by a 2.5-kV Capacitor Discharge Unit (CDU; LLL desig., specification LE 8283-1B). The main components of the firing system shown in Fig. 18 were located in the instrument trailer and consisted of a trigger unit. delay units to detonate multiple charges, and several trigger CDU's. To reduce the inductance introduced by the 600 -ft-long cables between the instrument trailer and the detonator, a booster CDU for each ietonator was placed near the emplacement hole.

The basic components of a CDU are shown in Fig. 19: a $6.5-\mu \mathrm{F}$ capacitor, a $96 \mathrm{~K}-\Omega$ charging resistor, a transformer, a three-element spark gap, and peripheral circuits to monitor the charging and discharge cycles. In operation, the capacitor is charged to a desired voltage and the bridgewire is isolated from the high-voltage source by the spark gap. The three-element spark gap consists of two flat plates about $1-3 / 4$ in. in diameter, separated by a gap of 0.055 in. filled with gas. The adjacent side of the gap is connected to the trigger circuit and the opposite to the bridgewire. To fire, a trigger pulse in excess of $1000 \mathrm{~V}$ is applied to the trigger circuit, which transforms it to a $5000 . \mathrm{V}$ pulse by the transformer. When the boosted trigger pulse is applied to the adjacent plate, it ionizes the gas within the gap, causing the capacitor to discharge, exploding the bridgewire and initiating the detonation train.

\section{Geophones}

The main instruments used to detect the ground motion were 4.5 - and $1.0-\mathrm{Hz}$, three-component electromagnetic velocity-sensitive geophones with a nominal response characteristic of 1.5 and $15.0 \mathrm{~V} / \mathrm{in} . / \mathrm{s} \mathrm{re-}$ spectively. Thiese are constructed of two coils each wound in opposite directions about a bobbin supported by springs, a centrally located cylindrical magnet rigidly attached to the casing of the geophone, and a cylindrical pole piece to direct the magnetic field perpendicular to the coil windings. When the earth moves, the magnet and its support also move. Because of inertia, the coil tends to remain stationary and lags behind the motion of the earth. The resulting relative motion between the coil and the magnet produces an electromagnetic force across the terminals of the coil that is proportional to the velocity of this motion. Figure $\mathbf{2 0}$ schematically illustrates a fixed magnet and a movable coil geophone.

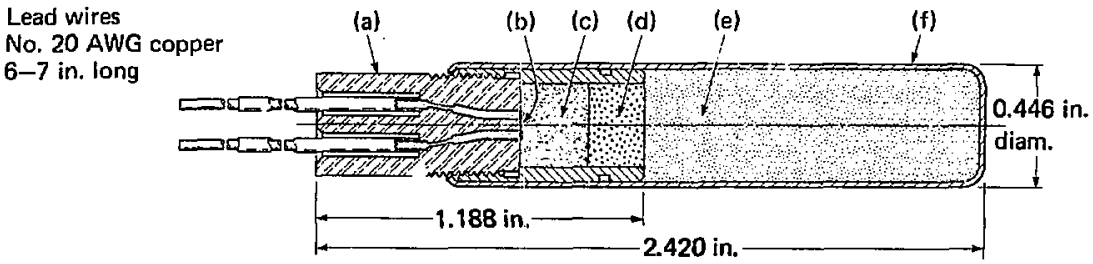

Fig. 17. Custom-made Reynolds RP-1 exploding-brldgewire detonator: (a) molded header; (b) bridgew/re, 5-mil; (c) inillating low-density PETN, 0.25 g; (d) high-density explosive, high-density PETN, 0.365 g; (e) booster explosive, high-density RDX, 3.7 g; and (D support sleeve, chrome-plated bress, $0.02 \mathrm{ln}$. 


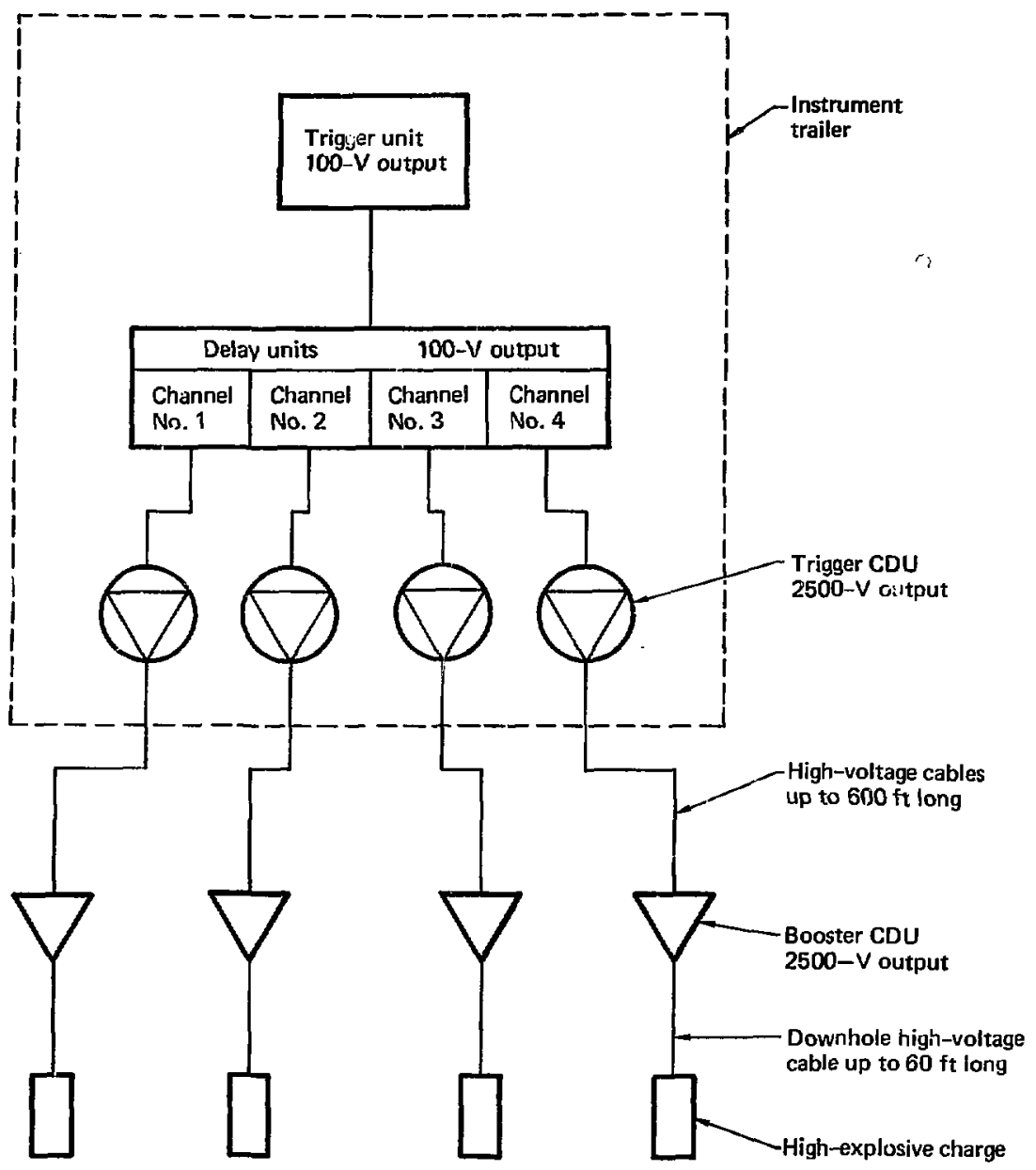

Fig. 1B. Firing system block diagran. 


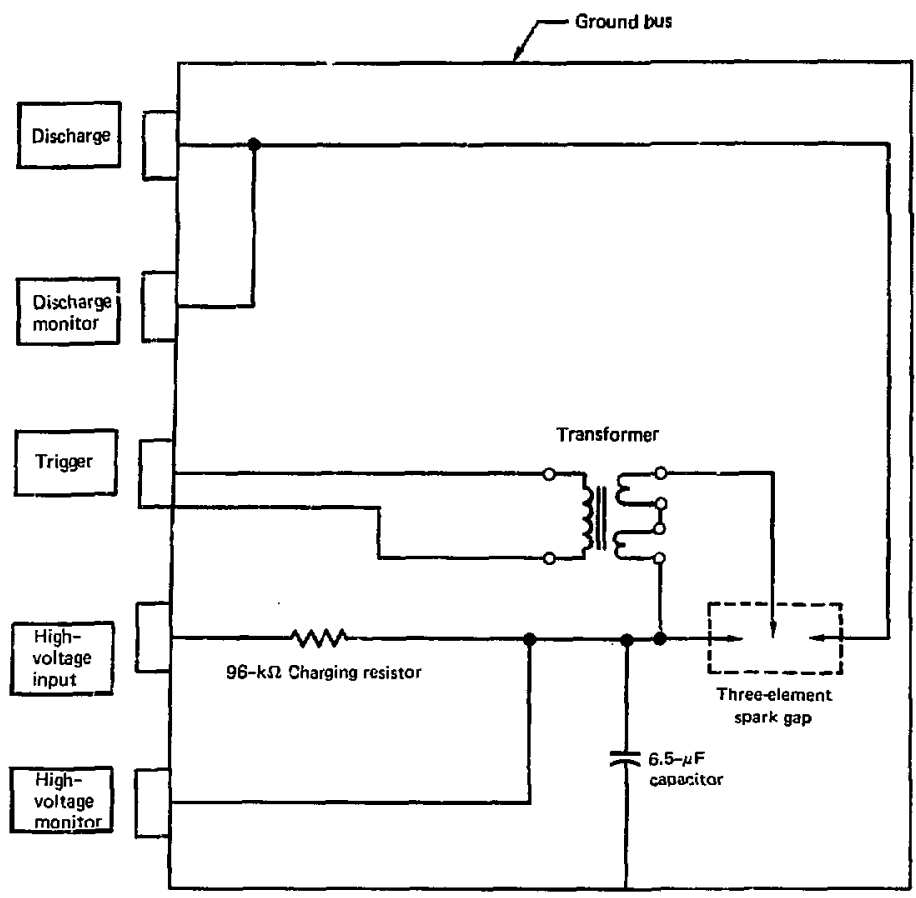

Fig. 19. Cepocitor discharge unit schematic.

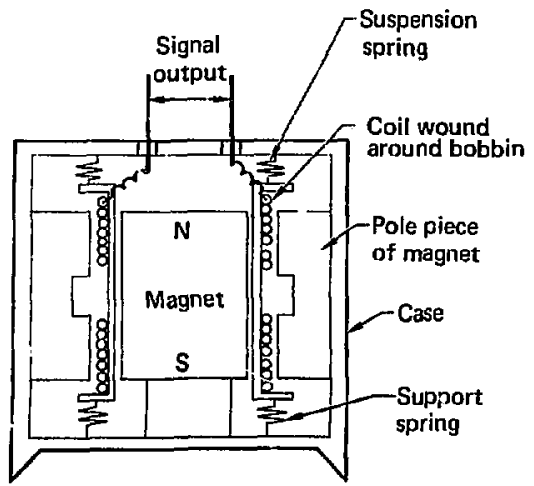

Fig, 20. Electromagneltc geophone schematic: cotl wound about the bobbin is inertial element; case moves with the earth.
The 4.5-Hz geophones (Fig. 21), manufactured by Mark Products, Inc., were sealed into a waterproof container by the manufacturer and did not require special handling except for grouting in the field with plaster of Paris. The 1.0-Hz geophones (Fig. 22), manufactured by Geo Space Corporation, were mounted in a special bracket for proper alignmeni (Fig. 23), and then placed into a waterproof container (Fig. 24). Both the bracket and the container were built to LLL specifications. The sealed container was then placed in the ground, leveled, and coupled to the surrounding medium with plaster of Paris (Fig. 25). Each geophone vas calibrated in situ by recording its natural frequency, the resistance of the coil and the resistance of the damping resistor.

In addition to the above mentioned irstruments, a number of other geophones were used to record the ground moxions. The exact locations, types of instruments, calibration procedures and specifications of all geophones are viven in the Appendix. 


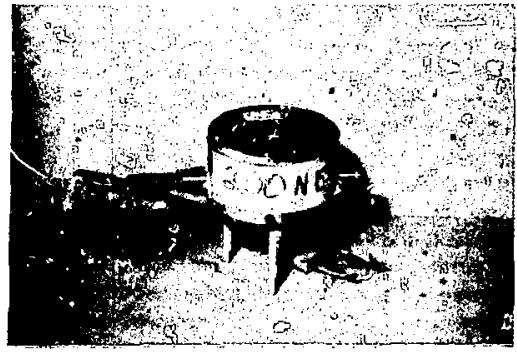

FTg. 21. Three-component 4.5-Hz geophone (Mark Products, Inc.).

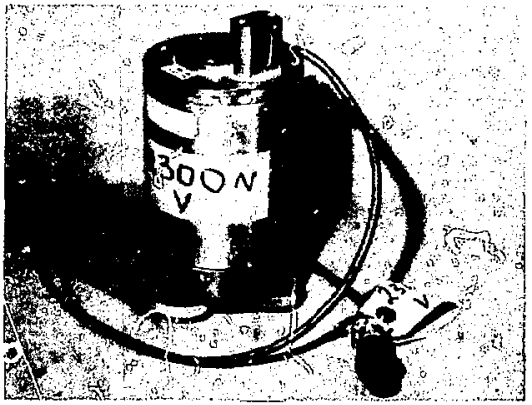

(a)

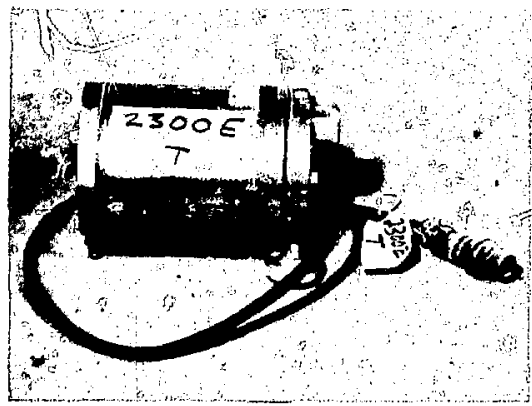

(b)

Fig. 22. Geophones: (a) vertical-component unit, 1.0 Hz; (b) horizontol-componeat unit, 1.0 Hz. (Both Geo Space Corp.)

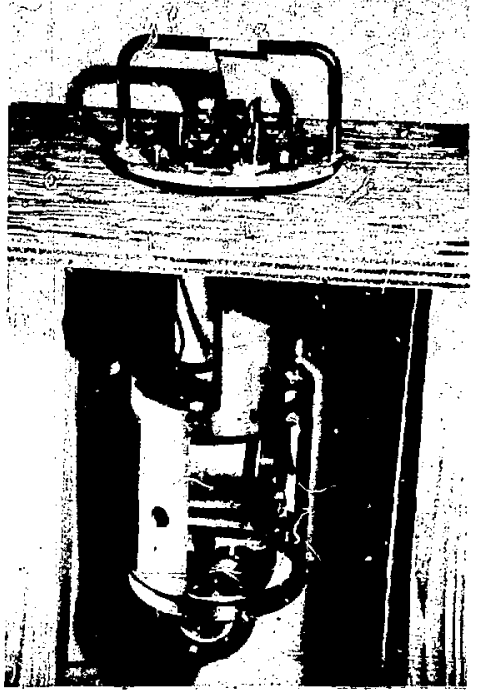

Fig.23. Geophone holder and alignment bracket for 1,0-Hz geophones.

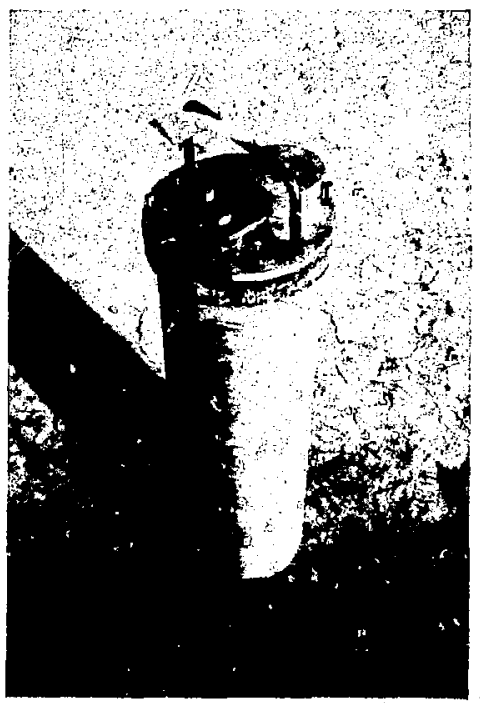

FIg. 24. Assembled three-component 1.0-Hz geophone package sealed in a watemroof container. 


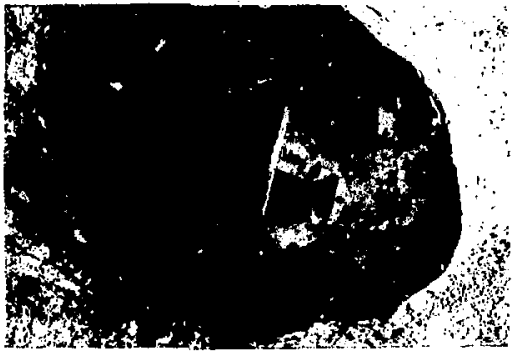

Fig. 25. Emplacement of three-component 1.0-Hz geophone container.

\section{Accelerometers}

To detect the extent of spall caused by the smallscale underground explosions, surface acceleration above the explosion was measured with accelerometers. Since the formation of spall is most readily identified by "free fall," only the vertical component of the acceleration was recorded. The instruments used to record the spall were "force balance" servo unitsKistler Model 305A. The accelerometers were placed 2 to $12 \mathrm{ft}$ from the emplacement holes and were mounted on 6-in.-long, 1-1/2-in.-by-1-1/2-in. wooden pegs driven flush into the ground.

The components of the accelerometer shown in Fig. 26 are the seismic mass consisting of a space-wound forcer coil and a capacitor plate, a truncated conical permanent magnet with a pole piece, a capacitive displacement sensor, and an amplifier. The seismic mass is supported by six flexures arms (Fig. 27) forming three dynamic parallelograms that have purely translational motion along the axis of the casing. The pole piece directs the magnetic field perpendicular to the windings of the forcer coil.

in operation, the seismic mass is minutely displaced with respect to the casing when the unit is subjected to acceleration. The displacement unit detects the movement of the mass relative to the case. The amplifier converts this displacement signal into an electrical current which is fed into the forcer coil located in the permanent magnetic field generating a proportional force that is applied to the seismic mass. In this manner, the spatial separation between the seismic mass and the displacement sensor is held constant by balancing the force created by acceleration against the electronically generated restoring force. Since the restoring force is proportional to the acceleration, the electrical output signal of the servo accelerometer is also proportional to the acceleration.

\section{Data Recording}

The signals from the geophones were amplified in the diagnostics trailer, converted from voltage to frequency records by Voltage-Controlled Oscillators (VCO's), and then recorded in the analog form several geophone signals per tape track (Fig, 28). This condinsed form allowed up to four geophone records per tape track. The analog tapes recorded in the field were digitized in Livermore, where the reverse process took place: the condensed data were read with discriminators corresponding to the carrier frequencies of the VCO's, converted to digital form, and recorded on magnetic tape. Subsequently, the digital data stored on tapes were processed by a Control Data Corporation (CDC) 7600 computer and stored on photostore, providing an easy access for analysis and data handling.

The signals generated by the accelerometers were displayed directly on oscilloscopes in the instrument trailer and recorded on Polaroid film.

\section{Cavity Excavation}

The seismic records were complemented by excavation of several selected cavities from Series II and IIIA. First a 3-ft-wide trench was dug with a backhoe along the row of the emplacement holes to a depth of several feet below the cavity location without exposing the cavity (Fig. 29). Then the cavities were carefully opened with handtools, cleaned, and photographed. Figure 30 shows an excavated cavity generated by $150 \mathrm{~g}$ of high explosive buried $4 \mathrm{ft}$ deep. The soot and smoke

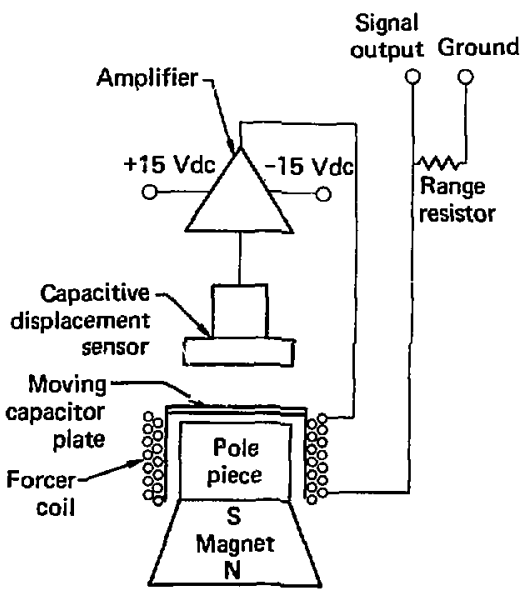

Fig. 26. Schematic of "force halance" servo accelerometer. 


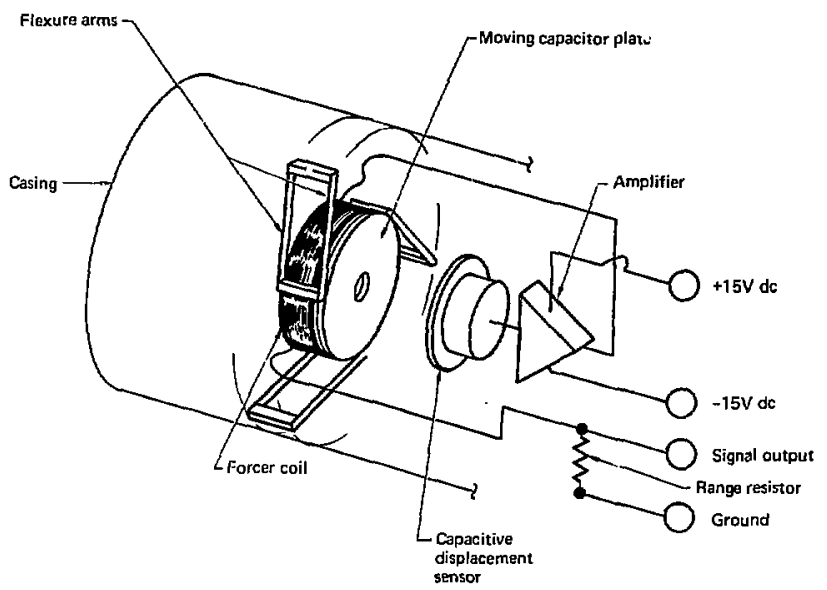

Fig. 27. Accelerometer assembly.
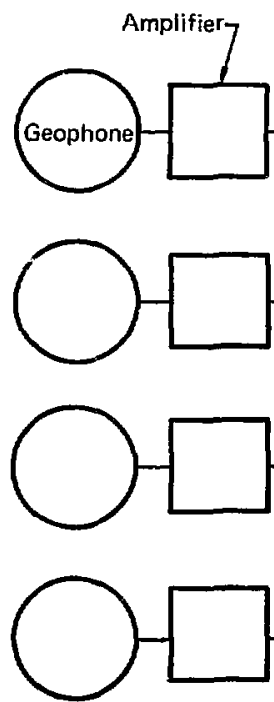

14-track analog tape

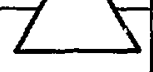

Track

No. 1
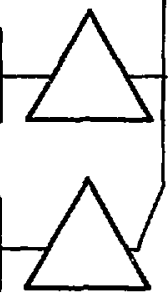

Field recording

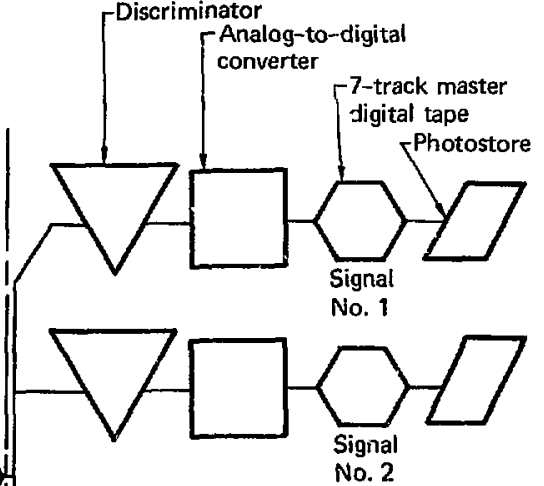

No. 2

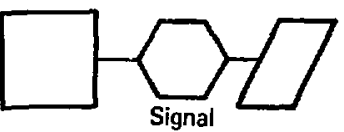

No. 3

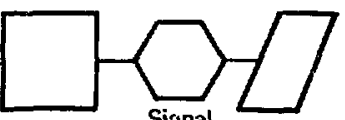

Signal

No. 4

Ng. 28. Schematic of field-recording and LLL-digitizing operations. 


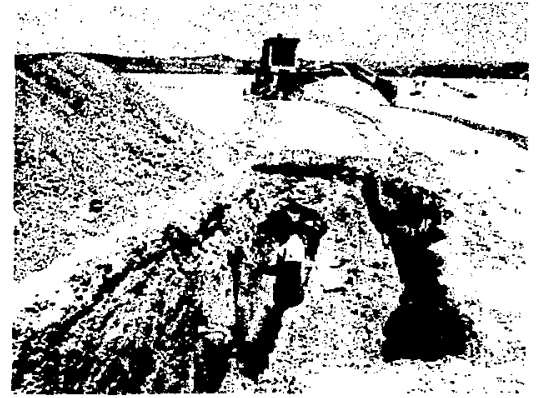

Fig. 29. Excavation of cavities.

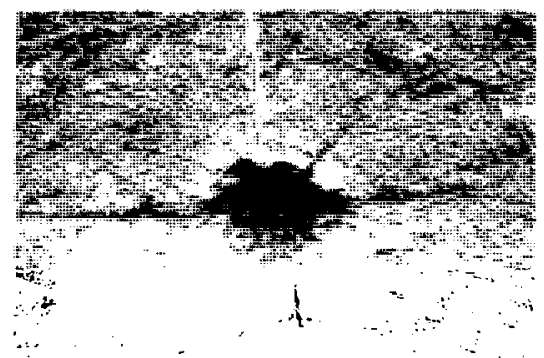

Fig. 31. Ekeavated cavity generated by $150 \mathrm{~g}$ Composition C-4 buried $4 \mathrm{f}$ deep (cavity diamcter $=-10 \mathrm{in}$. . generated during the explosion served as an excellent marker for outlining cracks formed during and immediately after the explosion. The recora shows the well-developed radial cracks radiating from the center of the cavity at an angle of $45^{\circ}$ with respect to the harizonial and rectangular cracking of the cavity walls. A close-up of the same cavity is shown in Fig. 31.

A view of a cavity excavated to show the cracks along the vertical plane is given in Fig. 32. Excavated cavities generated by a simultaneous explosion of three charges of $50 \mathrm{~g}$ each are shown in Fig. 33.

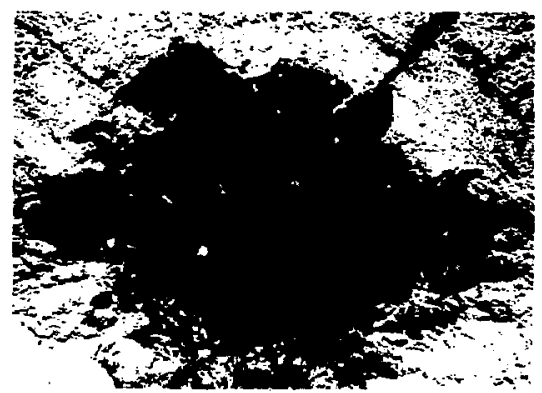

Fig. 31. Detail of cavîty shown in Fig. 30.

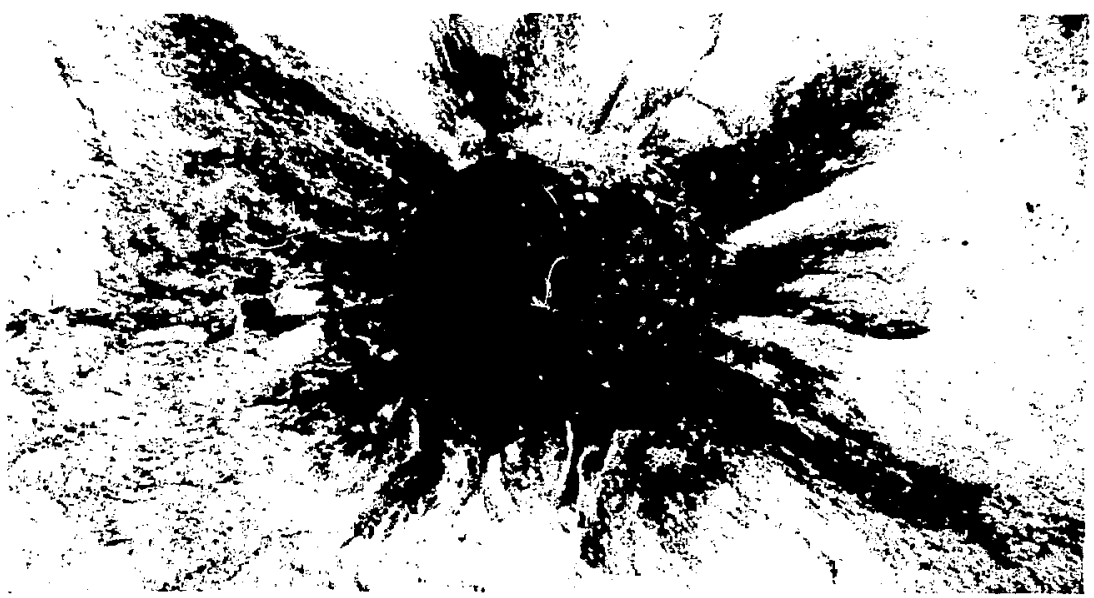

Fig. 32. Yertical cractis of excavated cavity. 


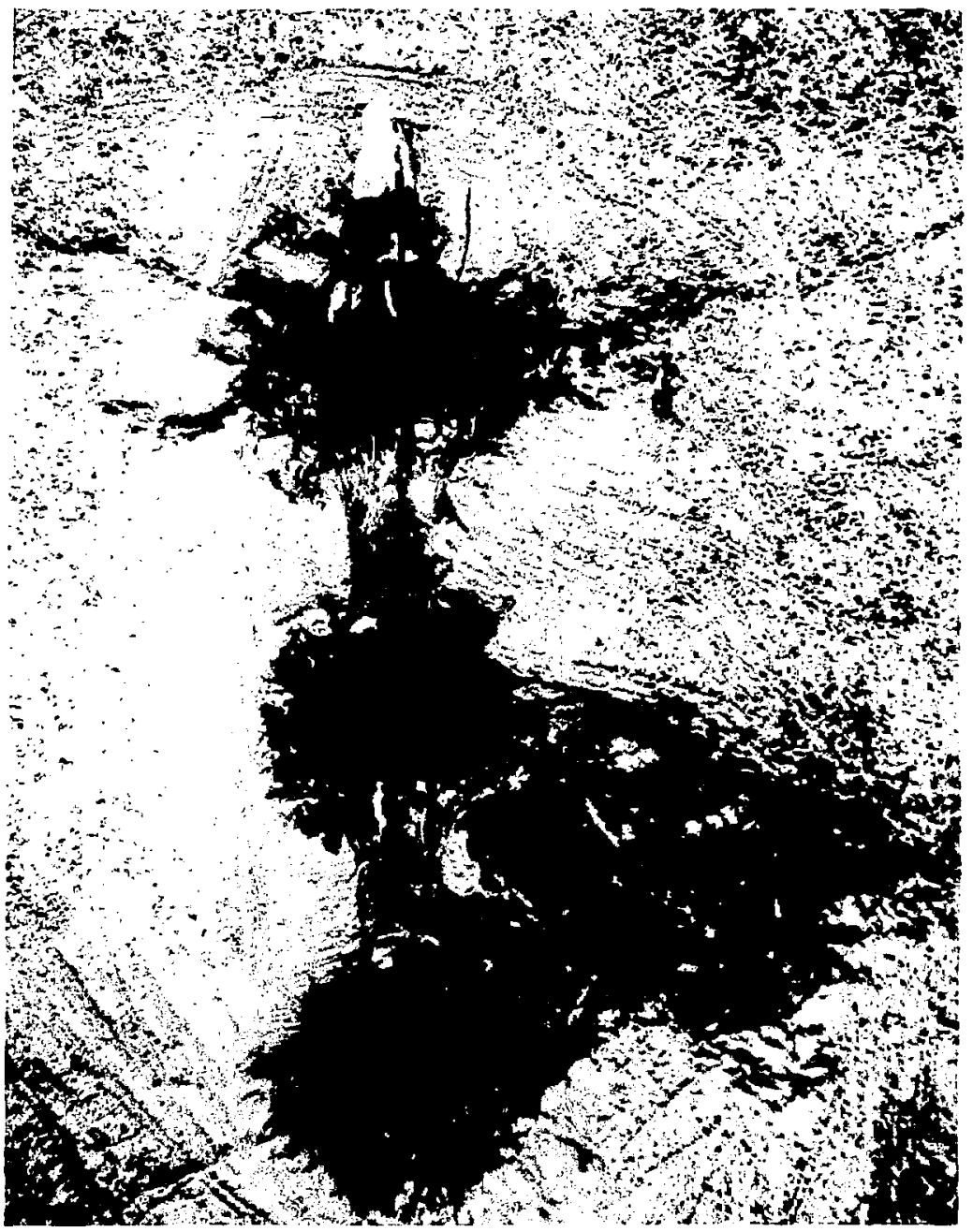

Fig. 33. Excavated cavities generated by three simultaneous explosions of Camposition $\mathrm{C}-4,50 \mathrm{~g}$ each, with depths of 4 , 5 , and 6 ft, respectively (cavity diameter $=\sim 7$ in.). 


\section{Data Storage}

In organizing the entire data base of some 5000 seismograms, special care was taken to identify the experiment each scismic record was part of. To achieve this, each record was labelled by its series number, shot number, units the data is represented in, location of the recording geophone and axis of the recorded ground motion. For example, the seismogram AK2, SHOT 1, BITS, I0OVS refers to Series 2, Shot 1, bit format, geophone location $100 \mathrm{ft}$ soutb from the explosion, vertical axis.

For direct access to the data for plotting, processing and viewing of the seismograms on a visual display unit-TMDS, the entire data set was digitized and then stored on magnetic tapes and on the LLL photostore.

\section{Analog-to-Digital Conversion}

The seismic field data recorded in analog form at NTS were digitized at LLL by the program-controlled EMR data-handling system composed of an EMR 6130 computer, an EMR telemetry console, and other peripheral equipment. This system can handle data rates of 750,000 8-bit data bytes per second in 27-ms segments. The typieal sampling rate for digitizing was $10 \mathrm{kHz}$ with 12,288 bits from bandedge to bandedge.

The digitized data were first stored on a 7-track digital tape using a routine called $B A B Y^{15}$, viewed for verification via a CRT with the BBYPLOT ${ }^{16}$ routine, and printed on the Line Printer with the CPLT ${ }^{37}$ routine. since a baseline shift was incurred due to the center-frequency variation, every seismic record or file was normalized with the $\mathrm{BBCAL}^{1 \mathrm{~B}}$ roitine to the baseline recorded several seconds prior to zero time.

\section{Photostore}

The digitized data were stored on photostore with LLL subroutines ELF ${ }^{19}$ and ADCFLS ${ }^{20}$, in the SOCKITTOME ${ }^{21}$ forinat, making them available for processing and plotting by this convient, conversational code. To facilitate the location of a desired seismogram, the data were stored in the available photostore directory format. To protect the original data. TAKF. files were created that permit users to access data but prevent them from writing over the original files.

The entire data set is strol under the YUCCA directory with other subdirectories referring to the actual identification of the series, the shot number, units, and finally the files themselves, identified by the geophone location and the direction of the recorded ground motion. The LLL subroutine LST": (Fig. 34) can be used to quickly locate the necessary file in the computer storage by entering the main directory YUCCA and subsequently opening the desired subdirectories froin the listing provided. 
ELF/ 22

- LST -R:YUCCA

DM-PO AK1

DM- PO AK2

DM- PO AK3

DM-PO MINE THROW

DM-PO NUCLEAR

LST

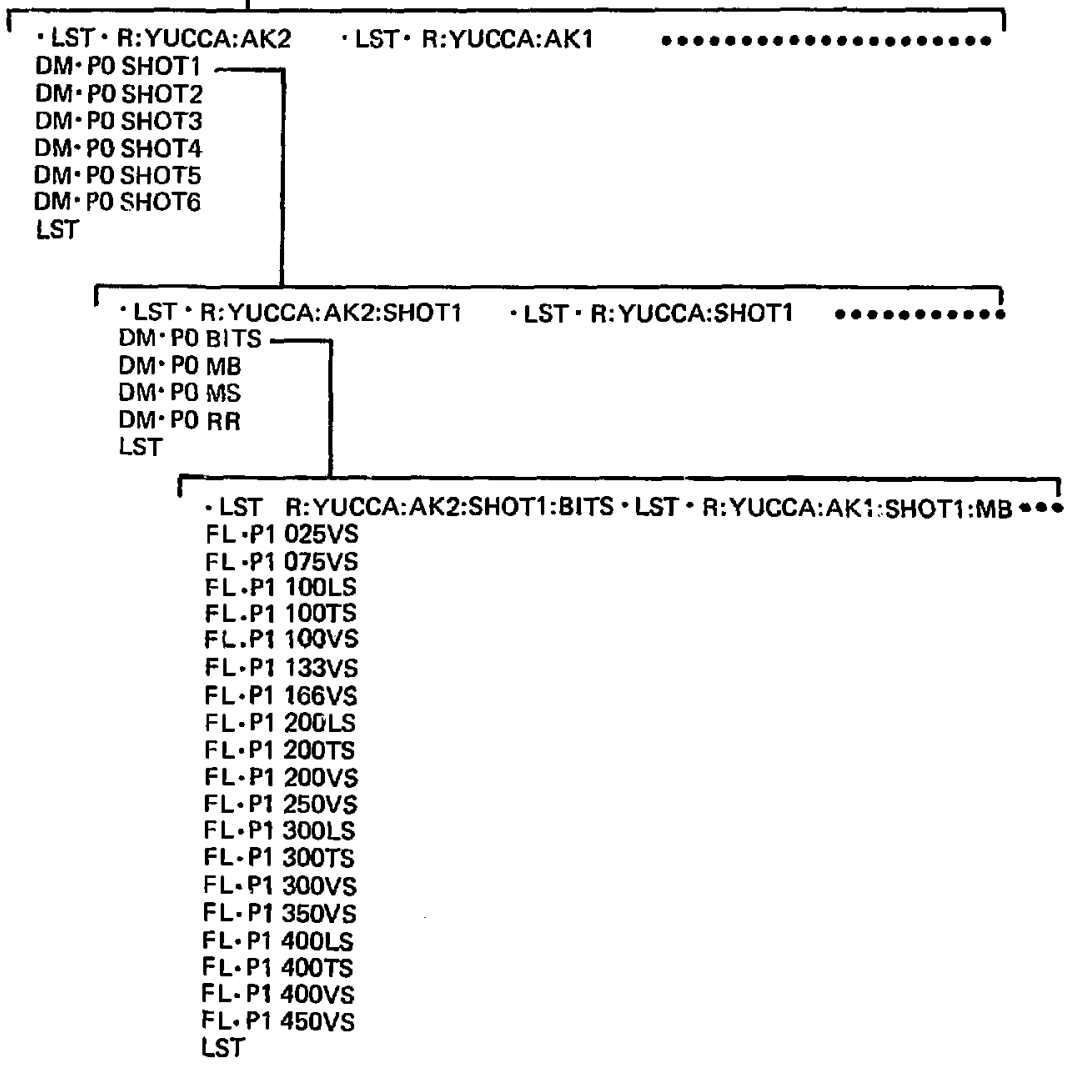

FL -P1 025VS

FL -P1 075VS

FL.P1 100LS

FL.P1 100TS

FL.P1 100VS

FL.P1 133VS

FL.P1 166VS

FL.P1 200LS

FL.P1 200TS

FL.P1 200VS

FL.P1 250VS

FL.P1 300LS

FL.P1 300TS

FL.P1 300VS

FL.P1 350VS

FL.P1 400LS

FL.P1 400TS

FL.P1 450VS

LST

ALL DONE

-BYE

Fig. 34. Call routine for locating selemic records malntained on photustare. 


\section{ACKNOWLEDGMENTS}

The reported work was part of the LLL Seismic Monitoring Research Program, performed under the management of $H$. Rodean, guided by $W$. Hannon and administered by D. Larson. The original concept of directional firing and the investigation of the depth of burial effect was suggested by P. Rodgers. The limit of superposition series was suggested by $T$. McEvilly of the University of Califomia, Berkeley, Califomia. Downhole logging was interpreted with the help of $J$. Richter from EG\&G. Data recording and firing of the high explosive charges were performed by \$. Spataro, C. Cornell, K. Moyle and J. Scarafiotti. Most of the field work support was provideal by J. Taylor with the assistance of Reynolds Electrical and Engineering Company. The high-explosive charges were designed with the help of D. Wooster and assembled by $\mathbf{S}$. Baker and $F$. Gorecki. Data storage and processing were assisted by $M$. Sharp. M. Higuera, $M$. Jepson. $D$. Taasevigen, and T. Meyer. The participation in the nuclear events was made possible by $\mathbf{F}$. Beane, $R$. Ide, and $L$. Crooks, and surface explosions were fielded by Physics International Corporation under the direction of F. Sauer.

This work was supported by the Defense Advanced Kesearch Projects Agency and the Department of Energy under contract No. W-7405-Eng-48. 


\section{APPENDIX}

\section{Selection of the Seismic Fields}

In selecting a suitable seismic field for each series of experiments on the surface of the Yucca Lake, three major constraints had to be taken into consideration.

The most obvious interference with the propagation uf seismic signals would, of course, arise from the deep cracks at the southern end of the Yucca Lake. Second, the ongoing Physics Intemational experiments required . that the LLL instrumentation trailers be at least $4000 \mathrm{ft}$ away from Event No. 6, 1000-ton surface shot, due to the expected overpressure from the explosion. The last major constraint, although not readily visibie, was the southem end of the Yucca fault cutting across the lake bed. Care was taken to locate the seismic fields at a safe distance to minimize the influence of the expected interference. Howsver, in the case where more than one seismic line was used, several geophones had to be located very close to the fault line.

The location of the seismic fields is shown in Figs. 35-37.

\section{Shot Description and Layout}

A description of each LLL-fielded experiment is provided in the paragraphs that follow. Since the fielding of nuclear and surface explosions was the responsibility of other experiment groups, only information directly pertinent to the recording of seismic signals is given.

Once the field for a particular LLL series of experiments was selected, care was exercised to minimize the interference between experiments by providing adequate spacing between emplacement holes and fire shots in an order that eliminated the passage of the seismic disturbance through a zone already rubbelized by previous explosions. To facilitate the comparison between experiments, all shots of a particular series of experiments were placed above or below the 23-ft velocity contrast.

The emplacement twoles varied ketween 2 to 8 in. in diameter. The 2-in.-diameter holes vere used for the smallest explosions, 4-in,-diameter holes for the intermediate, and the 8-in.-diameter holes for the largest high-explosive charges. The choice of diameters was partially influenced by the desire to maintain the length-to-diameter ratio of charges as close to 2 as practical.

The 2-in.-diameter explosions were stemmed only with plaster of Paris. The other shots were stemmed with alternating layers of Monterey sand and magnetite sand to attenuate the shock wave in the emplacement holes; they were capped with a plaster of Paris plug.

All explosive charges were lowered by hand into the emplacement holes with a nylon rope.

\section{Series I}

This first series of experiments consisted of explosions from $50-450 \mathrm{~g}$, and was mainly ashakedown series designed to check the firing and diagnostics systems, to develop a suitable high-explosive charge, and to answer a number of other questions associated with the field work. Figure 36 and Table 2 give the location and description of these experiments.

\section{Series II}

The main objective of Series II experiments consisting of explosions from $150-450 \mathrm{~g}$ was to determine the depth of burial effect and compare the Rayleigh-wave generaüng efficiency between single and multiple explosions arranged in a vertical array. The geophones for this series were also laid out to obtain a detailed seismic survey of the lake bed that included reverse firing. (Figs. 38-40).

For sequential detonations in the downward direction, the explosive chirges could not be placed into a single emplacement hole since the upper charge, which would be detonated first, would bave destroyed the firing cables of the lower charges. The bore-hole configuration for those experiments consisted of three separate emplacement holes-the upper charge was placed in a vertical hole and the lower two charges into emplacement holes drilled at an angle of $30^{\circ}$ with the vertical and offset radially with respect to each other to minimize communication during the drilling operation (Fig. 41).

The description of this series is summarized in Table 3. 


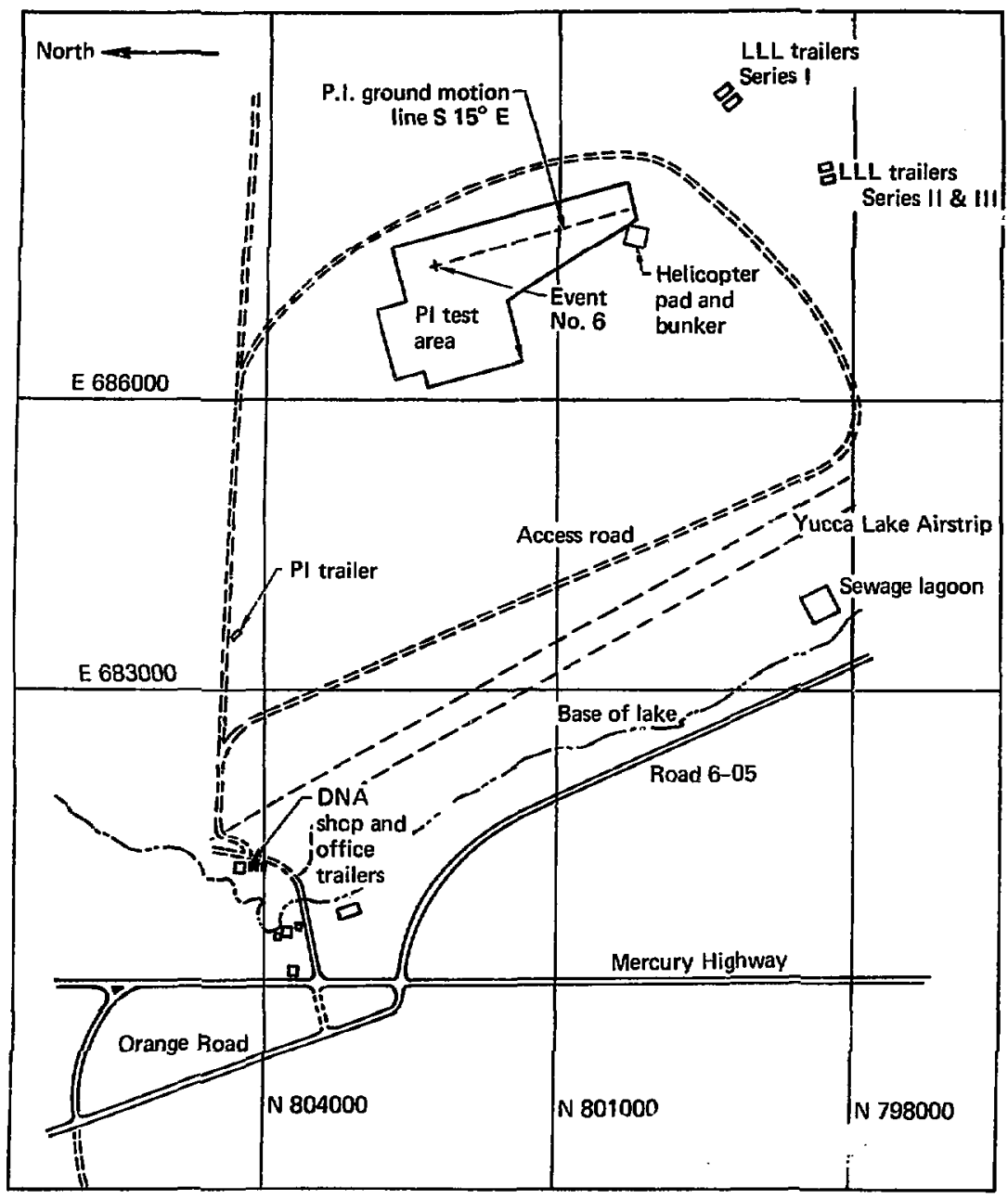

Fig. 35. Location of seismic experiments, 
Seismic line

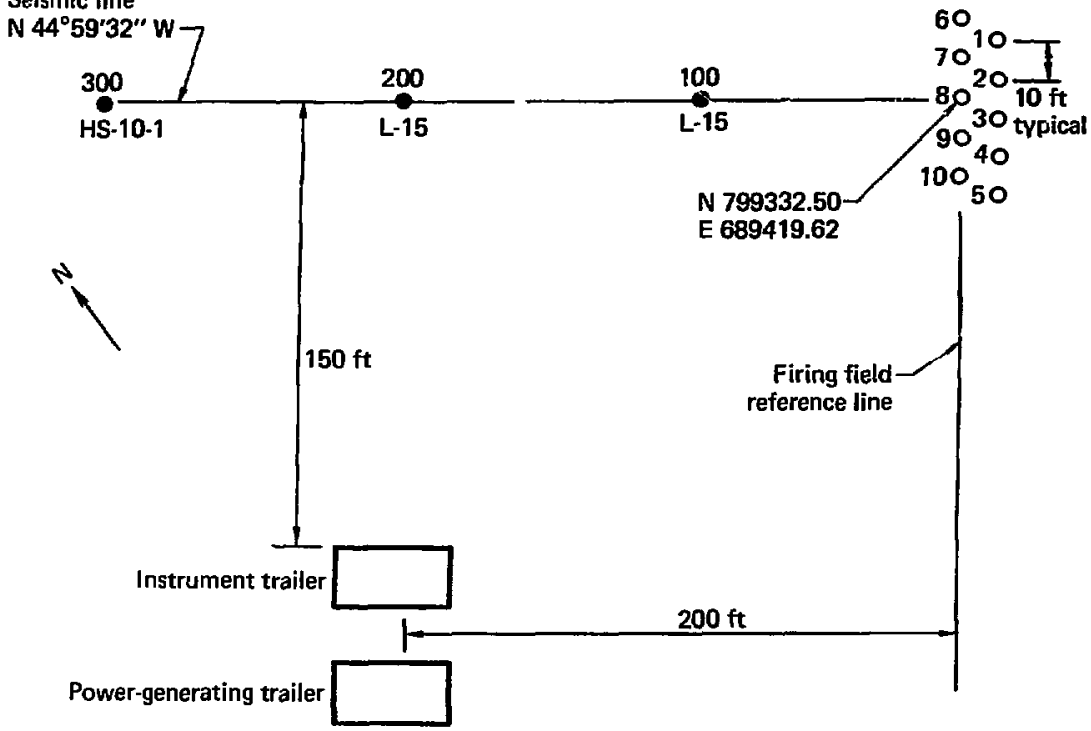

\section{Legend:}

L-15 - 4.5-Hz, 1.5-V/in./s, three-component geophone

HS-10-1-1.0 Hz, 15.0-V/in./s, vertical-component geophone

- Geophone location and corresponding distance in feet from the firing field reference line

o- Emplacement hole location and corresponding shot No.

Fig. 36. Series I selsmic Teld tayout.

Table 2. Series I shot deseription

\begin{tabular}{|c|c|c|c|c|c|}
\hline Shot Na. & No. charges & $\begin{array}{c}\text { Weight } \\
\text { each } \\
\text { charge, } \\
\text { g }\end{array}$ & $\begin{array}{c}\text { Depth of a } \\
\text { burial, } \\
\text { in. }\end{array}$ & $\begin{array}{l}\text { Delonatlou } \\
\text { configuration }\end{array}$ & $\begin{array}{c}\text { Delay } \\
\text { between } \\
\text { detonntloas } \\
\text { uns }\end{array}$ \\
\hline 1 & $\mathbf{I}$ & 150 & 55 & - & - \\
\hline 2 & $\mathbf{1}$ & $\mathbf{3 0 0}$ & 55 & - & - \\
\hline 3 & 1 & 450 & 55 & 一 & - \\
\hline 4 & 1 & 150 & 29 & 一 & 一 \\
\hline 5 & $\mathbf{1}$ & 300 & 33 & 一 & - \\
\hline 6 & 1 & 450 & 28 & 一 & - \\
\hline 7 & 3 & 50 & $40.5,55.5,70.5$ & Simultaneous & - \\
\hline 8 & - & 一 & - & 一 & - \\
\hline 9 & 3 & 50 & $40.5,55.5,70.5$ & - Sequentiol "up" & 0.5 \\
\hline 10 & 3 & 50 & $41.5,55.5,69.5$ & Sequential "up" & 0.3 \\
\hline
\end{tabular}




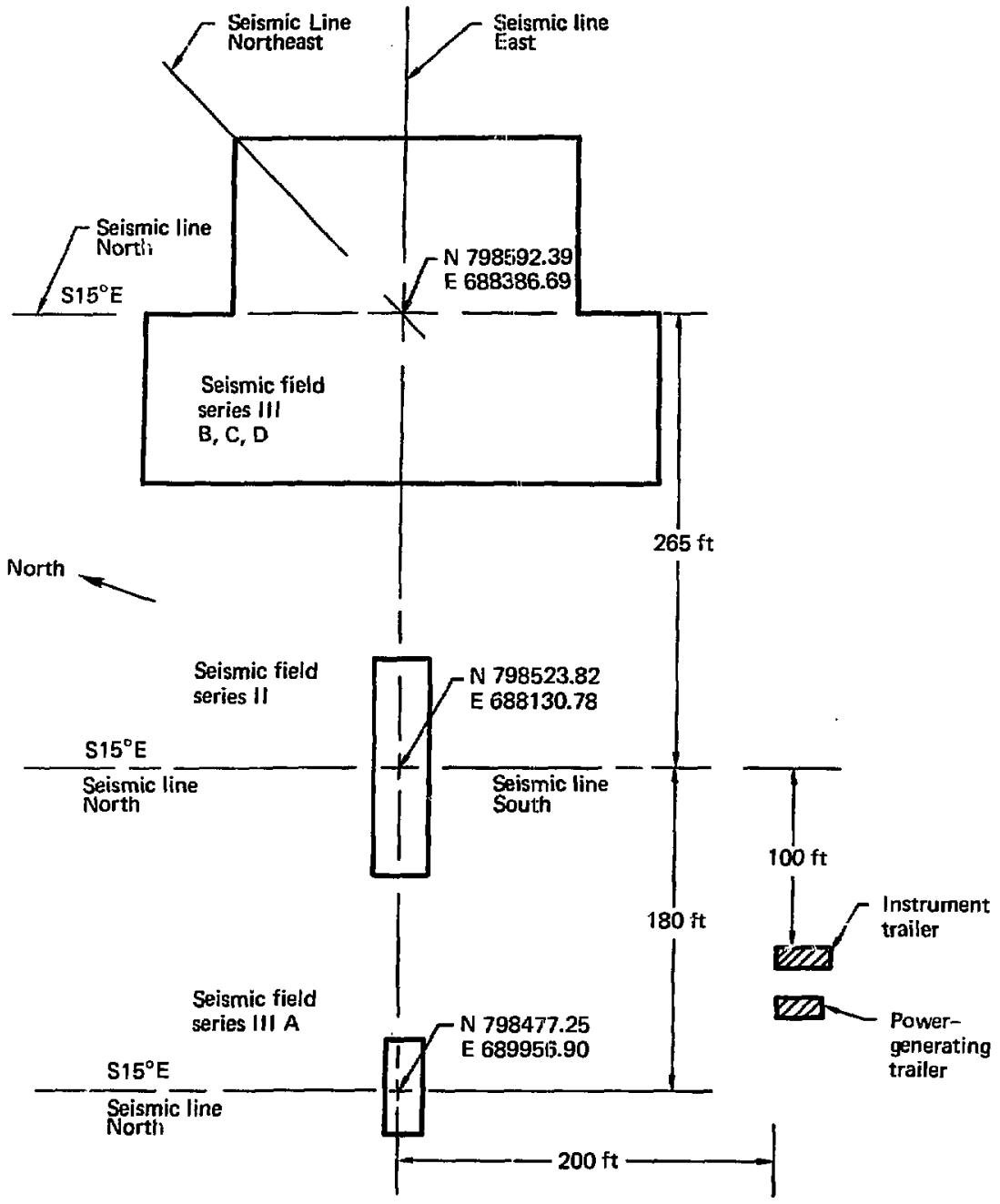

Fig. 37. Series II and IIl seisnic freld layout. 


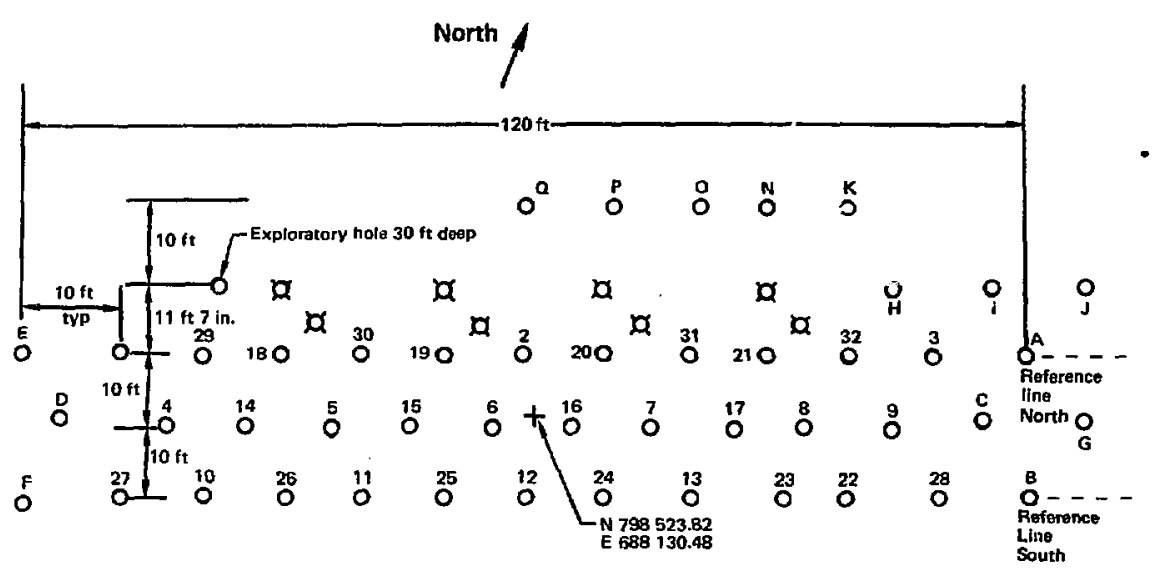

Legend:

O - Vertical emplacement hole location and corresponding shot No.

a $-30^{\circ}$ emplacement hole. (See Fig. 41)

Fig. 38. Sertes II firing field loyout.

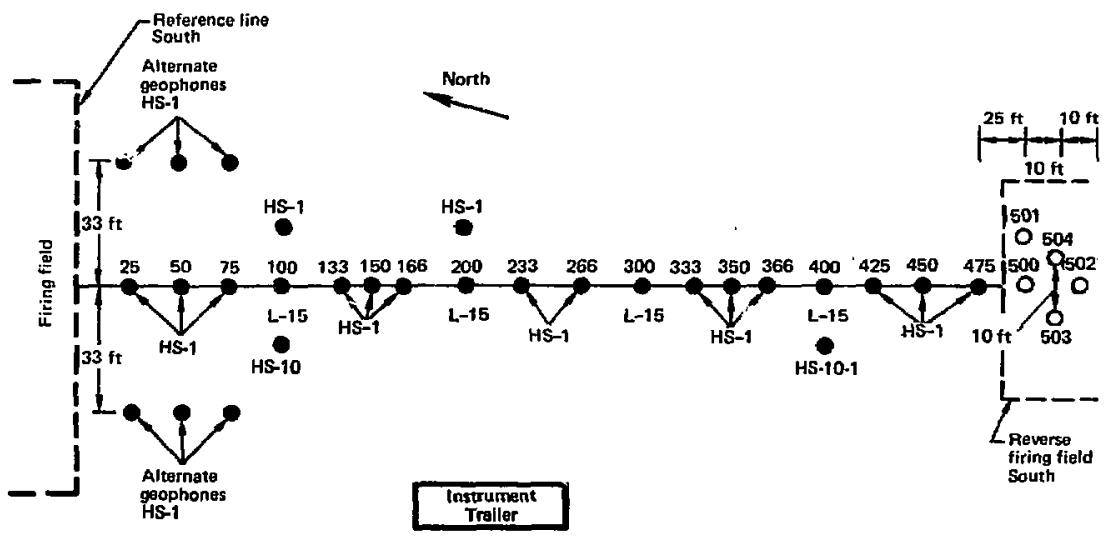

Legend:

HS-1 - 4.5- $\mathrm{Hz}, 0.5-\mathrm{V} / \mathrm{in} . / \mathrm{s}$, vertical-component geophone

HS-10 - $2.0 \mathrm{~Hz}, 3.0 \mathrm{~V} / \mathrm{in}$ /s, vertical-component yeophone

HS-10-1 - 1.0 Hz, 15.0-V/in./s, vertical-component geophone

$\mathrm{L}-15-4.5-\mathrm{Hz}, 1.5-\mathrm{V} / \mathrm{in} . / \mathrm{s}$, three-component geophone

- Geophone location, and corresponding distance in feet from the firing field Reference line - South

O- Emplacement hole location and corresponding shot No.

Fig. 39. Series II South selsmic Ine Lyout and reverse Iring field, South. 


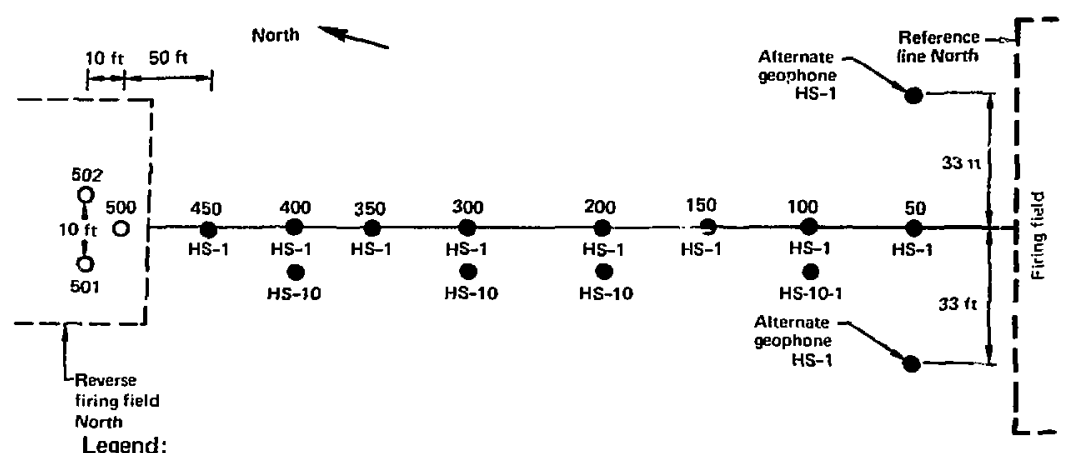

HS- I - 4.5-Hz, 0.5-V/in./s, vertical-component geophone

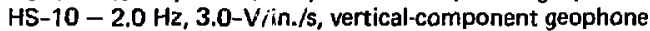

HS-10-1 - 1.0 Hz 15.0-vertical-component geophone

- Geophone location and corresponding distance in fiet from the firing field Reference line North

- Emplacement hole location and corresponding shot No.

Fig. 40. Series II North seismic tine layout and reverse firing field, North، 
Shot No. 18

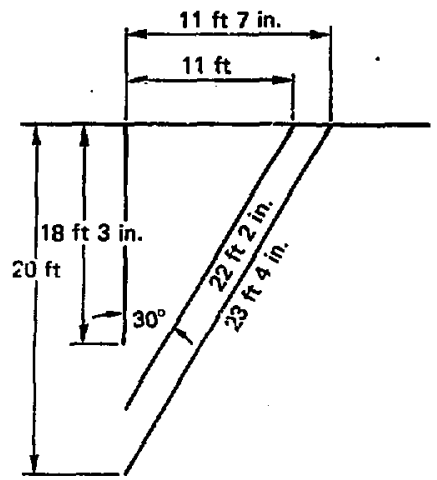

Shot No, 20

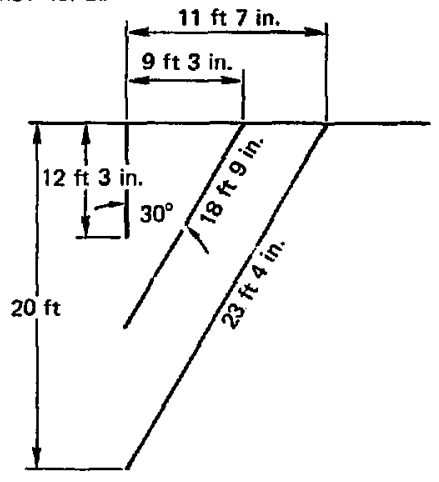

Shot No. 19

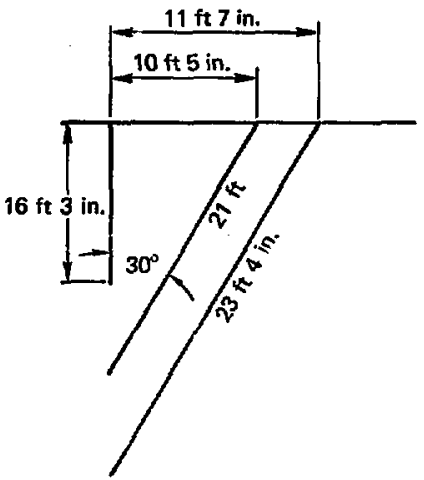

Shot No. 21

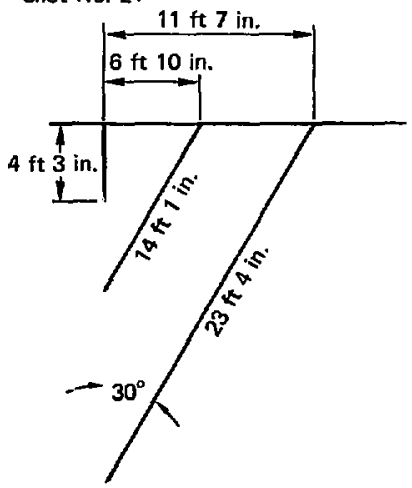

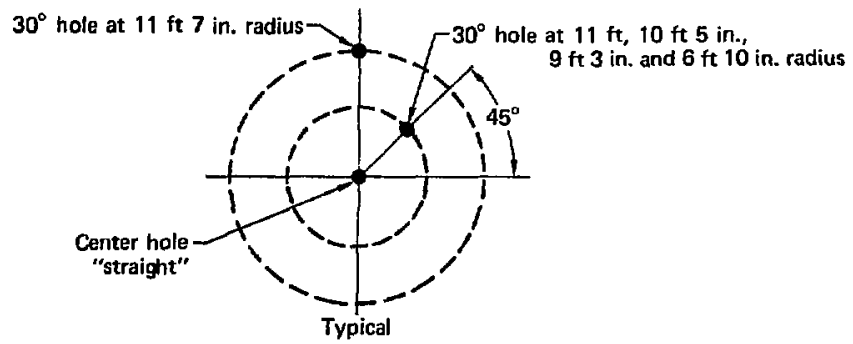

Fig. 41. Series II emplacement holes for sequentid "down" detonations. 
Table 3. Series II shot description

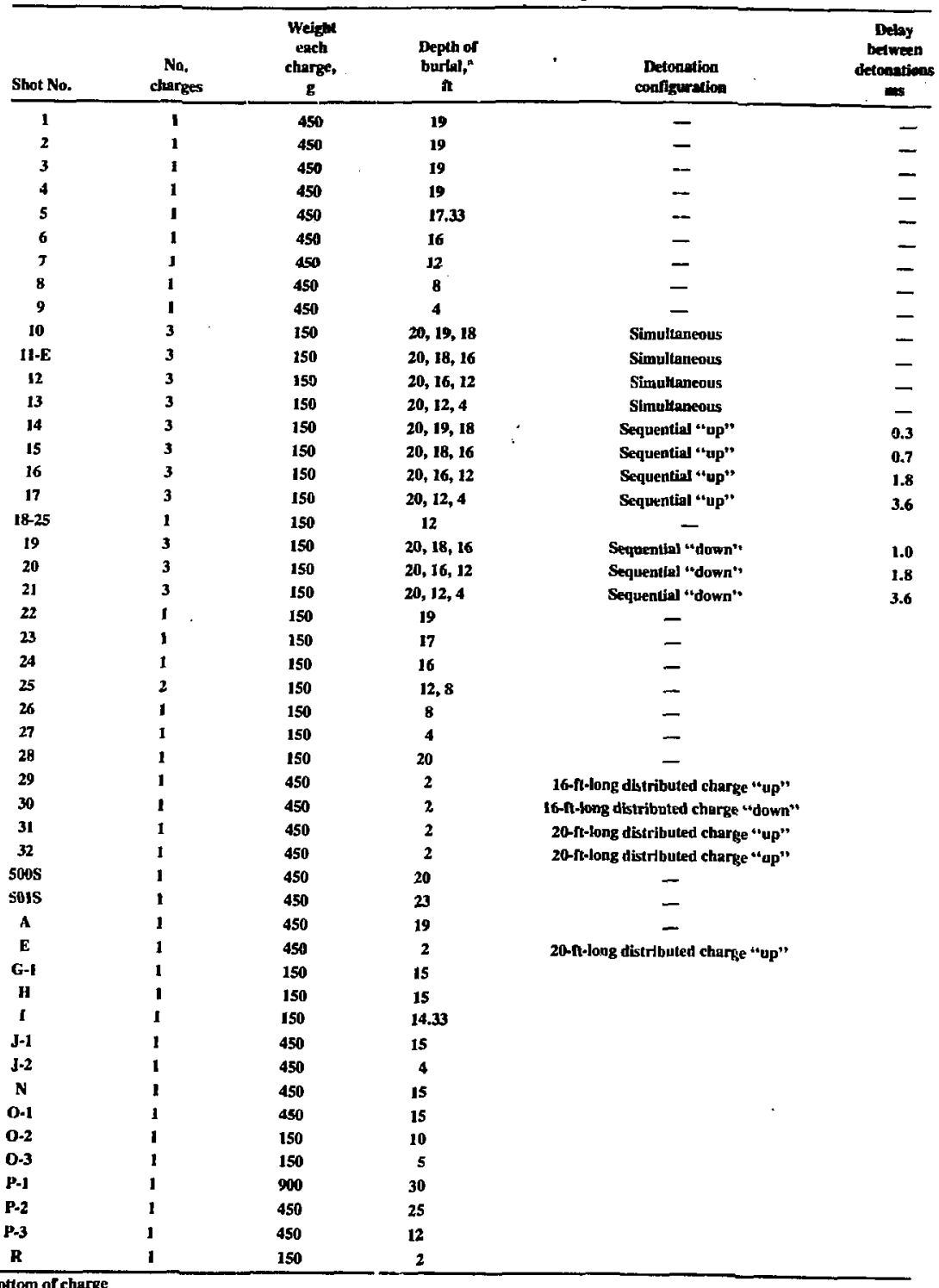




\section{Series III}

The third series of small-scale high-explosive experiments consisted of four parts-A, $B, C$ and $D$, with parts B, C, D grouped in a single seismic field (Fig. 37, 42). The main objective of this series of experiments (parts B, C, and D) was to compare the Rayleigh-wave generating efficiency between single and multiple explosions arranged in a horizontal array.

Part A was designed to complement results of Series $I$ and consisted of single and multiple explosions less than I lb. This series of experiments was also laid out to facilitate the excavation of cavities after explosions (Fig. 43, Table 4).

Part B consisted of 25- and 50-lb charges detonated in pairs at varying distances (Fig. 44, Table 5).

Part $\mathbf{C}$ was a minintal approximation for a horizontal circular charge consisting of four 1-lb charges detonated simultaneously (Fig. 45, Table 6).

Part $D$ consisted of $1-\mathrm{lb}$ charges aranged into a lirear horizontal array with three explosions detonated of varying delays (Fig. 46, Table 7).

The seismic line layout for these experiments is summarized in Fig. 47.

\section{Nuclear Explosions}

The recording of seismic signals from nuclear explosions in the kiloton range was mainly performed for scaling purposes and PNE applications. The seismic line tor these explosions was the same as for Series II experiments, thus providing an opportunity to study the response of readily available geophones relatively close to a nucleas explosion. Figure $\mathbf{4 8}$ summarizes the locations and types of geophones used in this series of experiments.

\section{Surface Explosions}

Recording the seismic signals from surface explosions of up to 100 tons of explosives had two purposes: scaling and observation of the response of geophones to air blast. Events 2 and 3 were among the first large-scale explosions to be recorded on the magnetic tape and, along with Series I, were part of the shakedown experiments. It was also in this series of experiments that the grouting of the triaxial $\mathrm{l}-\mathrm{Hz}$ geophones was perfected. The location of these explosions their magnitude and their seismic line are shown in Fig. 49.

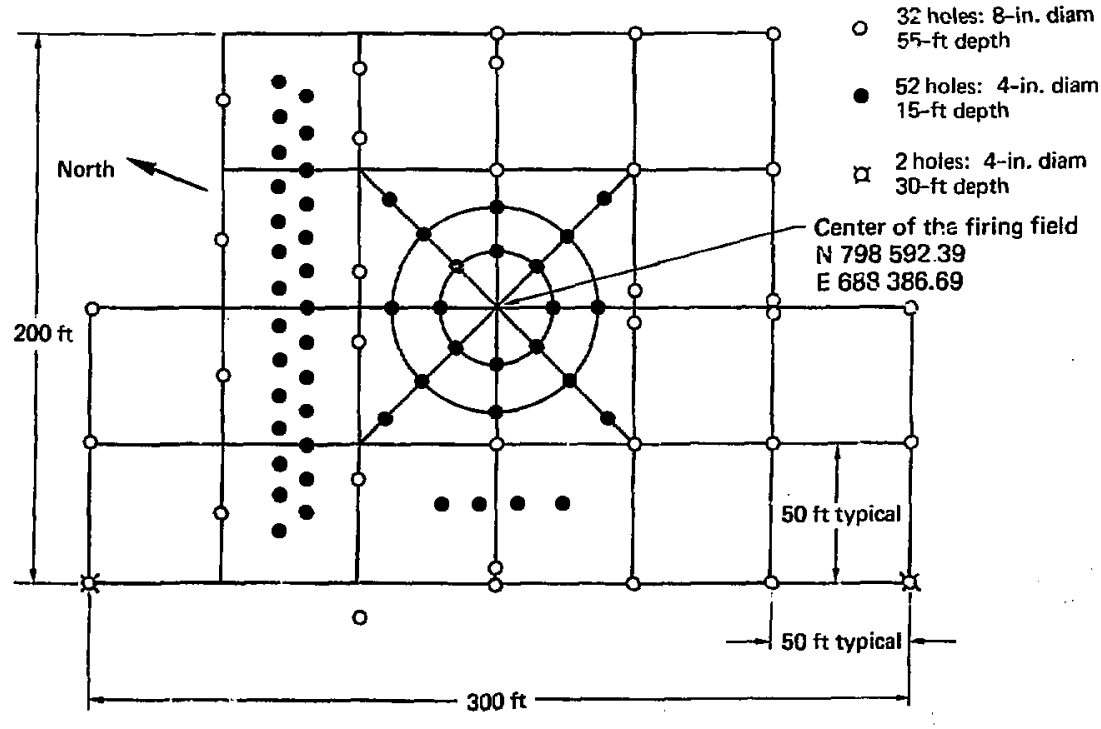

Fig. 42. Serles II B, C, and D firing teld layout. 


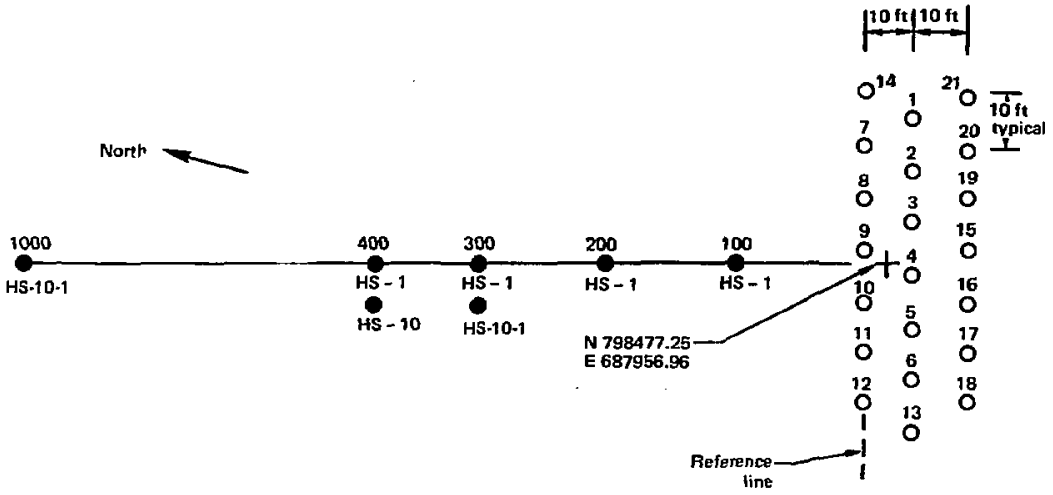

\section{Legend:}

$\mathrm{HS}-1-4.5-\mathrm{Hz}, 0.5-\mathrm{V} / \mathrm{in} . / \mathrm{s}$, vertical-component geophone

HS-10 - 2.0 Hz, $3.0 \mathrm{~V} / \mathrm{in.} / \mathrm{s}$, vertical-component geophone

$\mathrm{HS}-10-1-1.0-\mathrm{Hz}, 15.0-\mathrm{V} / \mathrm{in} . / \mathrm{s}$, vertical component geophone

- Geophone location and corresponding distance in feet from the firing field reference line.

- Emplacement hole location and corresponding shot No.

Fig. 43. Series Ill A seismic field layout.

Table 4. Series III A, shot deseription

\begin{tabular}{|c|c|c|c|c|c|}
\hline Shot No. & Nio. charges & $\begin{array}{c}\text { Wejght each } \\
\text { charge, } \\
\text { B }\end{array}$ & $\begin{array}{c}\text { Depth of } \\
\text { burial," } \\
\text { ft }\end{array}$ & $\begin{array}{l}\text { Detonation } \\
\text { configuration }\end{array}$ & $\begin{array}{c}\text { Delay } \\
\text { betreen } \\
\text { detonations } \\
\text { ms }\end{array}$ \\
\hline 1 & 3 & 50 & $6,4,2$ & Sequential, "up" & 0.75 \\
\hline 2 & 3 & so & $6,4,2$ & Simultaneous & 一 \\
\hline 3 & 1 & so & 6 & 一 & - \\
\hline 4 & 1 & 50 & 5 & - & - \\
\hline 5 & 3 & 50 & $6,5,4$ & Simultaneous & - \\
\hline 6 & 3 & 50 & $6,5,4$ & Sequential, "up" & 0.3 \\
\hline 7 & 3 & 100 & $6,4.6,3.2$ & Simuhaneous & \\
\hline 8 & 1 & 150 & $\mathbf{s}$ & & \\
\hline 9 & $\mathbf{1}$ & 150 & $\mathbf{5}$ & & \\
\hline 10 & 1 & 50 & 2 & & \\
\hline 11 & - & - & 一 & & \\
\hline 12 & $\mathbf{I}$ & 150 & 4 & & \\
\hline 13 & 1 & 450 & 6 & & \\
\hline 14 & 1 & 50 & 4 & & \\
\hline 15-I & I & $\mathbf{5 0}$ & 6 & & \\
\hline $15-2$ & 1 & 50 & 1 & & \\
\hline 16 & 1 & 150 & 4.6 & & \\
\hline 17 & 1 & 450 & 2 & & \\
\hline 18 & 1 & 150 & 2 & & \\
\hline 19 & 一 & - & 一 & & \\
\hline 20 & 1 & 50 & 1 & & \\
\hline 21 & 1 & 50 & 1.3 & & \\
\hline
\end{tabular}




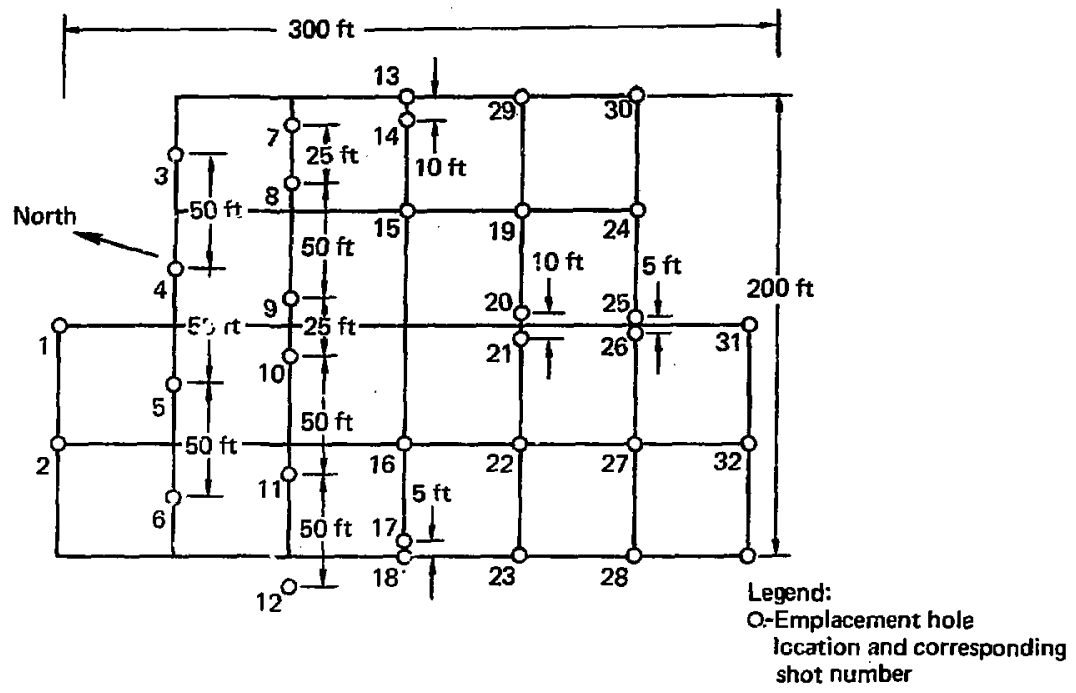

Fig. 44. Series III B firing field layout.

Table 5. Series III B shot description

\begin{tabular}{|c|c|c|c|c|c|}
\hline Shm to. & No. charges & $\begin{array}{l}\text { Weight each } \\
\text { charge, lb }\end{array}$ & $\begin{array}{l}\text { Depth of } \\
\text { burial, } 0 \text { it }\end{array}$ & $\begin{array}{l}\text { Horizonta! } \\
\text { spacing, ft }\end{array}$ & $\begin{array}{l}\text { Detonation } \\
\text { configuration }\end{array}$ \\
\hline $\mathbf{1}$ & 1 & 25 & 50 & - & - \\
\hline 2 & 1 & 25 & 50 & - & - \\
\hline 3 & 1 & 50 & 50 & - & - \\
\hline $4 / 5$ & 2 & 25 & 50 & 5L & Simultaneaus \\
\hline 6 & I & 50 & 50 & - & - \\
\hline $7 / 8$ & 2 & su & 50 & 25 & Simnltanewus \\
\hline $9 / 10$ & 2 & 25 & So & 25 & Simultaneous \\
\hline 11 & 1 & su & So & - & - \\
\hline 12 & $\mathbf{I}$ & 50 & 50 & - & - \\
\hline $13 / 14$ & 1 & 50 & so & it & Simultaneous \\
\hline $15 / 16$ & 2 & 25 & 5il & 100 & Simultaneous \\
\hline $17 / 18$ & 2 & so & 50 & 5 & Simultaneous \\
\hline $19 / 22$ & 2 & 50 & 50 & 100 & Simultaneots \\
\hline $20 / 21$ & 2 & 25 & 50 & 20 & Simultaneaus \\
\hline 23 & 2 & 25 & 50,46 & 4-fi vert spacing & Simultaneous \\
\hline 24 & I & 25 & 50 & - & - \\
\hline $25 / 2 \mathbf{h}$ & 2 & 25 & 50 & 5 & Simuhanevus \\
\hline 27 & 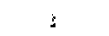 & 100 & 50 & & \\
\hline 28 & 1 & 50 & 50 & & \\
\hline $2 y$ & 1 & $1(N)$ & so & & \\
\hline 30 & 1 & 50 & so & & \\
\hline 31 & 1 & 25 & so & & \\
\hline 32 & 1 & 50 & 50 & & \\
\hline
\end{tabular}




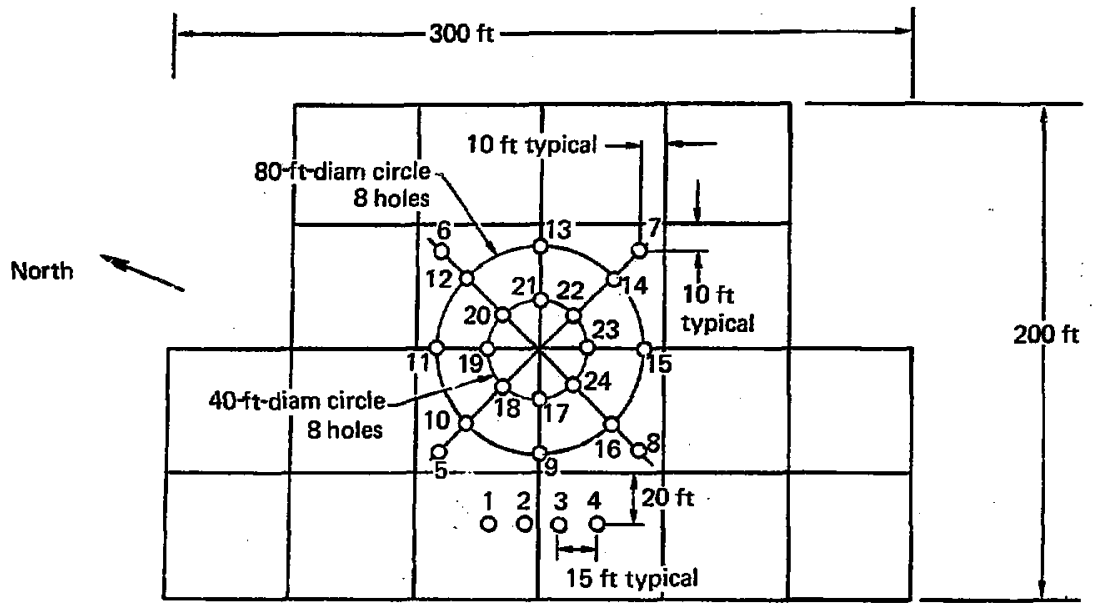

Legend:

O-Emplacement hole location and corresponding shot number

Fig. 45. Series III C firing field lay out.

Table 6. Series III C shot description

\begin{tabular}{|c|c|c|c|c|}
\hline Shot No. & No. charges & $\begin{array}{l}\text { Weight uach } \\
\text { charge, lb }\end{array}$ & $\begin{array}{l}\text { Depth or } \\
\text { burint" f }\end{array}$ & $\begin{array}{c}\text { Detonation } \\
\text { coufiguration }\end{array}$ \\
\hline 1 & 1 & 4. & 12 & - \\
\hline $2-1$ & $1 "$ & $\mathbf{I}$ & 12 & - \\
\hline 2.2 & $\mathbf{l}^{\mathbf{b}}$ & 1 & 12 & - \\
\hline $2-3$ & $1^{4}$ & 1 & 13 & - \\
\hline $2-4$ & $1^{b}$ & 1 & 12 & - \\
\hline $2-5$ & $\mathbf{l}^{\mathbf{b}}$ & 1 & 12 & - \\
\hline $2-6$ & $\mathbf{I}^{\mathbf{b}}$ & 3 & 12 & - \\
\hline 3 & $\mathbf{I}$ & 4 & 12 & - \\
\hline 4 & I & I & 12 & - \\
\hline $\mathbf{5}$ & 1 & a & 12 & - \\
\hline 6 & 1 & $\mathbf{1}$ & 12 & - \\
\hline 7 & 1 & 4 & 12 & - \\
\hline 8 & $\mathbf{1}$ & 1 & 12 & - \\
\hline $9 / 11 / 13 / 15$ & 4 & $\mathbf{I}$ & 12 & 80-ti diam circle, simultaneous \\
\hline $10 / 12 / 14 / 16$ & 4 & $\mathbf{1}$ & 12 & 80-it dlam circle, simultaneous \\
\hline $17 / 19 / 21 / 23$ & 4 & $\mathbf{1}$ & 12 & 40-n dirm circle, simultaneous \\
\hline $18 / 20 / 22 / 24$ & 4 & 1 & 12 & 40-ft diam circle, simultaneous \\
\hline
\end{tabular}




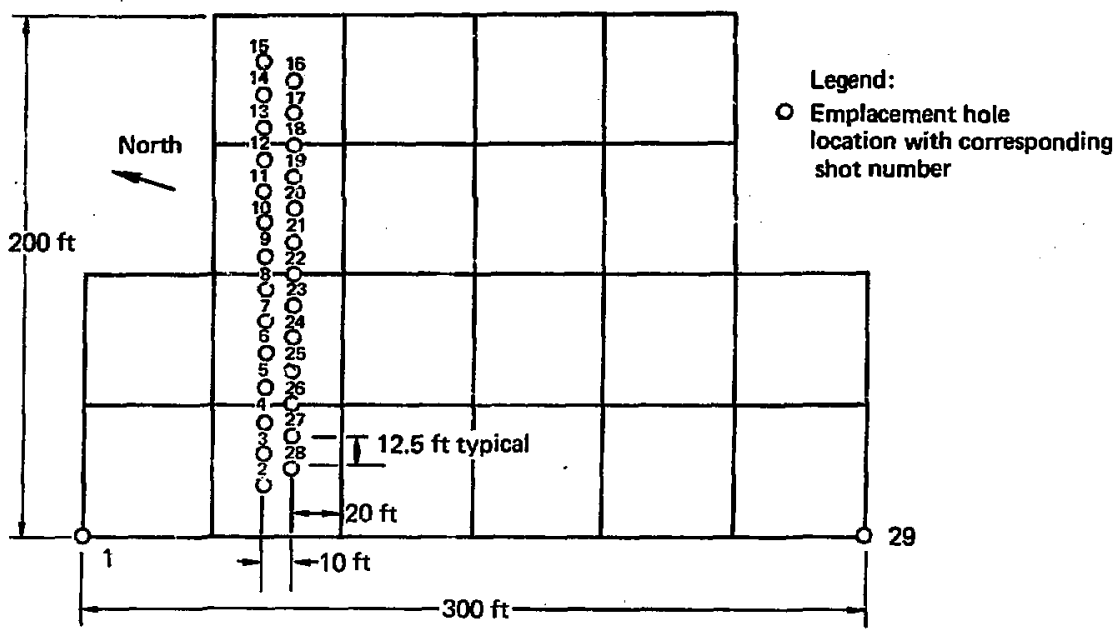

Fig. 46. Series III D Aring teld layout.

Table 7, Series III D, shot description

\begin{tabular}{|c|c|c|c|c|c|c|}
\hline Shot No. ${ }^{a}$ & No. charges & $\begin{array}{c}\text { Weight } \\
\text { each } \\
\text { charge, ib }\end{array}$ & $\begin{array}{c}\text { Depth of } \\
\text { berial, } \\
\mathbf{n}\end{array}$ & $\begin{array}{c}\text { Horzoms spacing, } \\
\text { n }\end{array}$ & Detonation configuration ${ }^{\circ}$ & $\begin{array}{c}\text { Deloy } \\
\text { betweer } \\
\text { detonations } \\
\text { ms }\end{array}$ \\
\hline 1 & - & - & - & - & disposal hale & 一 \\
\hline $8 / 5 / 2$ & 3 & 1 & 12 & $37.5,37.5$ & sequential & so \\
\hline 3 & $\mathbf{1}$ & 1 & 12 & - & - & 一 \\
\hline $10 / 7 / 4$ & 3 & 1 & 12 & $37.5,37.5$ & sequential & 150 \\
\hline 6 & $\mathbf{1}$ & 1 & 12 & 一 & - & - \\
\hline $15 / 12 / 9$ & 3 & 1 & 12 & $37.5,37.5$ & sequentipl & 100 \\
\hline 11 & 1 & $\mathbf{1}$ & 12 & 一 & 一 & - \\
\hline 13 & $\mathbf{I}$ & $\mathbf{I}$ & 12 & 一 & 一 & 一 \\
\hline 14 & $\mathbf{I}$ & 3 & 12 & - & - & - \\
\hline $16 / 19 / 23$ & 3 & 1 & 12 & $37.5,50.0$ & sequential & 17 \\
\hline $17 / 20 / 24$ & 3 & 1 & 12 & $37.5,50.0$ & sequential & 200 \\
\hline $18 / 21 / 25$ & 3 & 1 & 12 & $37.5,50,0$ & simulianeous & - \\
\hline 22 & 1 & 3 & 12 & & . & \\
\hline 26 & 1 & $\mathbf{1}$ & 12 & & & \\
\hline 27 & 1 & 3 & 12 & & & \\
\hline 28 & 1 & 3 & 12 & & & \\
\hline 29-1 & $\mathbf{F}^{\mathrm{C}}$ & 1 & 30 & & $\because$ & \\
\hline 29.2 & $I^{c}$ & 1 & 30 & & c & \\
\hline 29-3 & $1^{e}$ & 1 & 30 & & . & \\
\hline $29-4$ & $1^{d}$ & 1 & 30 & & & \\
\hline $29-5$ & $1^{d}$ & 1 & 25 & & & \\
\hline $29-6$ & $\mathbf{1}^{\mathbf{c}}$ & 1 & 20 & . & ' & \\
\hline 20.7 & $\mathbf{1}^{\mathbf{c}}$ & 1 & 18 & & & \\
\hline $29-8$ & $1^{d}$ & 1 & 18 & & & \\
\hline
\end{tabular}




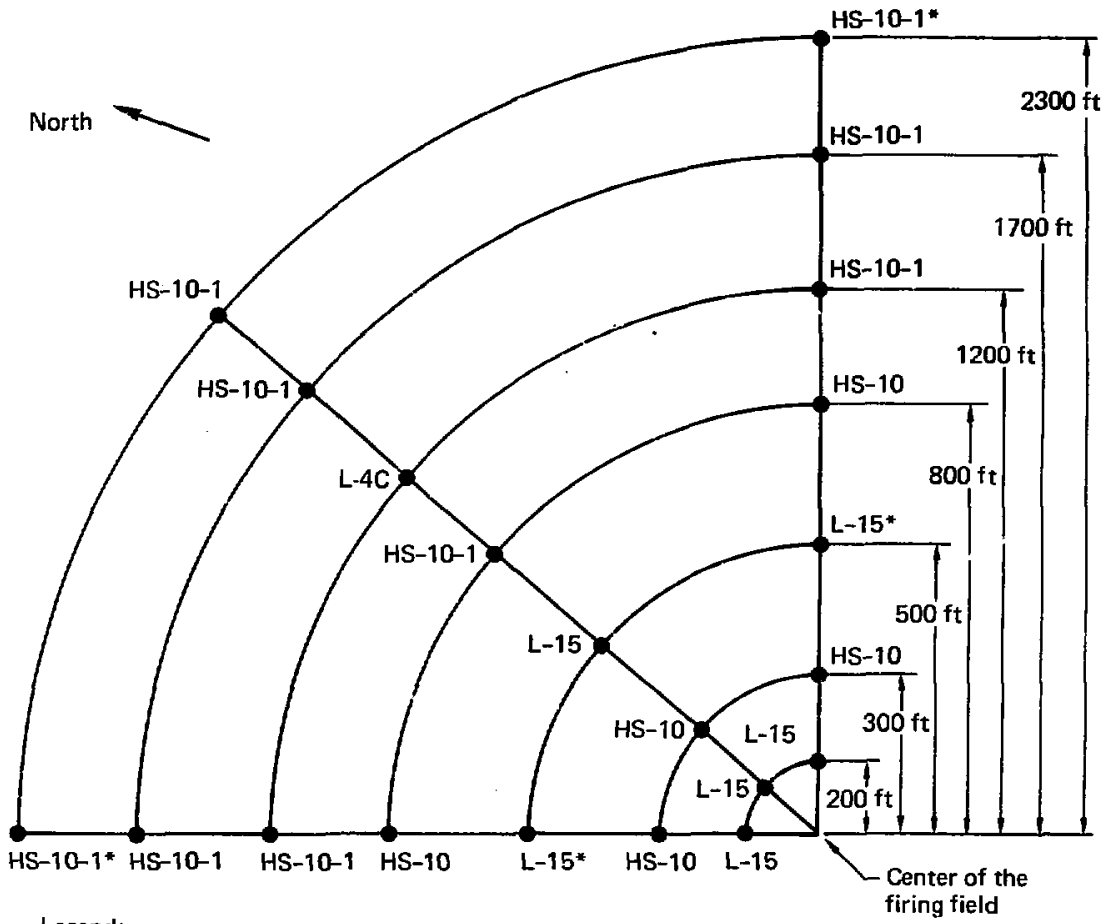

Legend:

- Geophone location

HS-10-2.0-Hz, 3.0-V/in./s, I vertical component geophone

HS-10-1 - 1.0-Hz, 15.0-V/in./s, three-component geophone

HS-10-1*-1.0-Hz geophone $41.0-\mathrm{V} / \mathrm{in} . / \mathrm{s}$, Vertical-and radial-components

$\mathrm{L}-15-4.5-\mathrm{Hz}, 1.5-\mathrm{V} / \mathrm{in.} / \mathrm{s}$, three-component geophone

$L-1 E^{*}-4.5-H z, 4.0-V / i n . / s$, three-component geophone

$\mathrm{L}-4 \mathrm{C}-1.0-\mathrm{Hz}, 11.0 \mathrm{~V} / \mathrm{in} . / \mathrm{s}$, three-component geophone

Fig. 47. Stries III B, C, and D seismic line layout. 


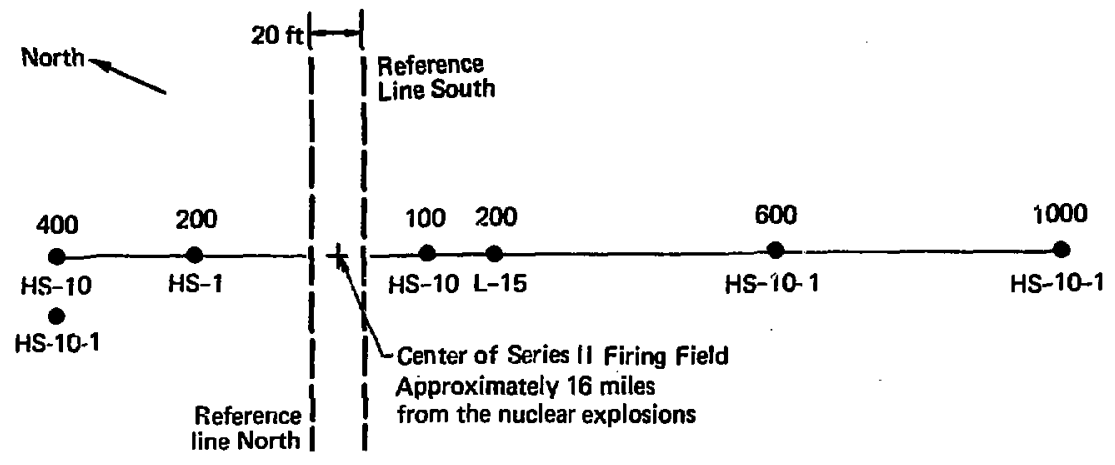

Legend:

Geophone location with corresponding distance in feet from the Series II

firing field reference lines, north or south, respectively.

HS-1 - 4.5-Hz, 0.5-V/in./s, vertical-component geophone

$\mathrm{HS}-10-2.0 \mathrm{~Hz}, 3.0 \mathrm{~V} / \mathrm{in} . / \mathrm{s}$, vertical-component geophone

HS-10-1 - 1.0 Hz, 15.0-V/in./s, vertical-component geophone

$\mathrm{L}-15-4.5-\mathrm{Hz}, 1.5-\mathrm{V} / \mathrm{in} . / \mathrm{s}$, three-component geophone

Fig. 48. Nuclear explosion selsinlc the layout.

PI Ground mation

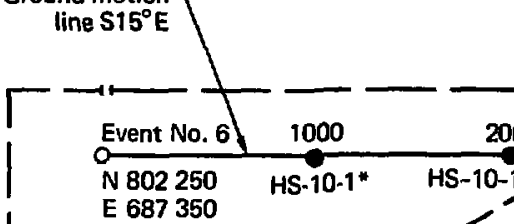

N 801917.74 OEvent No. 3

E 687017.74

O Event

N 801911.34 No. 2

E 686665.52

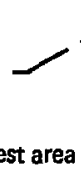

L<smiles>C1CCCCC1</smiles>

N

Legend:

- Geophone location with corresponding distance in feet for Event No. 6

o-Surface explosion location and corresponding event number

HS-10-1*-1.0-Hz, 15.0-V/in./s, vertical component geophone

HS $-10-1-1.0-H z, 15.0-V / i n . / s$, three component geophone

F7g. 49. Surtace explodion selsmic Reld layout and shot description. Eveat No. $2-0.5$ tons, Event No. 3-7.1 tons, Event No. 6100 tons. 
Firing System of the Small-Scale High-Explosive Charges and the Data Acquisition ${ }^{22}$

The following information was compiled to illustrate the spccifics of the electronics system from the users. point of view along with recommendations for the next generation of firing and data acquisition systems.

\section{Firing System Description}

Figure 50 is a block diagram of the existing firing system. The $2.5-\mathrm{kV}$ charging power supply is a CDU with the head removed. The firing currents are monitored for each shot by measuring the voltage across a $0.05 \mathrm{ohm}$ CVR (current viewing resistor) and displaying the voltage on an oscilloscope. The oscilloscope is calibrated at $20 \mathrm{~V} / \mathrm{cm}$. Each $\mathrm{cm}$ represents $20 \mathrm{~V} / 0.05 \Omega$ or $400 \mathrm{~A}$. The firing voltage is a measure of the charging voltage and is displayed on a meter and/or recorded on a strip chart recorder through a 100:1 divider. The firing system is test-fired just prior to each live detonation. In the event of a malfunction in the test firing, or a misfire, the monitors will usually show the reason for the malfunction. With the present system, it is possible to fire four charges simultaneously or sequentially and monitor each CDU. In addition, it is also possible to display zero time and two of four current monitors on a single scope in order to verify detonation times in sequential firings. Firing of the charges is done usually by an electronic echnician who has been checked out in high-explosi ie detonation procedures. During the audible countdov'n by the technician, which starts ap- proximately $5 \mathrm{~s}$ before zero time, the visicorder is started approximately $3 \mathrm{~s}$ before zero time, the camera shutters are opened at approximately $2 \mathrm{~s}$ before zero time and the shot is fired at zero time. Approximately $2 \mathrm{~s}$ after zero time, the camera shutters are closed. The magnetic tape recorder is started at about $30 \mathrm{~s}$ before zero time and stopped approximately $60 \mathrm{~s}$ after the explosion.

\section{Data Acquisition}

Figure 51 shows the existing data acquisition system. Data from the geophones are amplified (with setrable gains of 1 through 1000 ) by the differential amplifiers. The amplifier outputs are attached to the VCO inputs. Groups of 4 VCO's are then multiplexed and recorded on one track of the magnetic tape recorder. There are 12 tracks available for data recording, which allows for 48 geophone inputs. Track 13 is normally used for recording time from the time code generator. Track 14 records zero time through a $2.3-\mathrm{kHz}$ VCO from the output of the zero time scope. After each shot, it is possible to play back the tape recorded data. However, with the present system, it is necessary 10 make 48 passes of the data, due to lack of the necessary tape recorder output equipment and a suitable chart recorder.

In the present system, 24 amplifier outputs can be patched into two 13-channel visicorders through galvanometer-driver amplifiers. Channel 13 of each visicorder is reserved for recording zero time. 


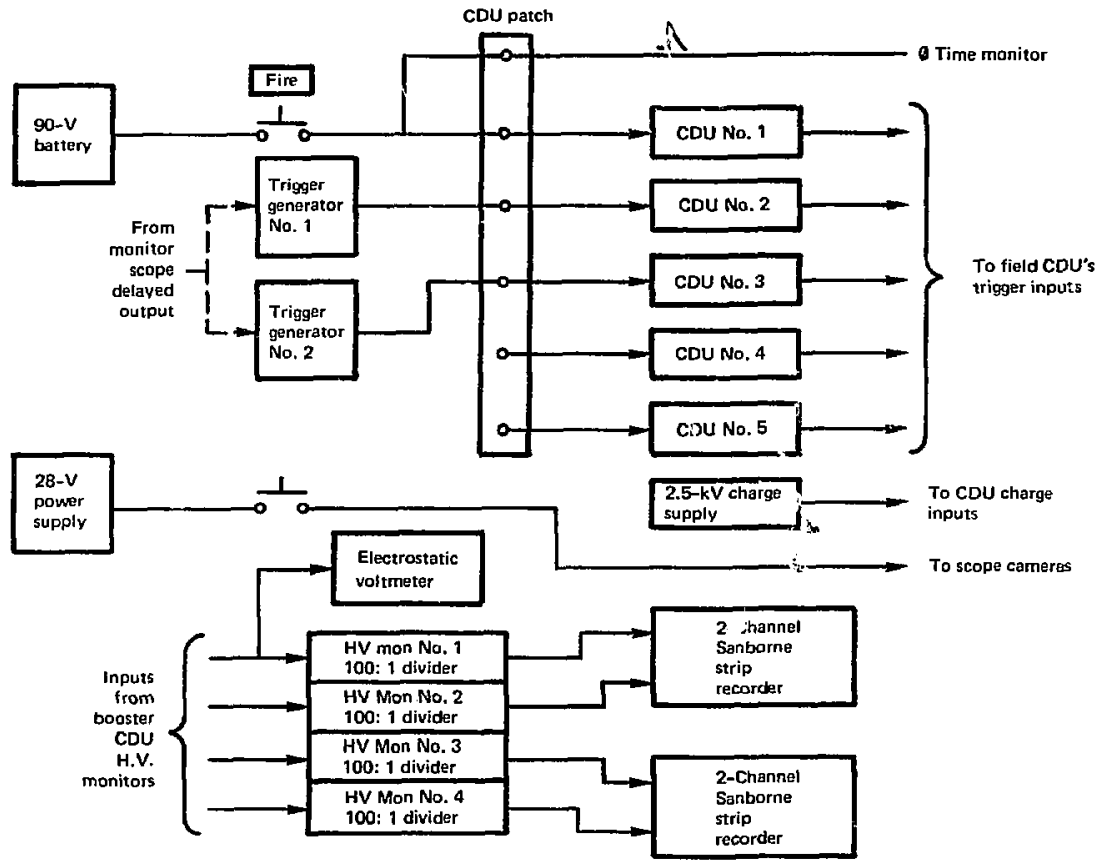

Fig, 50. Firing system. 


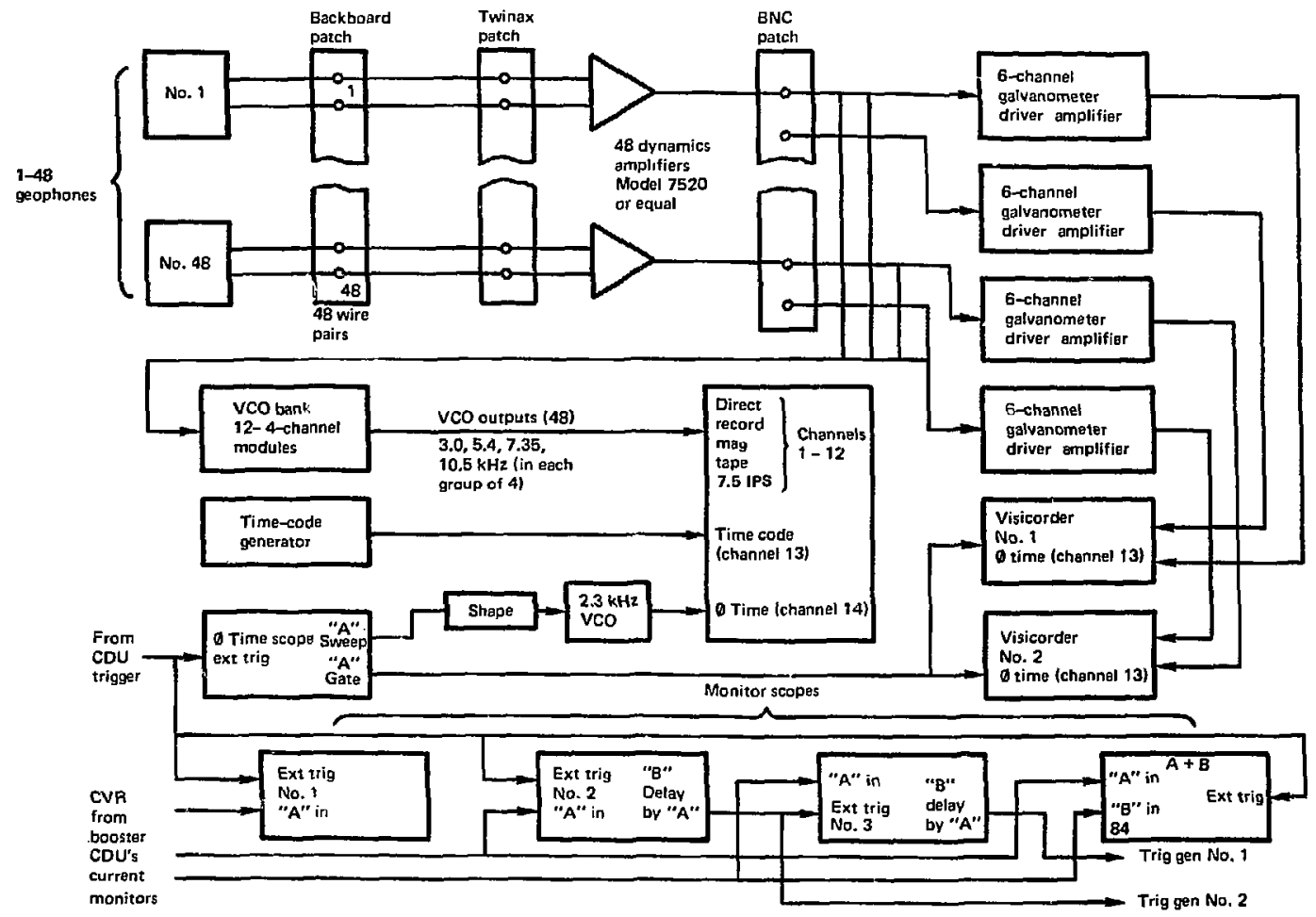

Fig. 51. Data recording sysiam. 


\section{Recommendations}

A number of improvements, as outlined below, can be made to the existing system that will allow for more ef.icient operation and produce better data.

- Installation of a variable-delay sequence timer would allow one operator to run the entire system. The sequence timer could remotely operate the equipment as follows:

The tape recorder would always be starled at the same time before zero time. This would allow a uniform time between shots which could help in data reduction in that the operator at the Jata reduction center would know exaçtly where data from a particular shot could be found.

The visicorders could be started at some predetermined time after the tape recorders by setting the proper time in the sequencer.

The monitor camera shutters could open at some preset time before zero time, and close at some time after zero time. The time would always be the same and would produce uniform exposures. In the past, exposure time varied and int some instances the pictures were very poor.

After the camera shutter is opened, a firing pulse would be sent to the CDU trigger (The zero time monitor for the tape recorder and visicorder could originate in the sequencer.)

The visicorder could be stopped at a tine afier the data has been collected.

The rape recorder would then stop automatically.

The sequencer would eliminate the need for an oscilloscope to produce a zera time pulse.

- A four-channel variable-delay-trigger generator would produce four $\mathrm{CDU}$ trigger pulses at 4 preset times for sequential firings. The chassis would take up about 5 in, of rack space instead of the present 24 in. The monitor scopes would function as monitors only and not as delay generators for sequential firing. The oscilloscopes must be reset before every shot and, if the operator forgets to reset the scopes, the $2 \mathrm{nd}$, 3rd, etc. detonations would not occur. Transients have triggered the scopes at various times also. The trigger gencrator could be designed such that it would not respond to transients.

- Currently, the VCO's used in Trailer 81 are LLL-designed and are extremsily temperature-sensitive. The minimum time required for stabilization of the center frequency is approximately 2 hours. The VCO's could be replaced with commercial VCO's with a maximum stabilization time of 15 nuinutes. The comnercial VCO's would take about half the space of the LLL-designed VCO's.

- If it is necessary to review shot data in the field, a system capable of playing back the 48 cha inels of data from the tape recorder in 6 to 8 passes woula save a great deal of time. Playback time now is 35 to 45 minutes for 48 channels; it is tedious and prone to errors.

- Another possible improvenent for the diagnostics system would be a digital data recording system. The main advantages would lie in obtaining data over a much wider range of amplifications and in data reduction. The output from the tape recorder could be computercompatible, to eliminate the need for digitizing. Digitizing analog data is both expensive and time-consuming.

\section{Conclusions}

System reliability and date quality were very good over the entire program. We lost probably no more than 1 or $2 \%$ of the data out of the thousands of individual signals recorded. The instrumentation methods provided the necessary information to support the small-scale high-explosive experiments. 


\section{Geophone Calibration}

To obtain a more accurate ground motion value, most of the geophones, in addition to a thorough calibration in the laboratory before the experiments,were calibrated in siru (i.e., a method was used to calibrate geophones after they had been grouted into the ground). The devised scheme consisted of measuring the natural frequency and the total resistance for witch geophone using the same transmission cables and damping resistors employed to record the seismic signals during the experiments. This method accounted for any differences between the laboratory calibration values and the response of the geophones during the experiments. The natural frequency was measured by the phase-resonance method based on Geo Space Corp. recommendations; the equipment consisted of an oscilloscope, a low-frequency oscillator, and a digital frequency meter. (See Fig. 52.)

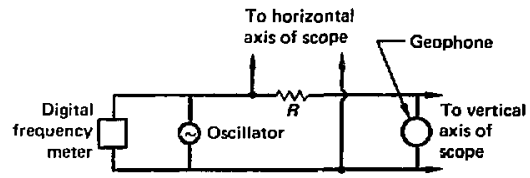

Fig. 52. Geophone calibration schematic ( $R$ should be 10 times the coil :esistance of the geophone, at a minimum).

The equipment configuration shown in Fig. 52 forms a Lissajous pattern on the oscilloscope. By adjusting the oscillator frequency in a range near the natural frequency of the geophone, the Lissajous pattern can be made to close. Since the voltage across the resistor is always in phase with the current, the pattem will close only when the current through the geophone is in phase with the voltage.

When the frequency of the oscillator is below the natural frequency of the geophone, the current through the geophone lags the voltage. When the natural frequency is higiner, the current leads the voltage. Only at its natural frequency does the geophone become a unity power factor load. Therefore, when the pattern closes, the oscillator frequency repiesents the natural frequency of the geophone. This method does not consider the effect of the inductance of the coil winding, which is negligible.

In practice, it was obscrved that the natural frequency of the instruments will change after it has been transported into the field and grouted. The changes were usually associated with the geophone not being quite level after grouting, resulting in higher natural frequencies. The geophones with lowest natural frequencies were affected the most and changes up in $1 \mathrm{~Hz}$ were observed on several occasions.

\section{Frequency Response Curves and Specifications}

The specifications of geophones and accelcrometers used to record seismic signals are listed in Tables 8-14 and Figs. 53-60. The frequency response curves shown in Figs. 53-59 represent response curves for each family of geophones. The response curves are similar for all geophones of a particular model except for constant voltage shift which can be calculated for each individual geophone. 


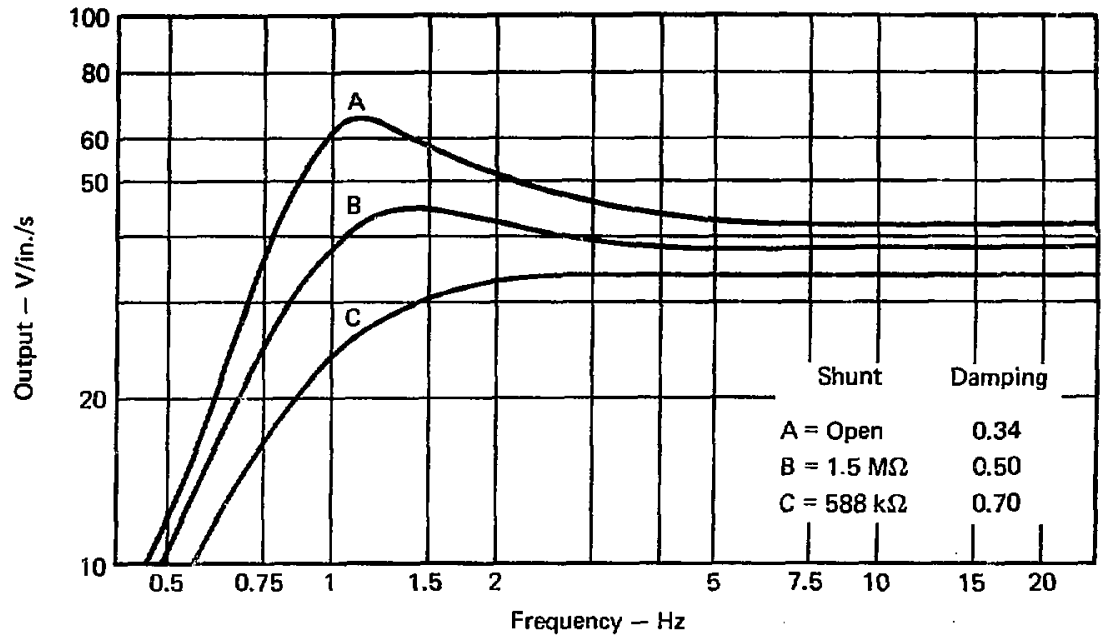

Fig. 53. Geophone response curve, Type HS-10-1, Model K, 1.0 Hz, 4i V/in./s (Geo Space Corp.).

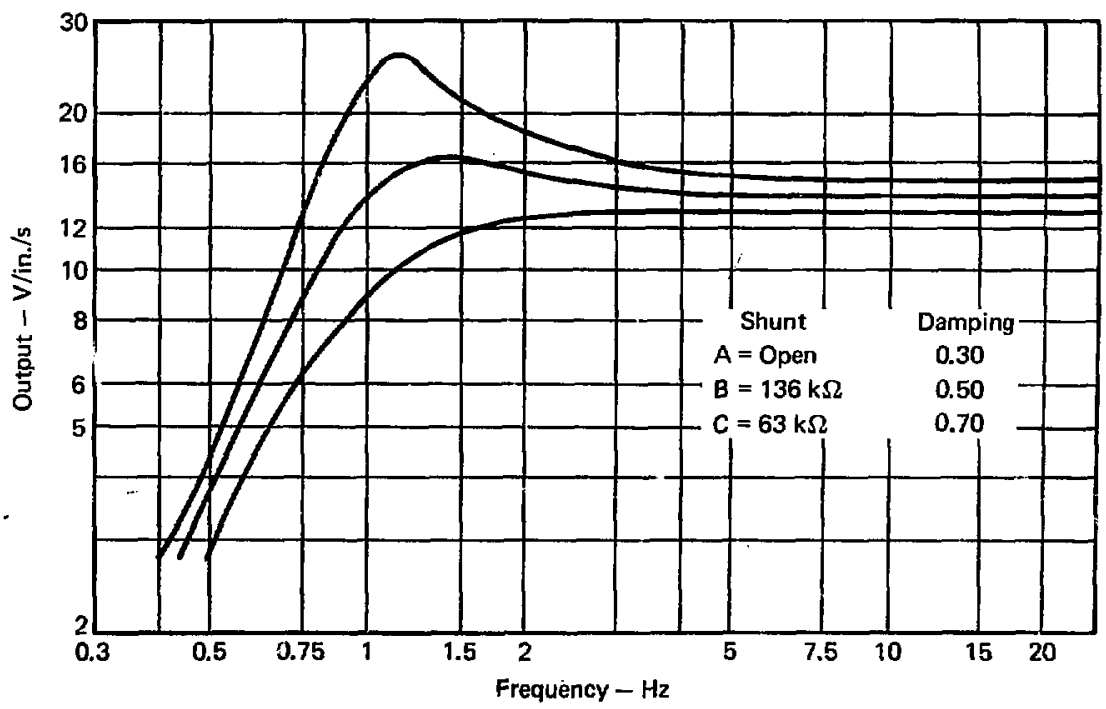

Fig. 54. Geophone response curve, Type HS-10-1, Model K, 1.0 Hz, 15V/hn./s (Geo Space Corp.). 
Table 8. Specifications", Type HS-10-1 geophone, Model K $1.0 \mathrm{~Hz}, 41 \mathrm{~V} / \mathrm{in} . / \mathrm{s}$

Frequency@5-10 mv

Frequency limits @ $\pm 0.1 \mathrm{~Hz}$.

DC resistance @ 25 $\mathrm{C}$ (DCR)

DCR Linits@ @ $5 \%$ 127,300 to $140,700 \Omega$

Number of turns 88,000 ttodal

Wire size and type No, 43 single soldereze

Mean length of turn (MLT) $.0 .716 \mathrm{ft}$

Length of wirc $.63,008$ f

Intrinsic voltage sensitivity

Open circuit damping $.34 \%$

Open circuil damping limits @ $10 \%$

30.6 to $37.41 / 2$

Open circuit overswing ration $.10 / 3.20$

Open circuatt overswiug ratio limits $10 / 3.65$ to $10 / 2.80$

Coil form veight, processed $.393 \mathrm{~g}$

Copper wejgit

Total moving mass $.833 \mathrm{~g}$

Totnl spring constant @ 1 Hz $.3 .28 \times 10^{\prime} \mathrm{dyn} / \mathrm{cm}$

Air gup .0 .3575 in, (0.9081 cm)

Flux, bottom of winding to top of winting $.4 .91 \times 10^{4} \mathrm{Mx}$ Gap area (per winding)

Flux density (measured at bottom winding)

Total impedance @ I Hz $.469,000 \Omega$

Motional impedance@ 1 Hz

$(\mathbf{R}+\mathbf{r})\left(\mathbf{b}_{\mathrm{t}}-\mathbf{b}_{\mathrm{v}}\right)$ $.260,000$

"Source: Geo Space Corp. 
Table 9. Specifications ${ }^{a}$, Type HS-10-1 geophone, Model K 1.0 Hz, 15V/in./s

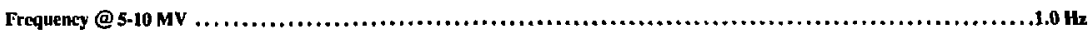

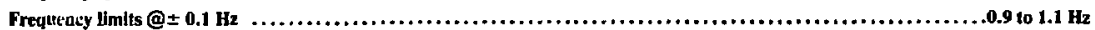

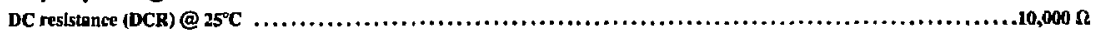

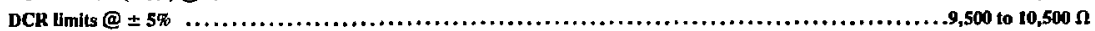

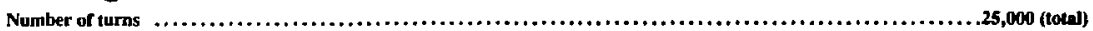

Wire size and sype $\ldots \ldots \ldots \ldots \ldots \ldots \ldots \ldots \ldots \ldots \ldots \ldots \ldots \ldots \ldots \ldots \ldots \ldots \ldots \ldots \ldots \ldots \ldots \ldots \ldots \ldots \ldots \ldots \ldots$. $\ldots \ldots \ldots, \ldots \ldots$, stngle soldereze

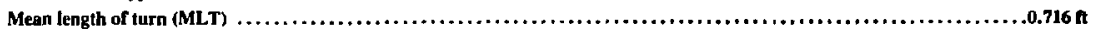

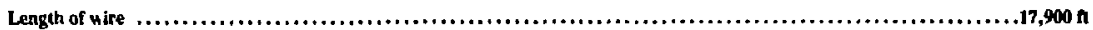

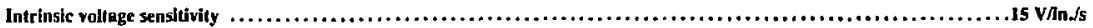

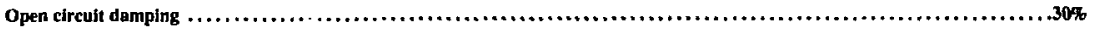

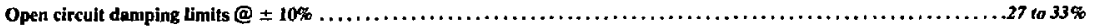

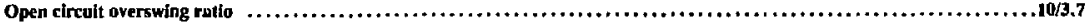

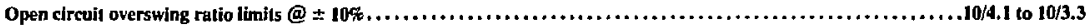

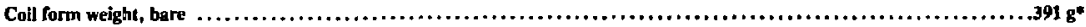

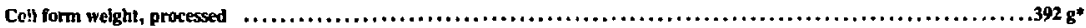

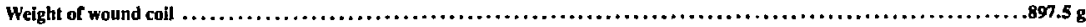

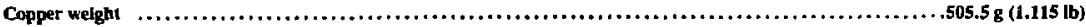

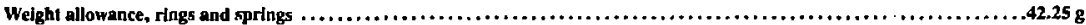

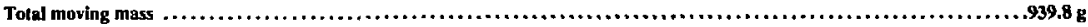

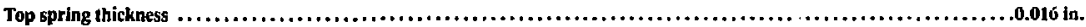

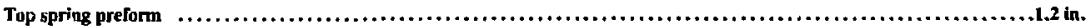

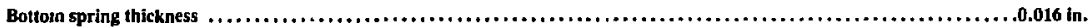

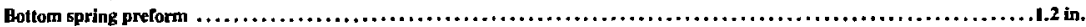

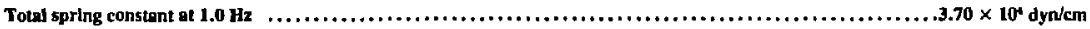

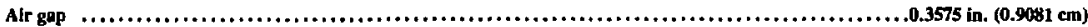

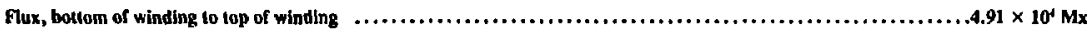

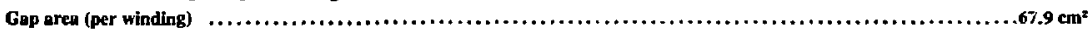

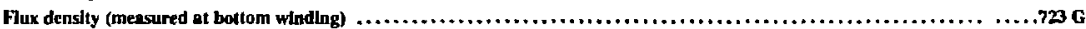

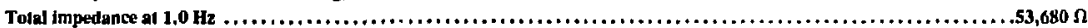

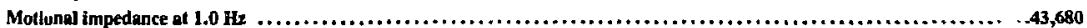

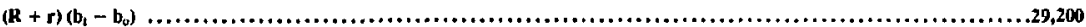

- Coll form weights indicated for bare processed forms include the weight ring with tle wire (100.73 grams).

"Source: Geo Space Corp. 


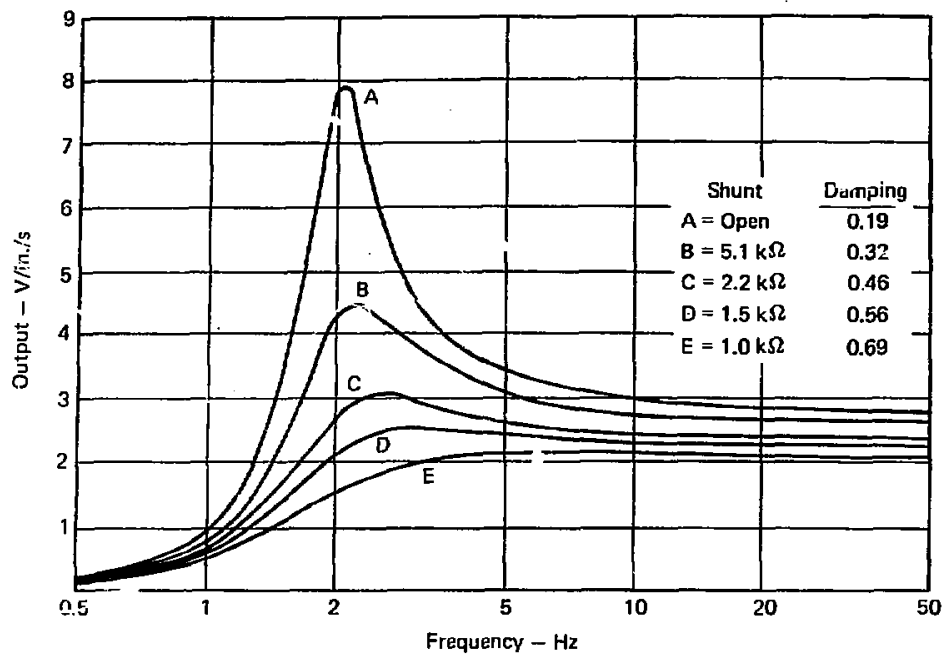

Fig. 55. Geophone response curve, Type HS-10, Model K, 2.0 Hz, 3V/in./s (Geo Space Corp.).

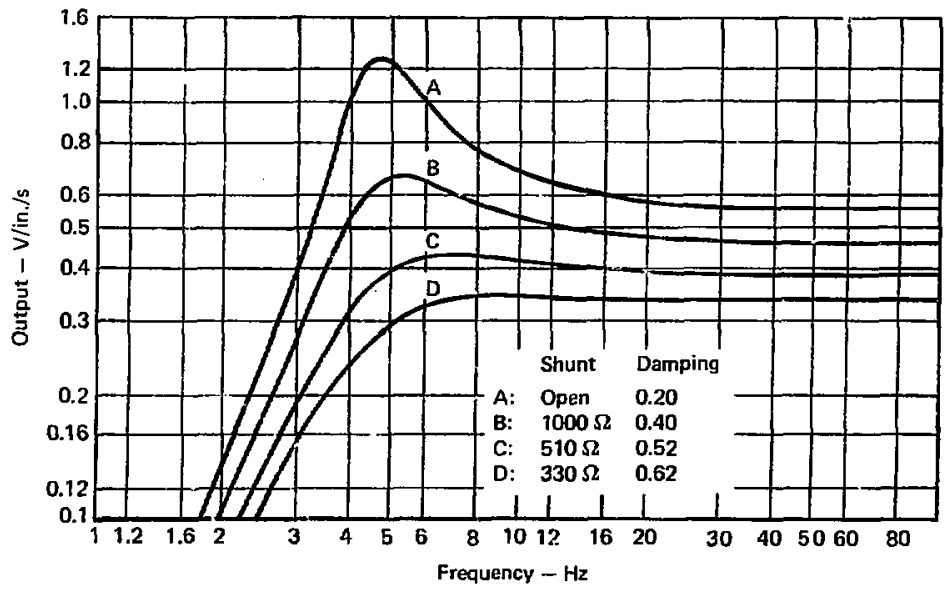

Fig. 56. Geophone response curve, Type HS-1, Model K, 4.5 Hz, 0.55V/in./s (Geo Space Corp.). 
Table 10. Specifications ${ }^{a}$, Type HS-10 geophone, Model K $2.0 \mathrm{~Hz}, 3 \mathrm{~V} / \mathrm{in} . / \mathrm{s}$

Frequency $.2 .0 \mathrm{~Hz}$

Frequency limits $1.85-2.15 \mathrm{fz}$

DC resistance (DCR) @ $25^{\circ} \mathrm{C}$ $390 \Omega$

DCR Itmits@+5\% $.371-409 \Omega$

Number of turis 5900 (total)

Wire sizf and type No. 30, single soldterese

Mean length of turn (MLT) $0.716 n$

Length of wire $3580 \mathrm{n}$

Intrinsic voltage sensitivity

Open circuit damping $.19 \%$

Open circuit damping limits $@ \pm 10 \%$.

$17.1-20.9 \%$

Open circuit overswing ratio $.10 / 5.43$

Open circuil overswing ratio Imits $@ \pm 10 \%$ damping

$10 / 5.78-10 / 5.08$

Coll form weight

$197.08 \mathrm{~g}$

702.68

Copper weight

$505.5 \mathrm{~g}$

Weight allowance, rings and springs .

$.26 .25 \mathrm{~g}$

Total moving mass

$728.9 \mathrm{~g}$

Total sp̣ring constant at $2.0 \mathrm{hz}$

$.1 .15 \times 10^{\circ} \mathrm{dyn} / \mathrm{cm}$

Air gap 0.3575 in. $(0.9081 \mathrm{~cm})$

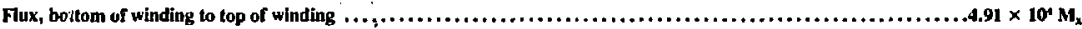

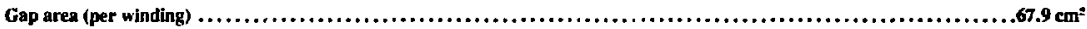

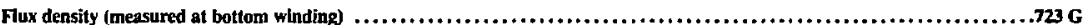

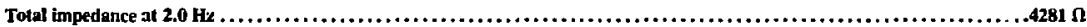

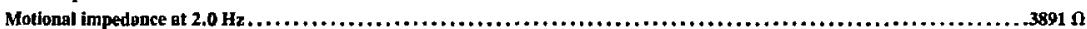

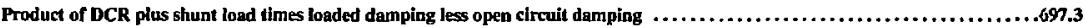

uSoures: Geo Space Corp. 
Table 11. Specifications ${ }^{a}$, Type HS-1 geophone, Modei X $4.5 \mathrm{~Hz}, 0.55 \mathrm{~V} / \mathrm{in} . / \mathrm{s}$

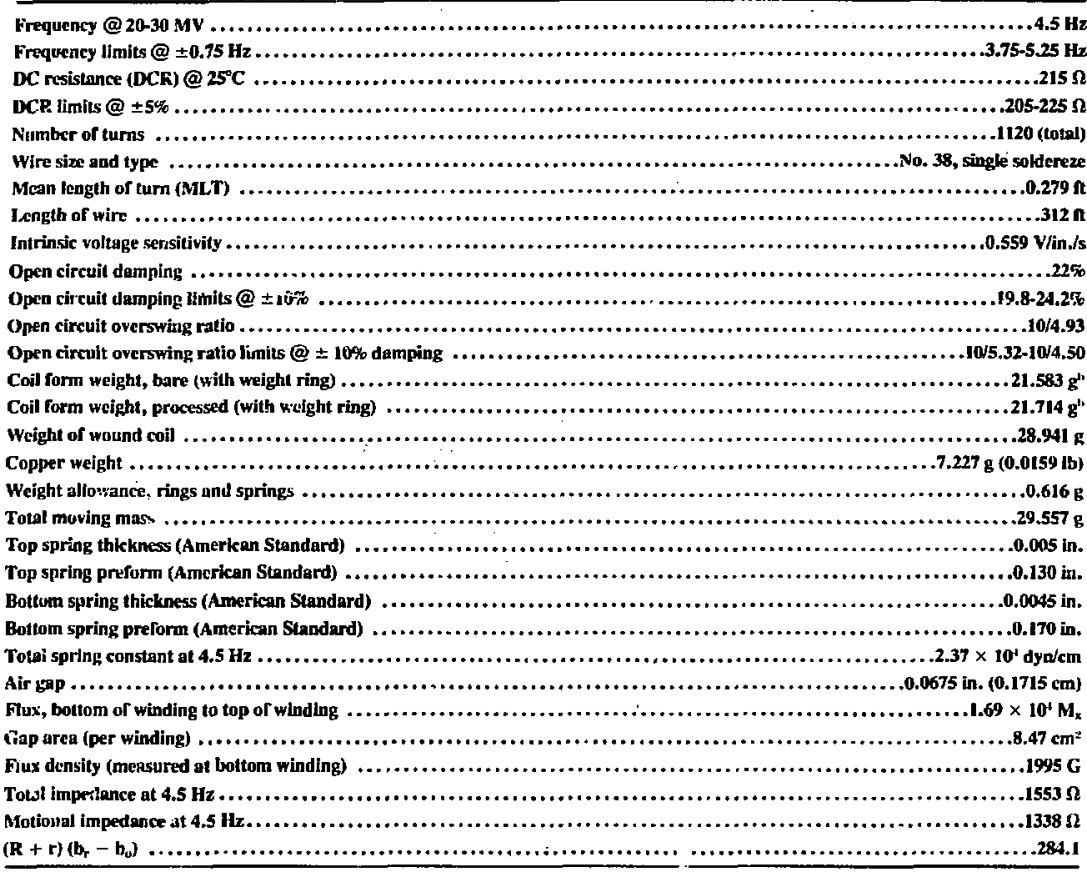

"Soures: Geo Space Corp.

"Weight ring atone weighs $6.615 \mathrm{~g}$ 


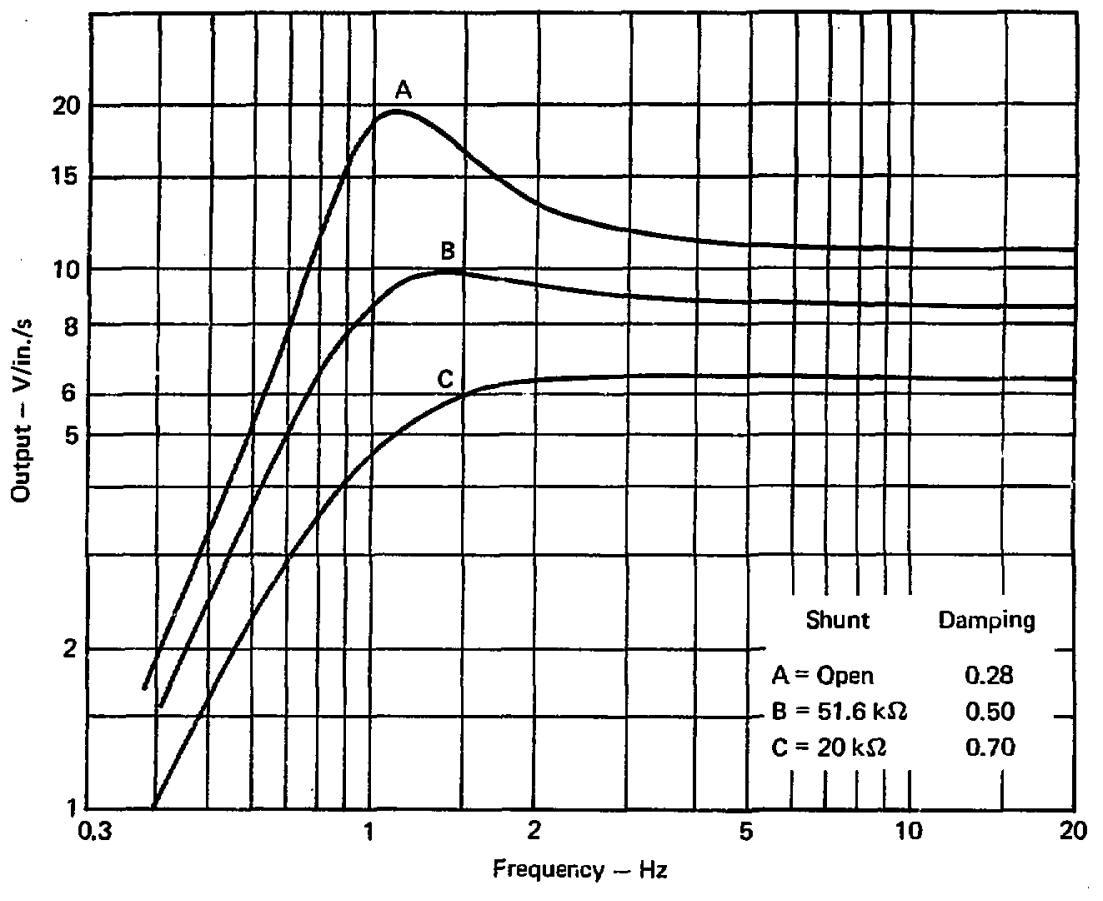

Fig. 57. Geophone response curve, Type L $4 \mathrm{C}, 1.0 \mathrm{~Hz}, 11 \mathrm{~V} / \mathrm{in} . / \mathrm{s}$ (Mark Products, Inc.). 
Table 12. Specifications ${ }^{\mathrm{a}}$, Type L $4 \mathbf{C C}$ geophone, $1.0 \mathrm{~Hz}$

General geophone specifications

Type

Moving dugl coll, humbuck wound

Erequency $.1 .0 \pm 0.05 \mathrm{~Hz}$ measured on 200 -lb weight $\mathrm{gt} 0.09 \mathrm{in} . / \mathrm{s}$

Frequency change with tilt .Less than $0.05 \mathrm{~Hz}$ at $5^{\circ}$ from vertical

Frequency change with excitation Less than $0.05 \mathrm{~Hz}$ from 0 to 0.09 in.. $\mathrm{s}$

Suspended mass

$.1000 \mathrm{~g}$

Standard coil resistance

See table

Leakage to case

$100 \mathrm{M} \Omega$ minimun at $500 \mathrm{~V}$

Transduction power

$8.810^{-3}$ watts ineh second or 13.6 watts meter second

Open circuil damplng . $\left(b_{4}\right)=0.28$ critical

Current damping $\left(b_{r}\right)=\frac{1.1 R_{r}}{R_{r}+R_{r}}$ where: $\mathbf{R}_{\boldsymbol{r}}=$ coil resistance $\boldsymbol{\Omega}$

$\mathbf{R}_{\mathbf{s}}=$ shunt resistance $-\Omega$

Coil Inductance $L_{\mathrm{r}}=0.0011 \mathrm{R}_{\mathrm{r}}$

$L_{i}$ in $H$

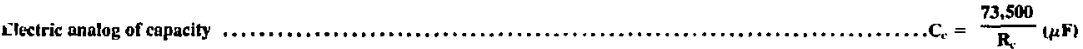

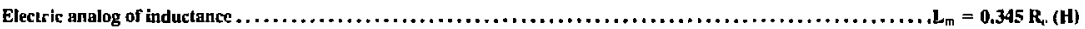

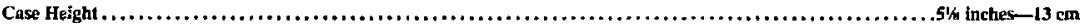

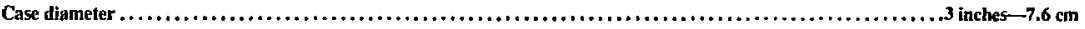

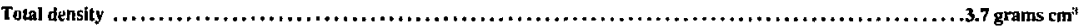

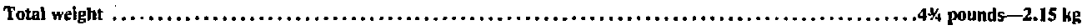

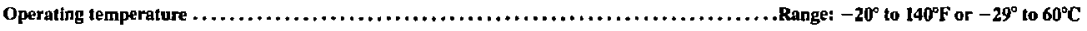

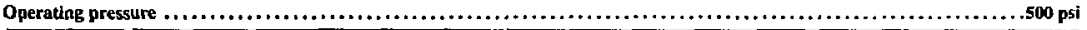

Type 2-4C geophone specifications (1.0 Hz, 11 V/in./5)

Coil resistance $\ldots \ldots \ldots \ldots \ldots \ldots \ldots \ldots \ldots \ldots \ldots \ldots$ 12.9k $\Omega$

Transduction ....................... 11 V/in./s

Coil inductance $\ldots \ldots \ldots \ldots \ldots \ldots \ldots \ldots \ldots \ldots \ldots \ldots .14 .19$.

Analog caparity equivalent $\ldots \ldots \ldots \ldots \ldots \ldots \ldots \ldots, 0.01, \mathbf{F}$

Anglog inductance equivalent $\ldots \ldots \ldots \ldots \ldots \ldots \ldots \ldots$ 445n II

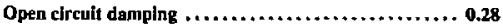

Shunt for 0.50 critical damping . . . . . . . . . . . $51.6 \mathrm{k} \Omega$

Shunt for 0.70 critical damping $\ldots \ldots \ldots \ldots \ldots \ldots \ldots 20 \mathrm{k} \Omega$

"Source: Mark Products, Inc. 


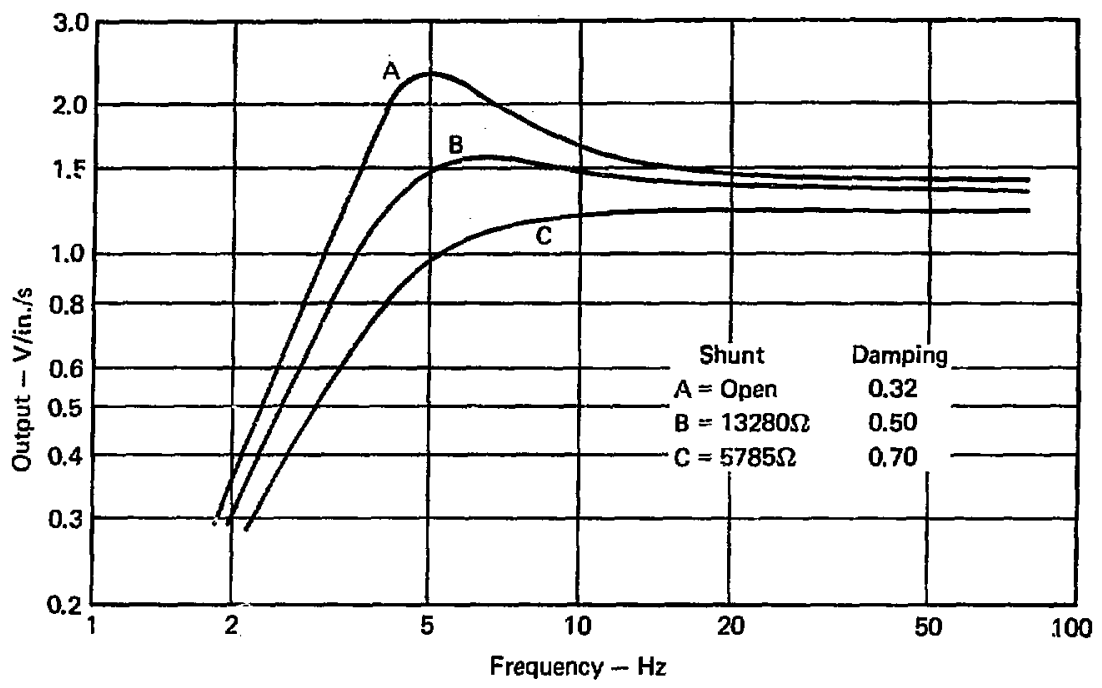

Fig. 58. Geophone response curve, Type L-15B, 4.5 Hz, 1.5V/in./5 (Mark Products, fnc.).

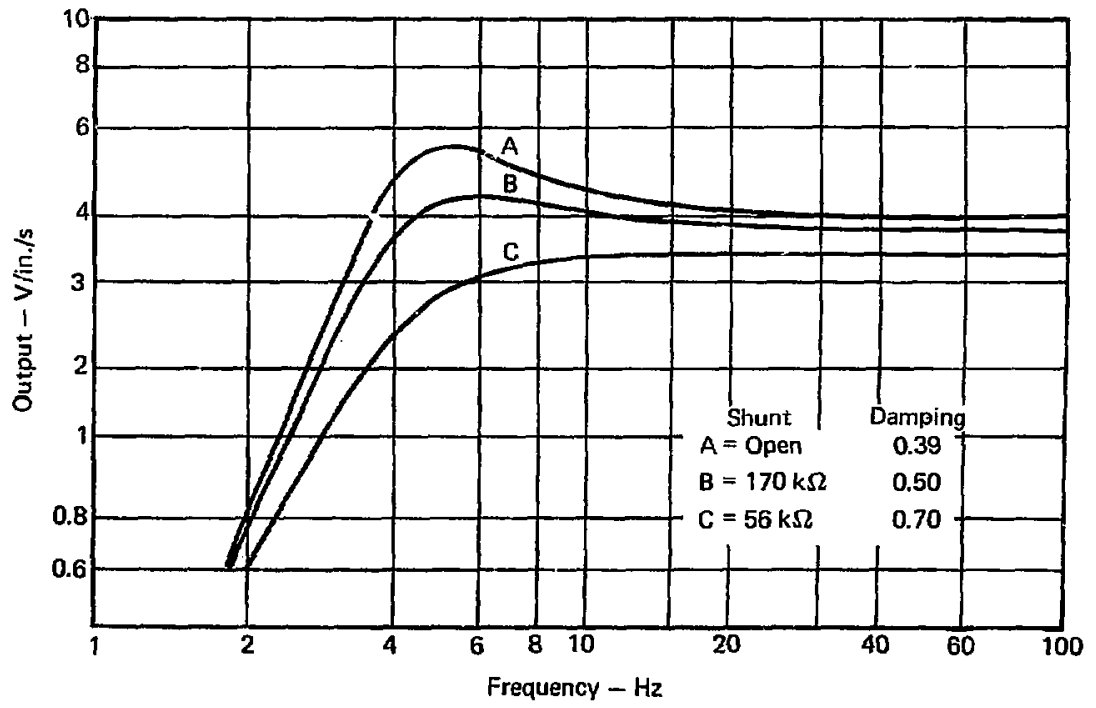

Fig. 59. Geaphoge respanse curve, Type L/16d, $4.5 \mathrm{~Hz}, 4 \mathrm{~V} / \mathrm{m} / \mathrm{s}$ (Mark Products, Inc.). 
Table 13. Specifications ${ }^{\mathrm{a}}$, Type L-15 geophone

\section{General geophone specifkations}

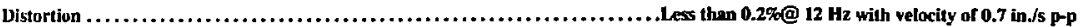

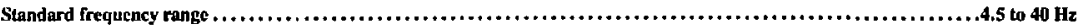

Frequency tolerance $\ldots \ldots \ldots \ldots \ldots \ldots \ldots \ldots \ldots \ldots \ldots \ldots \ldots \ldots \ldots \ldots \ldots \ldots \ldots \ldots \ldots \ldots \ldots \ldots \ldots \ldots \ldots \ldots \ldots \ldots \ldots \ldots \ldots \pm 0.5 \mathrm{~Hz}$ or $\pm 5 \%$

Standand coil resistances $($ Re) $\ldots \ldots \ldots \ldots \ldots \ldots \ldots \ldots \ldots \ldots \ldots \ldots \ldots \ldots \ldots \ldots \ldots \ldots \ldots \ldots \ldots .24,38,60,95,150,240,380,600,960 \Omega$

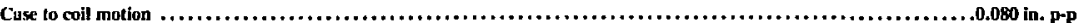

Frequency chunge wilh tilt $\ldots \ldots \ldots \ldots \ldots \ldots \ldots \ldots \ldots \ldots \ldots \ldots \ldots \ldots \ldots \ldots \ldots \ldots \ldots$. $\ldots \ldots \ldots$ than 0.1 Hz for vertical unit @ $20^{\circ}(8 \mathrm{~Hz})$

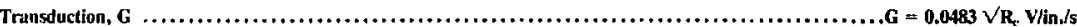

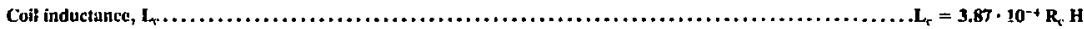

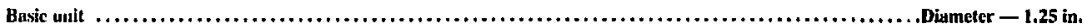

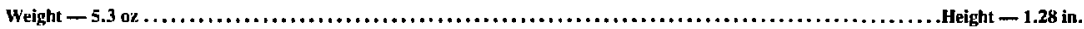

Type L-15B, geophone specifications (4.5-Hz)

\begin{tabular}{|c|c|c|}
\hline Coil resistance $-\Omega \ldots \ldots$. & 960 & 9400 \\
\hline Transduclion-V/in $/ \mathrm{s} \ldots \ldots \ldots \ldots$ & 1.50 & 4.0 \\
\hline Coil inductance $-H \ldots \ldots$. & 0.370 & 3.7 \\
\hline Analog capacitance- $\mu F$ & 6.00 & 0.70 \\
\hline Analog inductance $-H \ldots \ldots \ldots$ & 203. & 1910 \\
\hline $\begin{array}{l}\text { Open circuit damping } \ldots \ldots \ldots \ldots \ldots \ldots \\
\text { Shunt for } 0.50 \text { critical }\end{array}$ & $\mathbf{0 . 3 2}$ & 0.39 \\
\hline damping $-\Omega$ & 80 & 170000 \\
\hline $\begin{array}{l}\text { houl for } \mathbf{0 . 7 0} \text { criticel } \\
\text { deinping }-\Omega \ldots \ldots\end{array}$ & 5785 & 56000 \\
\hline
\end{tabular}

aSource: Mark Products, Inc. 


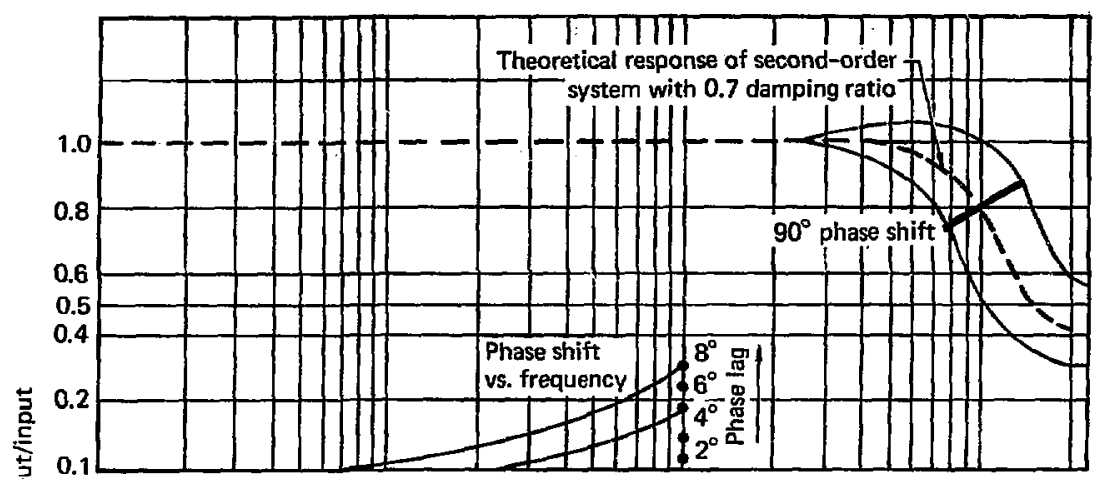

(a)

 
Table 14. Specifications ${ }^{a}$, Model 305-A accelerometer

\begin{tabular}{|c|c|}
\hline As current source & As voltage source \\
\hline 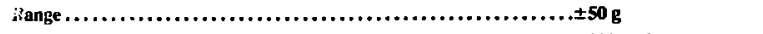 & $\pm 50 \mathrm{~g}$ \\
\hline 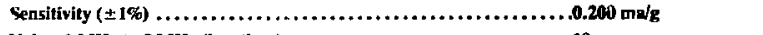 & $100 \mathrm{mV} / \mathrm{g}$ \\
\hline 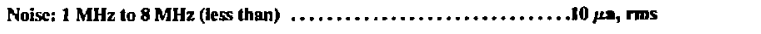 & $5 \mathrm{mV}, \mathrm{rms}$ \\
\hline below I MHz (less than) $\ldots \ldots \ldots \ldots \ldots \ldots \ldots \ldots \ldots \ldots \ldots 2 \mu, \ldots \ldots$ & $1 \mathbf{m V}, \mathbf{m m s}$ \\
\hline 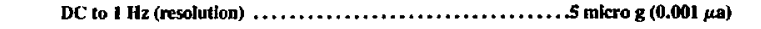 & 5 micro g \\
\hline 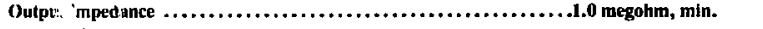 & $500 \Omega$ \\
\hline Frequency response (within $\pm 5 \%$; with \pm 15 V DC pwr) $\ldots \ldots \ldots \ldots \ldots$. & ve to $500 \mathrm{~Hz}$ \\
\hline 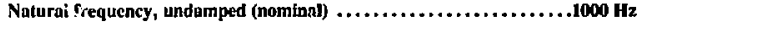 & $100 \mathrm{~Hz}$ \\
\hline 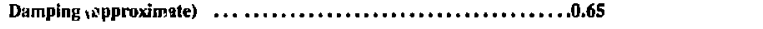 & 0.6 \\
\hline 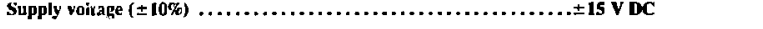 & \pm 15 V DC \\
\hline 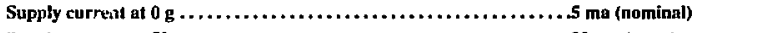 & 5 ma (nominal) \\
\hline 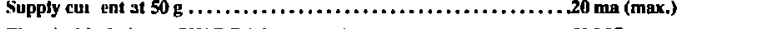 & $20 \operatorname{ma}(\max )$. \\
\hline Electrical isolation at $50 \mathrm{~V}$ DC (pins to case) $\ldots \ldots \ldots \ldots \ldots \ldots \ldots \ldots .50 \mathrm{M} \Omega$ & 50 MI \\
\hline 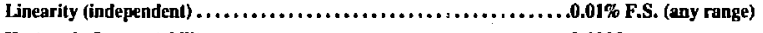 & $0.1 \%$ F. S. (any range) \\
\hline 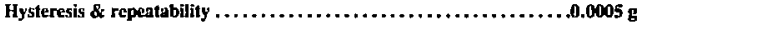 & $0.0005 \mathrm{~g}$ \\
\hline 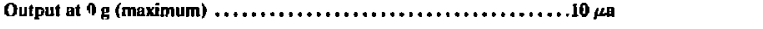 & $5 \mathbf{m V}$ \\
\hline 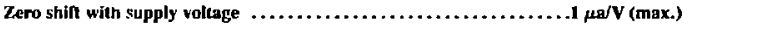 & $0.5 \mathrm{~m} V / \mathrm{V}(\mathrm{max})$. \\
\hline 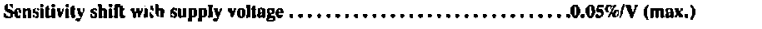 & $0.05 \% / V(m a x)$. \\
\hline Temperature range (storage $\&$ opcrating) $\ldots \ldots \ldots \ldots \ldots \ldots \ldots \ldots \ldots-65$ to $+185^{\circ} \mathrm{F}$ & -65 to $+185^{\circ} \mathrm{F}$ \\
\hline Temperature zero shin $(\max .) \ldots \ldots \ldots \ldots \ldots \ldots \ldots \ldots \ldots \ldots \ldots .0 .03 \mathrm{~g} / 100^{\circ} \mathrm{F}$ & $0.03 \mathrm{~g} / 100^{\circ} \mathrm{F}$ \\
\hline 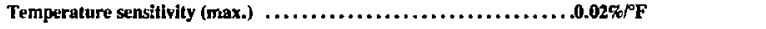 & $0.01 \% / F$ \\
\hline Transverse acceleration: DC to $5 \mathrm{~Hz} . . . \ldots$. & $\mathbf{5 0} \mathrm{B}$ \\
\hline $5 \mathrm{~Hz}$ to $2 \mathrm{~K} \mathrm{~Hz} \ldots \ldots \ldots \ldots \ldots \ldots \ldots \ldots \ldots \ldots \ldots \mathrm{g}_{\mathrm{g}}$ (peak) & $20 \mathrm{~g}$ (peak) \\
\hline $\begin{array}{r}\text { DC output from vibration (nectilleation error) } \ldots \ldots \ldots \ldots \ldots \ldots \ldots \ldots .001 \mathrm{~g} / \mathrm{g} \text { (nominal) } \\
\text { at } 250 \mathrm{~Hz} \& 10 \mathrm{~g} \text { peak }\end{array}$ & $\begin{array}{l}0.001 \mathrm{~g} / \mathrm{B} \text { (nominal) } \\
\text { at } 250 \mathrm{~Hz} \& 10 \mathrm{~g} \text { peak }\end{array}$ \\
\hline Cross coupling coemleient (pendulosity error) . .................. none & none \\
\hline Case alignment (to true sensitivity axls) $\ldots \ldots \ldots \ldots \ldots \ldots \ldots \ldots \ldots \pm \ldots \ldots \ldots \ldots \ldots$ & $\pm 1 / 2^{\circ}$ (maximum) \\
\hline Acceleration limit (non-operating) $\ldots \ldots \ldots \ldots \ldots \ldots \ldots \ldots \ldots \ldots \ldots+\ldots \ldots \ldots$ & $100 \mathrm{~g}$ \\
\hline Shock limit (5 msec pulse) $\ldots \ldots \ldots \ldots \ldots \ldots \ldots \ldots \ldots \ldots \ldots \ldots \ldots$. & $100 \mathrm{~g}$ max. for any axis \\
\hline Weight $\ldots \ldots \ldots \ldots \ldots \ldots \ldots \ldots \ldots$ & $3.4 \mathrm{oz}$ \\
\hline \multicolumn{2}{|c|}{ 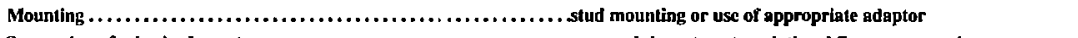 } \\
\hline uspension of selsmlc element & \\
\hline
\end{tabular}

"Source: Sundstrand Date Contiol, Inc. 


\section{References}

1. H. C. Rodean, Nuclear Explosion Seismology, U.S. Atomic Energy Commission, Division of Technical Information Extension, Oak Ridge, TE (1971).

2. R. Rohrer and D. Springer, The Massachusetss Mountain Earthquake at thr NTS, August 5, 197I, Compared fo an Underground Explosion at NTS STM.128, Rev L. Lawrence Livermore Laboratory, Internal Document (1972).

3. A. S. Kusubov, Surface and Body Waves from Surface and Underground Explosions, Lawrence Livermore Laboratory, Livmimore, CA, UCID-17222 (1976). Also published as Middle North Series Pre-Mine Throw IV Evem, Surface and Body Waves from Surface and Underground Explosions, Final Project Officers Report, prepared for the Defense Nuclear Agency, POR 6834 (1977).

4. R. M. Hazlewood, Seismic Refraction Survey at the UNa Site, Nevada Test Site, Nye Coumty, Nevada, USGS474-76 (1976).

5. W. J. Carr, Summary of Tectonic and Structural Evidence for Stress Orientation at the Nevada Test Site. USGS-474-181 (1974).

6. I. Y. Borg, Yucca Lake (Playa) Sedimenrs, UCON 74-2 Lawrence Livermore Laboratory, Internal Document (1974). Readers outside the Laboratory who desire further information on LLL internal documents should address their inquiries to the Technical Information Department, Lawrence Livermore Laboratory, Livcrmore. CA 94550 .

7. W. Beiriger, X-Ray Analysis of Core Samples from NTS, UPOKK 74-7 Lawrence Livermore Laboratory, Internal Document (1974).

8. N. Howard NTS Playa Samples, UOPKB 74-24, Lawrence Livermore Laboratory, Interna! Documenl (1974).

9. B. G. Rulev, "The Energy in a Rayleigh Surface Wave from Explosions in Different Kinds of Rock." /ar. Earth Sciences 4, 23 (1965).

10. J. A. Viecelli, "Spallation and the Generation of Surface Waves by an Underground Explosion, " J.G.R. 78, p2475 (1973).

11. L. Shock, "The Progresive Detonation of Multiple Charges in a Single Seismic Shot," Gerophyxic's 15, 208 (1950).

12. A. W. Musgrave, G. W. Ehler, and D. M. Nash, Jr., "Directivity Effect of Elongaied Charges," Geoplyysic's 23, 81 (1950).

13. T. Marner and D. Silve:man, "Broonstick Distributed Charge," Geophysics 22, 1007 (1962).

14. G. L. E. Perry, Pre-Mine Throw IV Test Execution Report, General Electric Co., TEMPT-Center for Advanced Studies, 7800 Marble Avenue, N.E., Albuquerque, NM 87115, Ref un Number POR6826 (WT-6826) (1975).

15. E. Frerkind et al., (LLL-originated software), (no ADC listing), Lawrence Livermore Laboratory, Internal Document (1972).

16. E. Frerkind et al., (LLL-originated software), ADC 72-12, Lawrence Livermose Laboratory, Internal Document (1972).

17. E. Frerkind et al., (LLL-originated software), ADC 72-42, Lawrence Livermore Laburatory, Intemal Document (1972),

18. E. Frerkind et al., (LLL-originated software), ADC 72-42, Lawrence Livermore Laboratory, Internal Document (1972).

19. J. C. Huskamp et al., (LLL-originated software), UR-003, Rev. 2, Lawrence Livermore Laboratory, Intemal Document (1975).

20. B. Gumm (LLL-originated software), ADC 71-76, Lawrence Livermore Laboratory, Internal Document (1976).

21. W. S. Derby, E. C. Lee, and R. D. Neifert, SOCKITTOME, An Imeractive Data Processing Code, Lawrence Livermore Laboratory, Livermore, CA, UCIR-807 (1974).

22. C. Cornell and S. Spataro, Instrumentation for Rayleigh Wave Experiments, Yucca Lake NTS (Trailer No. 81), KDG 75-3-7, Lawrence Livermore Laboratory, Internal Document (1975). 